PATRICK SANTOS DE OLIVEIRA

\title{
ANÁLISE METODOLÓGICA PARA A CONVERSÃO DE LINHAS DE DISTRIBUIÇÃO DE 34,5 KV PARA $69 \mathrm{KV}$
}





\title{
ANÁLISE METODOLÓGICA PARA A CONVERSÃO DE LINHAS DE DISTRIBUIÇÃO DE 34,5 KV PARA $69 \mathrm{KV}$
}

\author{
Dissertação apresentada à Escola \\ de Engenharia de São Carlos, da \\ Universidade de São Paulo, como \\ parte dos requisitos para a obtenção \\ do Título de Mestre em Ciências, \\ Programa de Engenharia Elétrica.
}

Área de Concentração: Sistemas Elétricos de Potência Orientador: Prof. Tit. Denis Vinicius Coury 


\section{FOLHA DE JULGAMENTO}

\section{Candidato(a): Engenheiro Eletricista PATRICK SANTOS DE OLIVEIRA.}

Dissertação defendida e julgada em 17/01/2011 perante a Comissão Julgadora:

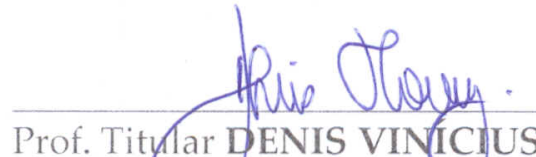

Prof. Tity 1 ar DENIS VINICIUS COURY - (Orientador)

(Escola de Engenharia de São Carlos/USP)

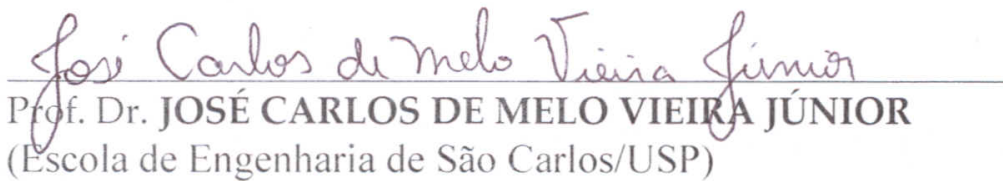

APROVADO

(Escola de Engenharia de São Carlos/USP)

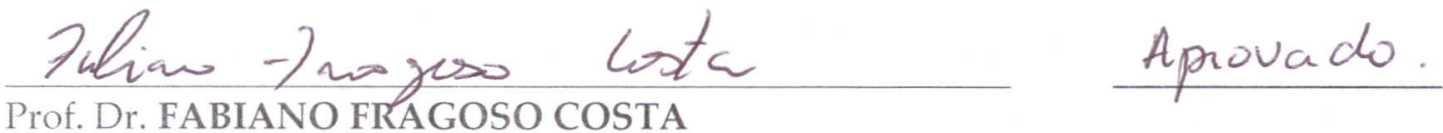

Prof. Dr. FABIANO FRAGOSO COSTA

(Universidade Federal do Rio Grande do Norte/UFRN)

Aprovado.
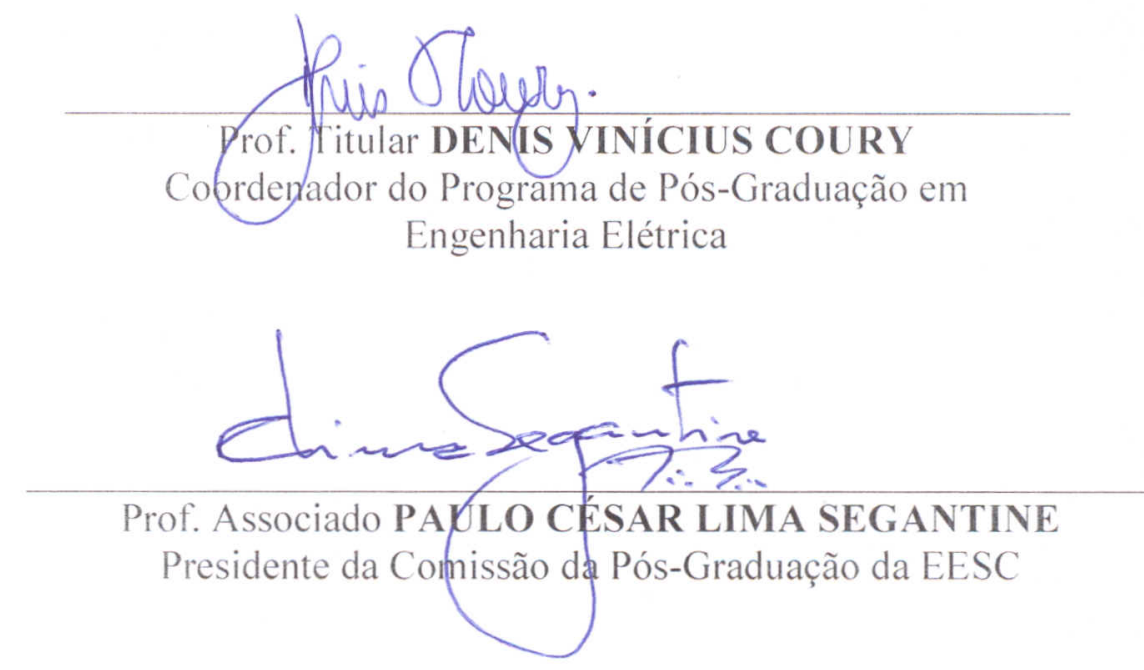


\section{Dedicatória}

Dedico este trabalho aos meus pais, Nivaldo e Antonia, à minha irmã Cintia, e a todos os amigos que de alguma forma contribuíram nessa caminhada. 



\section{Agradecimentos}

Agradeço a Deus por estar sempre ao meu lado.

Agradeço aos meus pais, Nivaldo e Antonia, por não terem medido esforços para que eu pudesse realizar esse trabalho. Também ao carinho e preocupação que dedicaram a mim.

À minha irmã Cintia e ao meu cunhado Franklin pelos momentos juntos ao longo desta trajetória.

Ao Prof. Denis V. Coury pela oportunidade concedida e pela orientação ao longo desse trabalho.

Aos Professores José Carlos de Melo Vieira Júnior e Mário Oleskovicz pela ajuda e atenção que me foi dada.

Aos amigos da república Goiás é Mais (RGEM), Alexandre, Eduardo e Gustavo, pela amizade e companheirismo.

Aos amigos que tive alegria de encontrar, dentre eles: Aldir, Breno, Camila, Etienne, Helson, Hermes, Lucas, Luciana, Marcel, Marcelo, Mariana, Marley, Milena, Monaro, Samuel, Sérgio, Suetake, Ulisses e todos que estiveram presentes nestes momentos tão especiais.

À Erika pela paciência e dedicação na correção do trabalho.

A todos os funcionários da Escola de Engenharia de São Carlos que sempre foram prestativos no cumprimento de suas obrigações, em especial à Marisa e Jussara. 



\section{Epígrafe}

"A mente que se abre a uma idéia, jamais voltará ao seu tamanho original." Albert Einstein 



\section{Sumário}

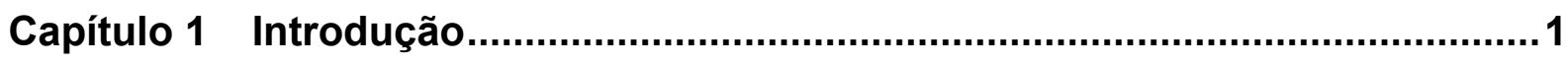

Capítulo 2 Repotenciação de Linhas de Transmissão....................................... 7

Capítulo 3 Simulações Computacionais Temporais via Software ATP ...........17

3.1 - Transitórios Eletromagnéticos .............................................................18

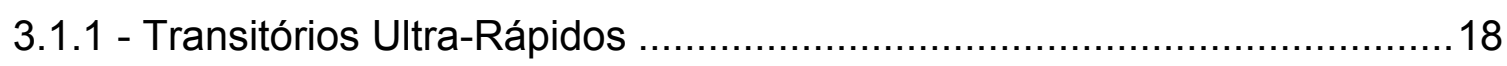

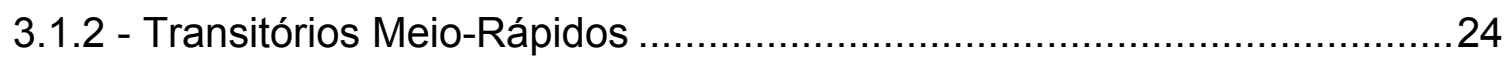

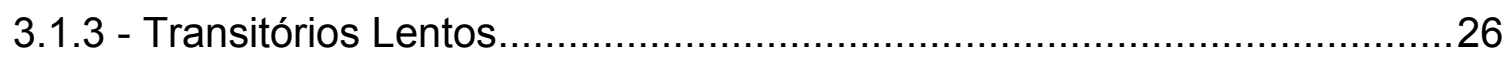

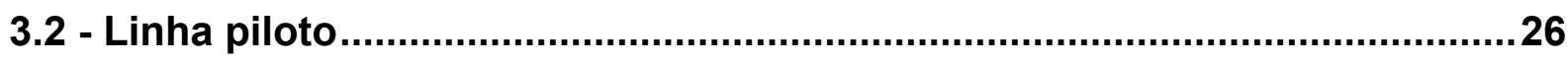

3.3 - Modelagem da linha ................................................................................

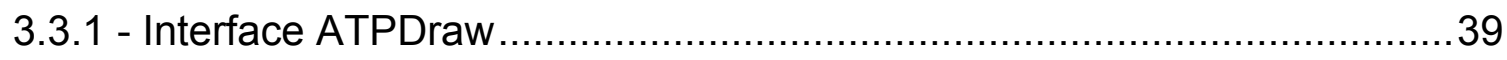

3.4 - Resultados das simulações realizadas ....................................................... 42

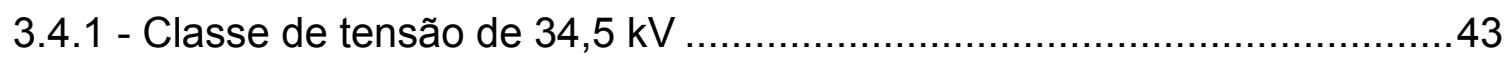

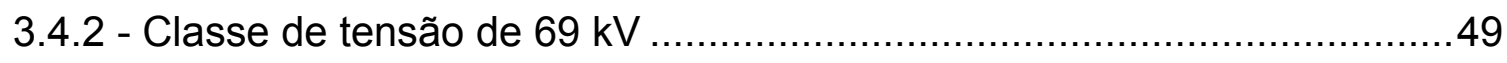

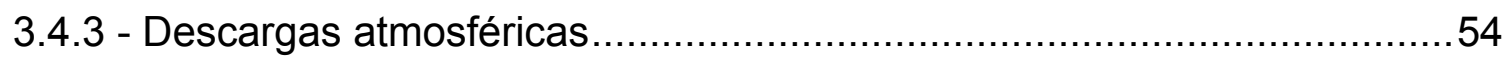

Capítulo 4 Simulações Computacionais Espaciais via Software FLUX ${ }^{\circledR}$.........59

4.1 - Método de Elementos Finitos ……………….............................................

4.2 - Aplicações do MEF em Sistemas Elétricos de Potência ................................62

4.3 - Modelagem e Simulação das estruturas estudadas no Software FLUX ${ }^{\circledR}$...66

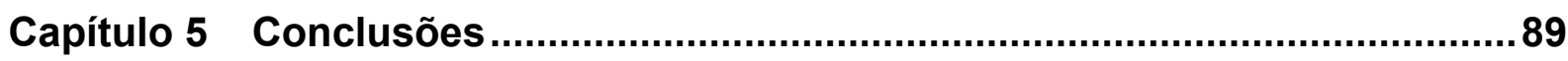

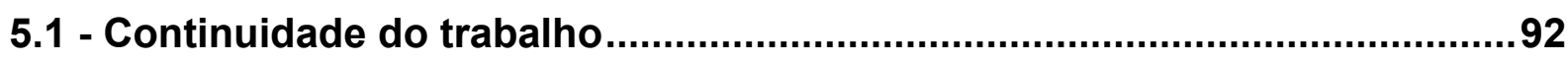

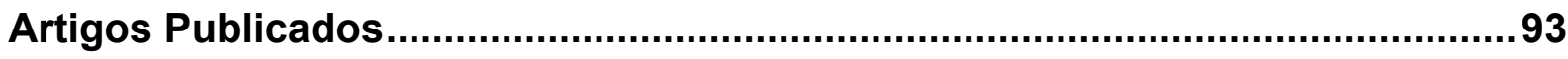

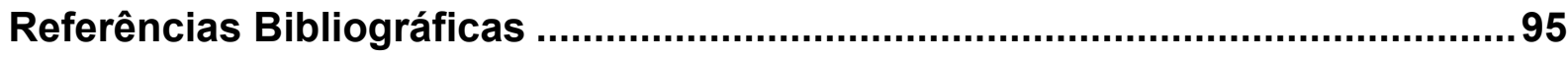





\section{Resumo}

OLIVEIRA, P. S. Análise metodológica para a conversão de linhas de distribuição de $\mathbf{3 4 , 5}$ kV para 69 kV, São Carlos, 2010, p. 102. Dissertação de Mestrado - Escola de Engenharia de São Carlos, Universidade de São Paulo.

Este trabalho visa apresentar uma análise metodológica para viabilizar a realização da repotenciação, elevando a classe de tensão de linhas de distribuição de 34,5 kV para a classe de subtransmissão de $69 \mathrm{kV}$. Foi realizado um levantamento de casos de repotenciação de linhas de transmissão, inclusive para a alternativa de elevação da tensão de operação da linha. Foram analisados modelos matemáticos apropriados para a representação da linha frente a transitórios eletromagnéticos como curtos-circuitos e descargas atmosféricas e ainda, um estudo sobre o procedimento a ser realizado dispondo-se de um software baseado na teoria de elementos finitos para a verificação do nível básico de isolamento das estruturas pertencentes à linha. Assim, a linha piloto foi representada no software ATP, utilizando-se a interface ATPDraw, e foi submetida a diversos transitórios eletromagnéticos. A partir dos valores de tensão observados nesses distúrbios, iniciaram-se novas simulações computacionais por meio do software FLUX ${ }^{\circledR}$, que é baseado na teoria dos elementos finitos, para avaliar o comportamento do campo elétrico nas diferentes estruturas da linha, considerando a cruzeta de madeira e os isoladores cerâmicos. Dessa forma, esse estudo, avalia as simulações computacionais realizadas e aponta quais as estruturas da linha estão aptas a operar na classe de tensão de $69 \mathrm{kV}$, ou ainda, quais alterações permitirão que 
estruturas menos seguras possam operar neste novo nível de tensão. Todas as etapas e as conclusões finais sobre o assunto delineado são apresentadas neste documento.

Palavras-chave: Repotenciação, Elevação da Classe de Tensão, Distribuição, Subtransmissão, Classe de 34,5 kV, Classe de 69 kV, ATPDraw, FLUX $^{\circledR}$. 


\section{Abstract}

OLIVEIRA, P. S. Methodological analysis to convert distribution lines from $\mathbf{3 4 , 5}$ kV to 69 kV, São Carlos, 2010, p. 102. Master Thesis - Escola de Engenharia de São Carlos, Universidade de São Paulo.

This work presents a methodological analysis to make repowering distribution line possible, raising the voltage level from $34.5 \mathrm{kV}$ to $69 \mathrm{kV}$ (sub transmission level). A literature review of transmission line upgrading was accomplished, including the alternative of raising the line operating voltage. Proper mathematical models were analyzed for the line representation facing electromagnetic transients such as short circuits and lightning. In addition, a software based on finite elements theory for the verification of the basic insulation level of the structures (poles and crossarms) belonging to the line was utilized. Thus, a pilot line was modeled in the ATP software, using the ATPDraw interface, and it was subjected to various electromagnetic transients. From the voltage values observed in these disturbances, new computer simulations were carried out using $\mathrm{FLUX}^{\circledR}$, a finite elements theory based software capable of evaluating the electrical field behavior in different structures of the line, considering wooden crossarms and ceramic insulators. In this context, the present study analyze the computer simulations and points out which line structures are able to operate in the $69 \mathrm{kV}$ voltage level, or even indicates which alterations will enable the less secure structures to operate in this new voltage level. All the stages and final conclusions about the outlined subject are presented in this document. 
Keywords: Transmission Line Upgrading, Voltage Elevation, Distribution, Subtransmission, Class of $34,5 \mathrm{kV}$, Class of $69 \mathrm{kV}$, ATPDraw, FLUX ${ }^{\circledR}$. 


\section{Lista de Figuras}

Figura 3.1 - Onda refletida na terminação da linha.

Figura 3.2 - Descargas diretas: 1- descarga direta na estrutura, 2 - descarga direta no cabo guarda, 3 - descarga direta no cabo energizado. .22

Figura 3.3 - Equivalente de Norton para caracterizar descargas atmosféricas. …...23

Figura 3.4 - Esquema de um curto-circuito trifásico .24

Figura 3.5 - Esquema de curto-circuito bifásico com e sem o envolvimento do terra .25

Figura 3.6 - Esquema de curto-circuito fase terra. .25

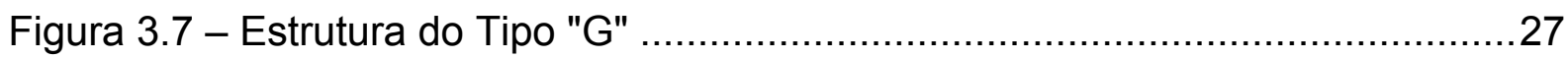

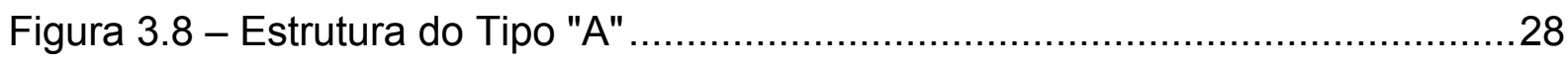

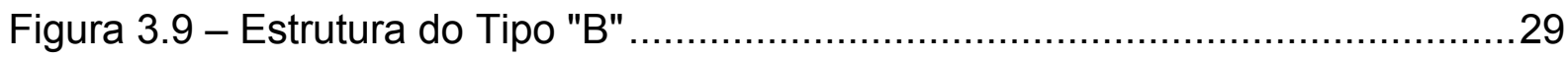

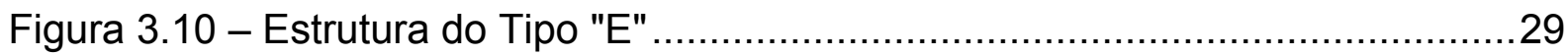

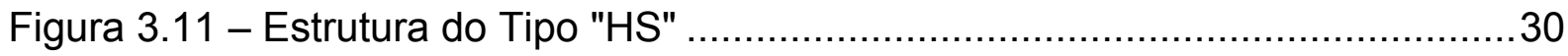

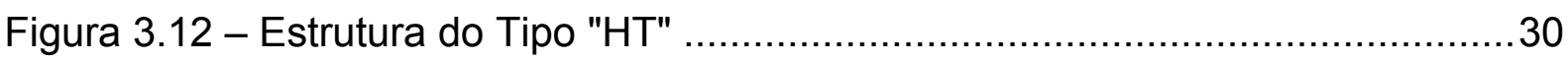

Figura 3.13 - Fluxograma para escolha do modelo computacional de linhas de

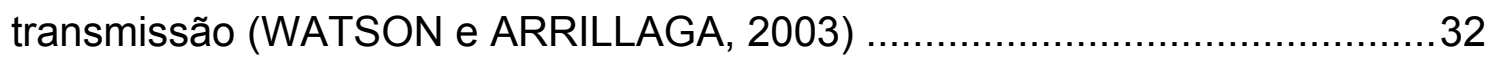

Figura 3.14 - Modelo da Linha Souzas - Salto Grande no software ATPDraw .........36

Figura 3.15 - Exemplo de transitório monofásico …………................................37

Figura 3.16 - Diagrama representativo do sistema elétrico simulado, considerando situações de descargas atmosféricas.

Figura 3.17 - Descarga atmosférica aplicada entre o Trecho 4 e o Trecho 5, com corrente de $10 \mathrm{kA}$, considerando o modelo $\mathrm{PI}$. 
Figura 3.18 - Descarga atmosférica aplicada entre o Trecho 4 e o Trecho 5, com corrente de $10 \mathrm{kA}$, considerando o modelo JMarti. 39

Figura 3.19 - Tela inicial do componente LCC 40

Figura 3.20 - Tela para a entrada dos dados representando os condutores do sistema simulado. 41

Figura 3.21 - Forma de onda da tensão devido a uma falta trifásica envolvendo o terra.

Figura 3.22 - Forma de onda da tensão devido a uma falta trifásica sem o terra. ... 45

Figura 3.23 - Forma de onda da tensão devido a uma falta bifásica entre as fases B e C envolvendo o terra. 45

Figura 3.24 - Forma de onda da tensão devido a uma falta bifásica entre as fases B e C sem o terra. 46

Figura 3.25 - Forma de onda da tensão devido a uma falta na fase C. 46

Figura 3.26 - Forma de onda da tensão devido a uma falta trifásica envolvendo o terra. 49

Figura 3.27 - Forma de onda da tensão devido a uma falta trifásica sem o terra. ... 50

Figura 3.28 - Forma de onda da tensão devido a uma falta bifásica entre as fases B

e C envolvendo o terra. 50

Figura 3.29 - Forma de onda da tensão devido a uma falta bifásica entre as fases B e C sem o terra. 51

Figura 3.30 - Forma de onda da tensão devido a uma falta na fase C. 51

Figura 3.31 - Forma de onda da tensão nas três fases devido a uma descarga atmosférica direta de $10 \mathrm{kA}$, com impedância paralela de $3 \mathrm{k} \Omega$, aplicada entre os Trechos 4 e 5 , e medida entre os Trechos 1 e 2. 
Figura 3.32 - Forma de onda da tensão nas três fases devido a uma descarga atmosférica direta de $10 \mathrm{kA}$, com impedância paralela de $3 \mathrm{k} \Omega$, aplicada entre os Trechos 4 e 5, e medida no mesmo ponto.

Figura 3.33 - Forma de onda da tensão nas três fases devido a uma descarga atmosférica direta de $10 \mathrm{kA}$, com impedância paralela de $3 \mathrm{k} \Omega$, aplicada entre os Trechos 4 e 5 , e medida entre os Trechos 7 e 8 .58

Figura 4.1 - Exemplo de malha de elementos finitos 62

Figura 4.2 - Etapas para simulações no software FLUX ${ }^{\circledR}$ 67

Figura 4.3 - Estrutura do tipo "A" (distâncias em mm) 68

Figura 4.4 - Estrutura do tipo "A" modelada no software FLUX ${ }^{\circledR}$ 69

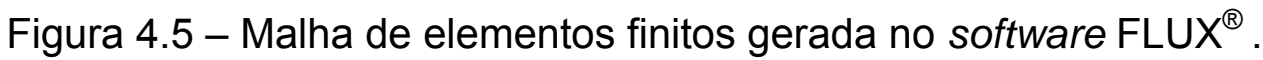
.70

Figura 4.6 - Campo elétrico gerado por um curto-circuito trifásico terra com pico na fase "A" .72

Figura 4.7 - Linhas de potencial elétrico geradas por um curto-circuito trifásico terra com pico na fase "A" 73

Figura 4.8 - Linhas de potencial elétrico gerado por um curto-circuito trifásico sem o envolvimento do terra com pico na fase $A$ .78

Figura 4.9 - Linhas de potencial elétrico gerado por um curto-circuito trifásico sem o envolvimento do terra com pico na fase B 79

Figura 4.10 - Linhas de potencial elétrico gerado por um curto-circuito bifásico entre as fases $A$ e $B$ com pico na fase $B$ .80

Figura 4.11 - Linhas de potencial elétrico gerado por um curto-circuito bifásico, envolvendo as fases $B$ e $C$, com pico na fase $C$

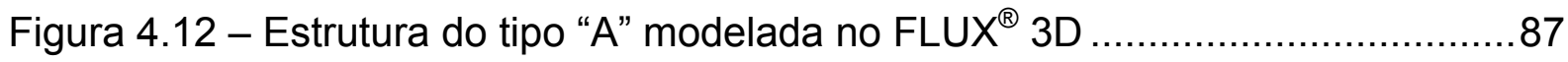

Figura 4.13 - Isolador tipo pino da classe de $69 \mathrm{kV}$ modelado no FLUX ${ }^{\circledR}$ 3D..... 87 
Figura 4.14 - MEF em um isolador tipo pino da classe de $69 \mathrm{kV}$ modelado no FLUX ${ }^{\circledR}$ 3D 88 


\section{Lista de Abreviaturas e Siglas}

\begin{tabular}{ll} 
AAAC & All Aluminium Alloy Conductor \\
ACSR & Aluminium Conductors Steel Reinforced \\
ATP & Alternative Transients Program \\
CAA & Condutor de Alumínio com Alma de Aço \\
CC & Curto-Circuito \\
COPEL & Companhia Paranaense de Energia \\
DR & Densidade de Raios por ano por Km² \\
EMTP & Eletromagnetic Transients Program \\
EPTE & Empresa Paulista de Transmissão de Energia Elétrica \\
IC & Índice Ceráunico \\
LT & Linha de Transmissão \\
MEF & Método de Elementos Finitos \\
NBI & Nível Básico de Isolamento \\
ONS & Operador Nacional do Sistema Elétrico \\
PCH & Pequena Central Hidrelétrica \\
SE & Subestação \\
SEP & Sistema Elétrico de Potência \\
SIL & Surge Impedance Loading \\
SOZ & Subestação Souzas \\
TNA & Transient Network Analyzer \\
USG & Usina Salto Grande \\
\hline
\end{tabular}





\section{Capítulo 1 Introdução}

O sistema brasileiro de transmissão de energia elétrica é o maior da América Latina, com uma capacidade instalada de $100 \mathrm{GW}$. Quase $90 \%$ da energia produzida são provenientes de usinas hidroelétricas, enquanto o restante da geração inclui gás natural, carvão, energia nuclear e óleo (BARROSO et al., 2009).

A otimização dos recursos hídricos faz-se com a ajuda de modelos estocásticos. Como resultado, a confiabilidade do suprimento é aumentada e, o uso de combustíveis fósseis em plantas térmicas é minimizado. Uma planta de geração dessa natureza exige uma integrada e robusta rede de transmissão sendo que, a malha principal do sistema de transmissão possui a extensão de $90.000 \mathrm{~km}$ (BARROSO et al., 2009).

Além de possuir uma malha tão extensa, o crescente aumento da demanda energética nacional, faz necessária a análise de alternativas que aumentem o SIL (surge impedance loading) das linhas de transmissão (OLIVEIRA, 2000).

MOREIRA et al. (1999) enfatizam que as empresas concessionárias de energia elétrica necessitam urgente e rapidamente aumentar a capacidade de transmissão das suas redes de energia elétrica, com qualidade e custos mínimos, visando à redução dos crescentes riscos de racionamento.

Essas alternativas surgem na literatura técnico-científica como repotenciação ou repotencialização de linhas de transmissão de energia elétrica, e são técnicas que sempre devem ser levadas em consideração diante de um cenário de expansão da capacidade das linhas de transmissão (OLIVEIRA, 2000). 
Devem-se observar as vantagens econômicas e ambientais para se optar pela alternativa da repotenciação de uma linha já existente, ao invés da construção de uma nova linha. Dentre as questões ambientais envolvidas, está a não necessidade de obtenção de licença ambiental, devido à utilização da faixa de servidão já existente. Essa é uma exigência que pode proporcionar grandes atrasos ao novo projeto devido às análises que devem ser feitas com relação ao impacto ambiental da construção de uma nova linha.

Cabe comentar que a existência da faixa de servidão depende do nível de tensão da linha, ou seja, quanto maior a classe de tensão de operação da linha, maior a largura da faixa desapropriada para sua passagem, segundo a norma ABNT 5422 (ABNT, 1985).

Em um cenário global em que as preocupações ambientais são cada vez maiores, um projeto de expansão que não necessite de liberações ambientais para um novo traçado de linha já possui grandes vantagens sobre os demais.

Além da questão ambiental, o custo da construção de uma nova linha pode representar um investimento bem superior se comparado ao capital necessário à repotenciação de uma linha existente.

MOREIRA et al. (1999) afirmam que o reisolamento e as reformas de linhas de transmissão na Companhia Paranaense de Energia permitiram incrementar de uma maneira rápida e significativa o SIL com consequente aumento da confiabilidade na operação, a um custo situado entre 15 e $20 \%$ do custo de uma LT (linha de transmissão) nova.

Neste trabalho, a alternativa de repotenciação a ser considerada é a elevação da classe de tensão operativa de uma rede primária de $34,5 \mathrm{kV}$ para a 
classe de subtransmissão de $69 \mathrm{kV}$, aumentando assim o SIL da linha, com o objetivo de manter o maior número possível de estruturas do padrão de $34,5 \mathrm{kV}$.

É importante colocar que a elevação da classe de tensão é apenas uma alternativa para a repotenciação de uma linha. Entre as demais alternativas, existe a possibilidade de recondutoramento, que consiste em substituir o condutor existente na linha por um de maior capacidade de transmissão de corrente, elevando assim a potência que a linha consegue transmitir. Existem também os condutores termoresistentes, que podem suportar temperaturas mais elevadas, proporcionadas por correntes mais altas, durante um determinado período de tempo. O recondutoramento também pode ser realizado adicionando-se um novo feixe de condutor em paralelo com os condutores pertencentes a cada fase da LT. A utilização de materiais mais resistentes e mais leves pode melhorar o desempenho da linha repotenciada. A repotenciação também pode ser feita dispondo-se de duas ou mais alternativas em conjunto, como o aumento da classe de tensão de operação e ainda a troca do condutor, potencializando os ganhos obtidos com o aumento do SIL (OLIVEIRA, 2000).

Este trabalho propõe uma análise sobre a repotenciação de uma linha de distribuição de $34,5 \mathrm{kV}$ elevando sua classe de tensão para $69 \mathrm{kV}$. Busca-se um procedimento para determinar a viabilidade técnica da conversão da linha em estudo para um nível de tensão mais elevado, aumentando assim, a capacidade de transmissão de potência da linha.

Além dos ganhos de potência, visa-se manter a maior parte das estruturas da linha através de um estudo que considere as sobretensões que possam ocorrer no sistema. As distâncias entre as fases das estruturas ao longo da linha, 
observando-se as propriedades elétricas dos materiais que estas são constituídas, devem suportar a diferença de potencial provocada entre as fases.

Analisando-se a alternativa de elevação da classe de tensão, é preciso avaliar quais os tipos de estruturas presentes na linha podem operar nessa nova classe de tensão, e é proposta então, uma série de simulações computacionais dispondo-se dos softwares ATP e FLUX ${ }^{\circledR}$.

O primeiro passo é fazer o levantamento e o cadastramento da linha piloto e realizar sua modelagem no software ATP. Em seguida devem ser feitos estudos de desempenho via simulações computacionais das duas configurações desejadas, a rede primária de $34,5 \mathrm{kV}$ e a linha de subtransmissão de $69 \mathrm{kV}$.

A linha modelada é submetida a todos os tipos de curtos-circuitos, monofásicos, bifásicos e trifásicos, com e sem o envolvimento do terra, e as sobretensões provocadas por esses curtos-circuitos são registradas em tabelas que são posteriormente utilizadas no software FLUX ${ }^{\circledR}$.

O software FLUX ${ }^{\circledR}$ se baseia na teoria de elementos finitos e sua aplicação neste trabalho visa determinar, em detalhe, a influência do campo elétrico entre os condutores e demais componentes das estruturas (isoladores, poste e cruzeta), considerando as sobretensões mais severas a que a linha está submetida. As conclusões do trabalho se baseiam nas figuras de campo elétrico e linhas equipotenciais obtidas aplicando-se os valores de sobretensão provenientes das simulações no software ATP. Em resumo, o método de elementos finitos é utilizado em uma aplicação eletrostática para avaliar o nível básico de isolamento das estruturas da rede primária de $34,5 \mathrm{kV}$. 
As estruturas que possuem as menores distâncias entre fases são modeladas no software $\mathrm{FLUX}^{\circledR}$, contemplando o poste, padrão da cruzeta, pino do isolador, isolador e mão francesa.

Uma vez que as estruturas estão modeladas no software FLUX ${ }^{\circledR}$, os valores de tensão registrados provenientes dos transitórios eletromagnéticos aplicados na linha modelada no software ATP são aplicados na região do condutor de cada fase no modelo da estrutura no software FLUX ${ }^{\circledR}$.

O software $\mathrm{FLUX}{ }^{\circledR}$ gera figuras que produzem linhas equipotenciais em torno da estrutura modelada, no qual essas figuras são analisadas para verificar as diferenças de potencial que a cruzeta de madeira é submetida. Este método utiliza as características elétricas dos materiais da estrutura como o ferro dos pinos, a madeira da cruzeta e a cerâmica do isolador.

Ao final do trabalho, é apresentada uma análise com relação à utilização destes dois softwares para avaliação do NBI (nível básico de isolamento) das estruturas e uma conclusão com relação à possível utilização das estruturas do padrão de 34,5 kV operando na classe de subtransmissão de 69 kV.

Uma breve descrição dos assuntos tratados nos capítulos a seguir é mostrada abaixo. No capítulo 1 foi apresentada a introdução do trabalho proposto, a metodologia empregada e os procedimentos realizados para viabilizar a repotenciação de uma linha de distribuição de $34,5 \mathrm{kV}$ para a classe de $69 \mathrm{kV}$, vislumbrando a utilização das estruturas já existentes na linha para a nova classe de tensão.

No capítulo 2, um levantamento bibliográfico referente à repotenciação de linhas de transmissão no Brasil é abordado, relatando alternativas além da elevação da classe de tensão operativa da linha. 
Já no capítulo 3, são apresentadas simulações computacionais via software ATP (Alternative Transients Program), uma breve descrição de transitórios eletromagnéticos em sistemas elétricos de potência, assim como o levantamento e modelagem da linha piloto e, finalmente, a aplicação de curtos-circuitos na linha modelada, obtenção e registro das sobretensões provocadas por esses transitórios.

O capítulo 4 é constituído das simulações computacionais via software FLUX $^{\circledR}$, análise das linhas equipotenciais em torno das estruturas da linha modeladas geradas a partir da aplicação dos valores de tensão obtidos com as simulações no software ATP.

Por fim, são apresentadas no capítulo 5 as conclusões e análises pertinentes ao estudo realizado, bem como estudos futuros que possam dar continuidade ao trabalho. 


\section{Capítulo 2 Repotenciação de Linhas de Transmissão}

Neste capítulo, é relatado um levantamento bibliográfico sobre a repotenciação de linhas de transmissão, abrangendo todas as alternativas existentes, inclusive a elevação da classe de tensão.

A repotenciação de linhas de transmissão tornou-se nos últimos anos uma popular opção em companhias de energia elétrica para atender a crescente demanda de energia devido principalmente à dificuldade de se obter novas licenças ambientais para faixas de servidão e ao fato de exigir um capital de investimento bem menor comparado ao necessário para a construção de uma nova linha. Neste contexto, há vários trabalhos na literatura técnica especializada que relatam a experiência de pesquisadores, engenheiros e companhias de energia elétrica neste tópico. Como exemplo, tem-se LU et al. (2006) que tratam do aumento do limite térmico de uma linha de transmissão de $138 \mathrm{kV}$ com circuito duplo. Foi utilizada a técnica Light Detection and Ranging (LiDAR) que trata de um levantamento dos dados da linha a partir de reconhecimento feito por helicóptero. O re-tensionamento dos condutores e a elevação da cintura das torres foram considerados como uma solução de baixo custo e o software PLS-CADD foi utilizado como ferramenta de análise das soluções propostas. O trabalho mostra que o PLS-CADD é uma poderosa ferramenta para projeto de novas linhas, e também pode ser muito útil na repotenciação de linhas já existentes. A combinação de técnicas como o retensionamento de condutores somada à elevação das torres pode minimizar o custo 
da alternativa escolhida para repotenciação, levando a uma solução de baixo custo. A cooperação entre equipes de projeto, construção e manutenção de diferentes áreas (mecânica, estrutural, elétrica) foi essencial para chegar àquelas soluções.

ALBIZU et al. (2005) refere-se a grande pressão atual para aumentar o fluxo de potência nas faixas de servidão já existentes utilizando o máximo possível a infraestrutura já presente. Diversas opções de se aumentar a classificação de linhas aéreas, como o aumento da seção do condutor e o aumento da tensão são apresentadas e, um estudo comparativo das vantagens e desvantagens de cada método é descrito. Conclui-se que muitos fatores devem ser considerados para a escolha do método mais adequado de repotenciação e a escolha da solução ótima varia caso a caso.

HANSON (2005) também analisa estudos de caso em que a elevação da classe de tensão das linhas é a alternativa escolhida para a repotenciação. As vantagens e desvantagens do método e os custos relativos à repotenciação comparado à construção de uma nova linha são delineados. Neste, quatro casos de elevação da tensão são analisados e alterações como as disposições da cadeia de isoladores em postes de madeira são considerados. Os casos estudados mostram que a repotenciação tem um custo benefício adequado e futuramente, com a diminuição da capacidade de reserva e com a dificuldade ou impossibilidade de se obter novas faixas de servidão, muitos casos de repotenciação serão necessários.

O re-tensionamento e re-condutoramento são considerados os mais populares métodos de se aumentar a capacidade de potência das linhas aéreas existentes. Uma metodologia para o cálculo da ampacidade dos condutores sob quaisquer temperaturas em estruturas de linhas aéreas é usada em KOPSIDAS (2010) para ilustrar como a propriedade dos condutores permitem oportunidades de 
elevação da tensão e do limite térmico das linhas. Os estudos comparativos mostraram que os condutores AAACs (all aluminium alloy conductor) tem melhor relação ampacidade/peso que facilita o recondutoramento por permitir uma maior ampacidade e exigir menos esforços nas estruturas e fundações.

PEREIRA et al. (2004) apresentam um estudo de caso relacionado ao campo elétrico e magnético gerado por uma linha de transmissão de energia elétrica repotenciada em um ambiente urbano. Um modelo computacional foi criado para calcular os campos elétricos e magnéticos e medições também foram feitas para verificar o cumprimento dos limites de exposição recomendados pela Organização Mundial da Saúde. O estudo mostra que os valores não ultrapassaram os limites de referência no perfil horizontal, mas, não foram respeitados em algumas áreas no perfil vertical e, sendo assim, deve ser reforçada a regulamentação da zona.

BRAGA et al. (2000) relatam procedimentos de execução e soluções adotadas na repotenciação e reforma de uma linha de transmissão de 69 kV para $138 \mathrm{kV}$, utilizando técnicas de trabalho com linha viva. O custo dos serviços executados com linhas vivas é de 10 a 12 vezes mais alto que os custos envolvidos na execução com a linha desligada. As vantagens em realizar serviços em linha viva compensam os investimentos iniciais, eliminando-se interrupções ao fornecimento de energia elétrica.

MOREIRA et al. (1999) enfatizam que as empresas concessionárias de energia elétrica necessitam urgente e rapidamente aumentar a capacidade de transmissão das suas redes de energia elétrica, com qualidade e custos mínimos, visando à redução dos crescentes riscos de racionamento. Os autores afirmam que o reisolamento e as reformas de linhas de transmissão na COPEL têm permitido incrementar de uma maneira rápida e significativa, a capacidade de transmissão 
com um conseqüente aumento da confiabilidade na operação, a um custo situado entre 15 e $20 \%$ do custo de uma LT nova. O objetivo do autor foi descrever a experiência da COPEL nas soluções adotadas para o reisolamento e reforma de 21 linhas de transmissão ocorrido entre o período de 1982 a 1997. Nesse período foram reisolados $1152 \mathrm{~km}$ de LT, ou seja, $17,8 \%$ da totalidade do seu sistema de transmissão na época. Deste total de linhas reisoladas, $835,3 \mathrm{~km}$ correspondem ao reisolamento de $69 \mathrm{kV}$ para $138 \mathrm{kV}$ e, 316,7 km de $88 \mathrm{kV}$, para $138 \mathrm{kV}$. As primeiras linhas de transmissão reisoladas estão em operação desde 1983 e os dados sobre desligamentos coletados até a data da publicação do trabalho indicam que o desempenho das linhas reisoladas é equivalente ao das outras linhas de $138 \mathrm{kV}$. Logo, os autores confirmaram que, apesar das diversas dificuldades encontradas, o reisolamento é uma medida economicamente conveniente e tecnicamente viável.

Segundo OLIVEIRA (2000), a crescente demanda do sistema elétrico brasileiro e a preocupação ambiental requerem estudos para que seja ampliada sua capacidade de transmissão, sem deixar de satisfazer nenhuma dessas questões. Assim, torna-se fundamental o desenvolvimento de técnicas que permitam aumentar a capacidade de transporte de energia a baixo custo com as instalações existentes e, para tanto, a recapacitação de linhas aparece como uma alternativa a ser analisada. O trabalho apresenta alternativas de técnicas de recapacitação de linhas de transmissão segundo a ótica do dimensionamento elétrico e da determinação das distâncias mínimas de coordenação de isolamento necessárias na torre. Desse modo, visa-se maximizar a energia transportada por área ocupada pela faixa da linha de transmissão, reduzindo assim, a necessidade de negociação de novas faixas de passagens e, portanto, diminuindo o impacto ambiental, o que permite 
ainda, maior agilidade na ampliação da capacidade de transporte da malha existente.

São necessários também, segundo a autora, que o solo e a topografia da região do traçado da linha em operação sejam conhecidos, além da realização de um enfoque detalhado sobre as condições ambientais destas regiões, não só para o dimensionamento elétrico, mas também para as condições mecânicas das torres.

A autora conclui que a recapacitação das linhas de transmissão em operação é possível para a maioria dos casos e, enfatiza que os levantamentos de dados meteorológicos reais da região de cada linha em questão, sejam estudados com o intuito de alcançar a recapacitação otimizada dessa linha.

As técnicas de recapacitação que permitem o não desligamento da linha para sua implantação estão em vantagem em relação às demais. Estas alternativas devem ser analisadas, considerando o sistema elétrico interligado como um todo, admitindo as subestações existentes, seus níveis de tensão e a alteração dos fluxos de potência nas linhas devido a estas mudanças.

DA COSTA et al. (2001) apresentam estudos desenvolvidos no sentido de avaliar a possibilidade de recapacitação de uma linha de transmissão do sistema da EPTE (Empresa Paulista de Transmissão de Energia Elétrica). Dentre outros aspectos, são abordados critérios de projeto, atendimento à potência requerida a médio e longo prazo, análises estruturais das torres e fundações, reforços, avaliação de corrosão nos elementos enterrados, estimativa das perturbações elétricas previstas e proposição de medidas mitigadoras de impactos ambientais, uma vez que parte da linha de transmissão está inserida em área de preservação ambiental. Com a repotenciação, mesmo que haja a necessidade de substituição de algumas estruturas, principalmente daquelas submetidas a elevadas solicitações mecânicas, 
o impacto causado pela linha é significativamente atenuado, sobretudo em função da aplicação de técnicas construtivas que venham a dispensar a remoção da vegetação nativa. Conclusões preliminares desse trabalho conduzem para a possibilidade de reaproveitamento de parcela considerável das torres de transmissão instaladas, permitindo, desta forma, a mudança da classe de tensão de $230 \mathrm{kV}$ para $345 \mathrm{kV}$. Considerando avaliações relativas à previsão de demanda futura e a necessidade de conexões adicionais para a confiabilidade do sistema interligado, os autores afirmam que a proposta apresentada mostra-se bastante interessante, tanto do ponto de vista econômico quanto dos aspectos de redução dos impactos ambientais decorrentes da implantação de linha de transmissão em área de preservação ambiental. Além disso, segundo as previsões de alterações do setor elétrico brasileiro na época da publicação do trabalho, sua proposta apresentase ainda mais atraente do ponto de vista financeiro, pois a repotenciação viria a atender às necessidades de médio prazo, cerca de 7 a 8 anos, reduzindo 0 investimento imediato por parte dos poderes públicos. Finalmente, os autores recomendam que, sempre que possível, a alternativa de repotenciação de linhas de transmissão deve ser avaliada nos estudos preliminares de ampliação do sistema elétrico face às sensíveis reduções de custo que podem ser obtidas.

FONSECA e CIMINI (2003) apresentam uma análise da vida útil de cabos condutores CAA (condutor de alumínio com alma de aço) para linha aérea de transmissão de energia elétrica em função de seu limite de resistência mecânica à tração e de seu limite de resistência mecânica à fadiga. Fatores da vida útil são apresentados juntamente com uma metodologia implementada para essa análise. Uma vez que a análise da viabilidade do projeto de repotenciação em questão utiliza os mesmos cabos condutores já presentes nas linhas, um estudo do envelhecimento 
dos cabos é extremamente importante. A metodologia implementada apresenta resultados conservativos em relação à perda de resistência mecânica do cabo condutor. O valor calculado pela metodologia é $136 \%$ acima do valor encontrado nos ensaios. O trabalho também apresentou resultados conservativos em relação à análise da perda da resistência à fadiga do cabo condutor nos casos de recapacitação. Nos casos em que a linha de transmissão mantém suas características originais será necessário o desenvolvimento de curvas que representem os diferentes níveis de tensão dinâmica a que o condutor estará submetido e a quantidade de ciclos representativos destes níveis de tensão. Com essas curvas é possível analisar a influência das características da região sobre a vida útil do cabo condutor. Para os casos de recapacitação de linha de transmissão, o resultado final apresenta-se conservativo em relação à análise tanto de perda de resistência mecânica quanto de perda de resistência à fadiga. Por outro lado, para linhas de transmissão com suas características originais (linhas novas), o resultado final mostra-se conservativo somente em relação à vida útil residual devido à perda de resistência mecânica, ou seja, para análise da resistência à tração do cabo condutor. Paralelamente a essas conclusões, os autores afirmam que novos estudos e ensaios são necessários com o objetivo de otimizar a metodologia e reduzir a diferença entre os resultados práticos e teóricos.

DUTRA et al. (2005) tratam de uma contribuição técnica que apresenta a experiência da Eletrosul Centrais Elétrica S.A. na recapacitação de linhas de transmissão em $230 \mathrm{kV}$. O trabalho consistiu na troca do cabo condutor ACSR (Aluminium Conductor Steel Reinforced) Grosbeak existente pelo cabo termoresistente TACSR Grosbeak e a recapacitação no reforço de suportes auto-portantes de aço galvanizado. São relatados aspectos que levaram à escolha desta solução, 
aspectos de engenharia de projeto e construção, ensaios dos materiais, critérios de projeto e execução de reforços dos suportes. Os resultados mostraram que a Eletrosul aumentou a capacidade de transmissão de energia das linhas repotenciadas em $50 \%$, sendo necessário um investimento reduzido em relação à construção de uma nova linha de transmissão. Um aspecto importante é que se utilizou a mesma faixa de segurança, reduzindo a zero os impactos ambientais e sociais do recondutoramento, que seriam significativos caso se optasse pela construção de novas linhas. Além disso, outro benefício da repotenciação foi o atendimento aos prazos curtos estabelecidos para viabilização das obras, tendo em vista que as mesmas foram consideradas emergenciais. A recapacitação e repotenciação dessas linhas resultaram em um benefício sistêmico, reconhecido pelo ONS (Operador Nacional do Sistema Elétrico), à empresa transmissora ressarcida dos custos envolvidos.

STEPHAN e COSTA (2007) apresentam a experiência da Eletrosul na recapacitação e repotenciação de linhas de transmissão em 138, 230 e 500 kV, fazendo uma síntese dos principais procedimentos para análise e verificação da adequação de uma linha de transmissão. Para tanto, tiveram em vista sua repotenciação e/ou recapacitação, bem como, apresentaram procedimentos efetuados durante as fases de estudo de viabilidade técnico-econômica, anteprojeto, projeto e construção das linhas repotenciadas e/ou recapacitadas. Nesse trabalho são apresentados os conceitos sobre os quais foram baseados os critérios de avaliação dos componentes das linhas, como suportes e fundações, assim como os principais aspectos das metodologias utilizadas para tal.

SILVA et al. (2007) abordam a reforma da linha de transmissão de $230 \mathrm{kV}$ que liga Bandeirantes - Brasília Geral, construída em 1959/1960 e transferida à 
FURNAS Centrais Elétrica S.A. em 1971. Essa linha vinha operando com pouca carga e, mesmo assim, apresentava diversos vãos com cabo baixo que eram corrigidos, caso a caso, pelas equipes de manutenção de FURNAS. Ficou definido que essa linha iria alimentar a SE (Subestação) Pirineus, o que ocasionaria o aumento da carga e o agravamento do problema de cabo baixo. Tal fato acarretou a necessidade de realizar uma reforma em larga escala da linha. Assim, o trabalho consistiu em descrever o levantamento de campo, os estudos, as soluções adotadas e os trabalhos de campo realizados para esta reforma. A metodologia adotada para a reforma da linha em questão mostrou-se altamente eficiente e econômica. $\mathrm{O}$ trabalho todo foi, contando com as interrupções causadas por problemas de autorização para desligamentos e o atraso na entrega de materiais, realizado em 189 dias corridos. O custo total do empreendimento foi de $\mathrm{R} \$ 2.287 .477,57$, enquanto o custo ELETROBRÁS de uma linha nova de $230 \mathrm{kV}$ similar, com $160 \mathrm{~km}$, seria de $\mathrm{R} \$ 41.479 .606,40$, o que corresponde, portanto, a 5,5\% do custo de uma LT similar nova, com um prazo de execução muito menor.

Após este levantamento de alguns casos de repotenciação, iniciam-se os estudos no capítulo 3 da linha piloto e as simulações no software ATP para gerar os transitórios eletromagnéticos que são posteriormente utilizados no software FLUX ${ }^{\circledR}$. 



\section{Capítulo 3 Simulações Computacionais Temporais via Software ATP}

Neste capítulo são apresentadas as simulações computacionais, via software ATP, abordando curtos-circuitos monofásicos, bifásicos e trifásicos, com e sem o envolvimento do terra para a obtenção dos máximos valores de tensão de cada fase. Esses valores máximos de tensão são utilizados nas simulações via software $F L U X^{\circledR}$, aplicando-os nos condutores, para realização de uma análise dos campos elétricos na estrutura modelada, conforme será abordado no Capítulo 4.

A partir do levantamento e cadastramento dos dados físicos e elétricos da linha, como altura do meio vão, resistência do condutor, distâncias entre fases e resistividade do solo, é modelada a configuração de $34,5 \mathrm{kV}$ representando a linha o mais próximo possível da condição real de operação. Além da configuração de 34,5 $\mathrm{kV}$, o capítulo contempla as análises e estudo de desempenho via simulações computacionais da mesma linha convertida para a classe de tensão de $69 \mathrm{kV}$.

Como referência à análise dos resultados das simulações tem-se o IEEE Guide for Improving the Lightning Performance of Eletric Power Overhead Distribution Lines (IEEE STD 1410, 2004), padrão este que visa a melhoria do desempenho da linha de distribuição, ou seja, o aumento do nível básico de isolamento $(\mathrm{NBI})$, com níveis de tensão de até $69 \mathrm{kV}$. Este padrão aborda os procedimentos para avaliar e melhorar o desempenho das linhas de distribuição aéreas frente às descargas atmosféricas, considerando a rigidez dielétrica do ar e dos materiais que compõem as estruturas. 
Antes de descrever as simulações computacionais temporais por meio do software ATP, a seção a seguir trata sobre transitórios eletromagnéticos em sistemas elétricos de potência. De acordo com sua velocidade, os transitórios eletromagnéticos podem ser classificados em ultra-rápidos, meio rápidos e lentos (ELGERD, 1981). As seções seguintes se dedicam a explanação dos mesmos.

\section{1 - TRANSITÓRIOS ELETROMAGNÉTICOS}

Sobretensões transitórias provocadas por transitórios eletromagnéticos em sistemas de potência são principalmente relacionadas a chaveamentos, ocorrência de faltas e descargas atmosféricas. Para níveis de tensão maiores que $230 \mathrm{kV}$, chaveamentos e faltas, comumente chamados de distúrbios internos, podem ser mais importantes que descargas atmosféricas. Isto simplesmente é devido ao fato de que as sobretensões internas estão diretamente relacionadas à tensão nominal do sistema (GOMEZ, 2007).

Em geral, descargas atmosféricas produzem os surtos mais elevados e assim determinam os níveis de isolação. Entretanto, sob tensões de operação de $400 \mathrm{kV}$ e acima, sobretensões geradas pelo sistema, como por exemplo, causadas pela energização da linha de transmissão, podem ser o fator determinante para a coordenação da isolação (WATSON e ARRILLAGA, 2003).

\subsection{1 - TRANSITÓRIOS ULTRA-RÁPIDOS}

Transitórios ultra-rápidos são causados por descargas atmosféricas nas linhas de transmissão expostas ou pelas mudanças abruptas na rede resultantes de operação de chaveamento. 
Estes transitórios, de tensão e de corrente, são de natureza inteiramente elétrica, em que ocorrem ondas refletidas nos terminais da linha, como pode ser visto na Figura 3.1. Nesses casos, as intensidades das tensões e correntes refletidas são dependentes da resistência no receptor (ou terminal) da linha (FUCHS, 1979). Se a resistência terminal $\mathrm{R}$ for maior que a impedância característica da linha, a corrente refletida $\mathrm{i}_{2}$ será menor que $\mathrm{i}_{1}$ e a energia magnética perdida pela diminuição da corrente $i_{1}$ tem como destino o campo elétrico, que se manifesta na forma de uma elevação da tensão $V_{2}$. Caso contrário, se a resistência de terminação da linha for menor que a impedância característica da linha, $\mathrm{i}_{2}$ sofre um aumento em relação a i 1 e a energia que o campo magnético deve receber se dá pela diminuição do campo elétrico, provocando uma diminuição de $\mathrm{V}_{2}$ com relação a $\mathrm{V}_{1}$.

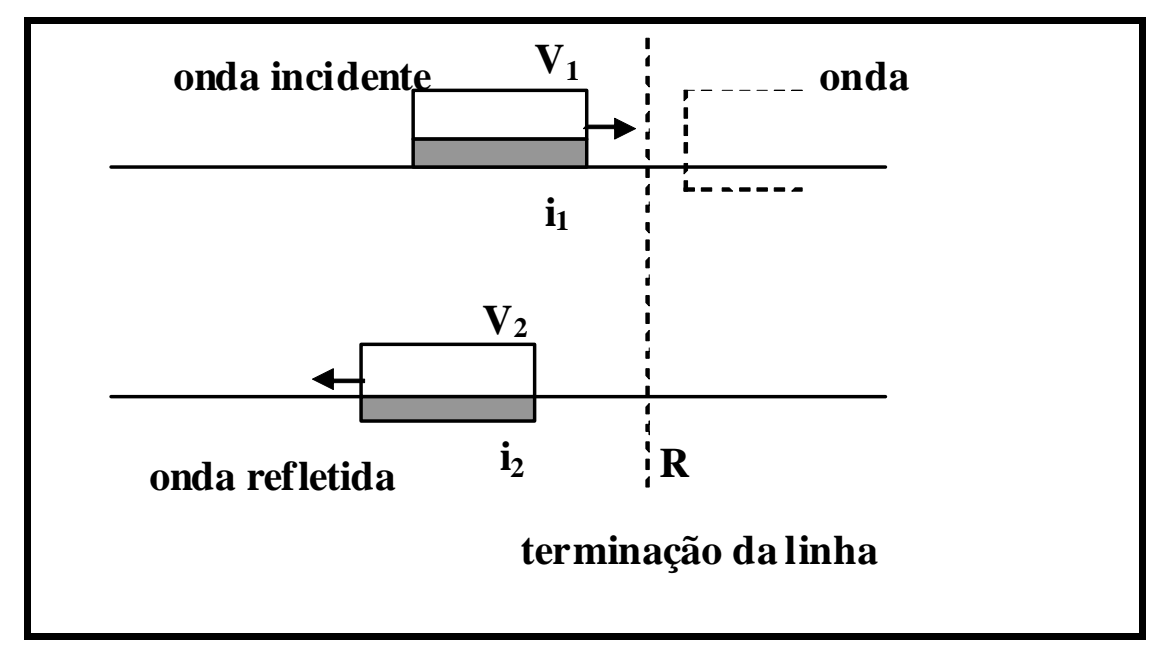

Figura 3.1 - Onda refletida na terminação da linha

\subsubsection{1 - DESCARGAS ATMOSFÉRICAS}

Como fato, tem-se que as descargas atmosféricas ocorrem com o intuito de neutralizar as nuvens carregadas eletricamente. Uma nuvem torna-se carregada eletricamente devido às fortes correntes de ar para cima e para baixo existentes na atmosfera, que fazem com que as cargas negativas fiquem localizadas na parte 
inferior da nuvem e, as cargas positivas, na parte superior. Essa neutralização pode ocorrer entre nuvens ou entre nuvem e a terra. A descarga atmosférica é iniciada através de uma sucessão de descargas menores que a principal, e que buscam o caminho de menor resistência, rompendo o dielétrico que nesse caso é o ar. A descarga inicial cresce e se ramifica buscando o menor caminho até o solo ou algum ponto condutor mais elevado, culminando na descarga principal. Essa descarga é caracterizada pelo efeito de alta luminosidade chamado de relâmpago e do barulho estrondoso o qual é chamado de trovão (DIESENDORF, 1974).

Um conceito fortemente relacionado às descargas atmosféricas é o índice ceráunico (IC), que por definição é o número de dias por ano que apresentam trovoadas. Utilizando este índice, pode-se calcular a densidade de raios para o solo (DR) que caem por ano em um $\mathrm{km}^{2}$ utilizando a Eq. (3.1).

$$
D R=0,0024 \cdot I C^{1,63}
$$

De acordo com Kindermann (1992), o índice ceráunico de Campinas, região onde se situa a linha de transmissão escolhida para a repotenciação durante esse estudo, é de 51. Com a Eq. (3.1), calcula-se a densidade de raios para a região da linha de transmissão:

$$
D R=0,0024 \cdot 51^{1,63}=1,457
$$

Ou seja, a densidade de raios é de 1,457 raios por $\mathrm{km}^{2}$ por ano.

Para a proteção de linhas de transmissão contra as descargas atmosféricas, outro item importante é a quantidade de raios incidentes na linha por km por ano. Esse item pode ser calculado através da Eq. (3.2).

$$
\text { Raios Incidentes }=\mathrm{DR} \cdot \frac{\left(28 \mathrm{~h}^{0,6}+\mathrm{b}\right)}{10}
$$

Sendo: 
DR - Densidade de Raios;

h - Altura da estrutura e

b - Largura da estrutura.

Das situações em campo, tem-se que correntes de descargas atmosféricas podem atingir as linhas de transmissão diretamente e/ou indiretamente, causando sobretensões. As descargas indiretas são as mais freqüentes, porém geram sobretensões menores do que as descargas diretas. As descargas diretas atingem a estrutura, os cabos energizados ou o cabo guarda da linha de transmissão, como podem ser observadas na Figura 3.2 e são responsáveis por causar os maiores prejuízos ao sistema. Após atingir um determinado ponto da linha, a corrente de descarga gera duas ondas de tensão que percorrem a linha em direções opostas até que se amortizem. Para a realização do cálculo da magnitude da tensão gerada pela corrente de descarga, é preciso dispor de informações como a impedância natural, obtida através da Eq. (3.3), onde L e C são a indutância e a capacitância por metro da linha em questão (DIESENDORF, 1974).

$$
Z_{0}=\sqrt{\frac{L}{C}}
$$

Dessa forma, o cálculo da tensão é realizado através da Eq. (3.4):

$$
V=\frac{I \cdot Z_{0}}{2}
$$




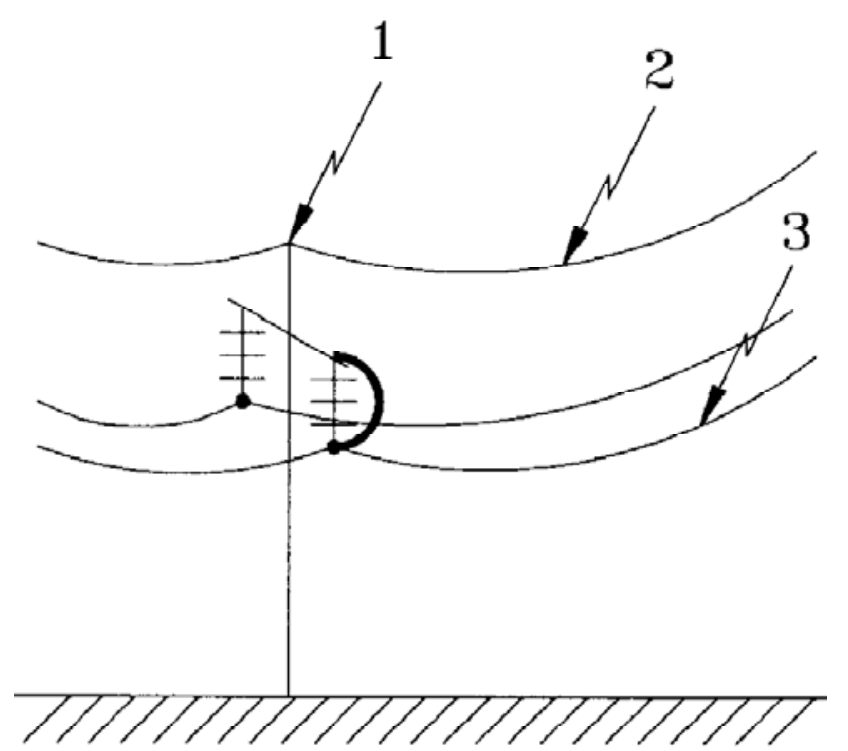

Figura 3.2 - Descargas diretas: 1- descarga direta na estrutura, 2 - descarga direta no cabo guarda, 3 - descarga direta no cabo energizado.

O número de desligamentos de uma linha pode ser facilmente calculado, pois é a quantidade de vezes em que o valor calculado pela Eq. (3.4) ultrapassa o nível básico de isolamento da linha. Isso só é possível, porém, se as estruturas forem desprezadas, o que pode ser feito apenas nos casos em que as estruturas existentes sejam de pequeno porte.

Para simular a descarga atmosférica, a corrente de descarga é aplicada em um ponto da linha em paralelo com um canal de impedância que varia entre $1000 \Omega$ e $3000 \Omega$ (DIESENDORF, 1974).

O equivalente de Norton para descargas atmosféricas está representado na Figura 3.3, onde $I_{0}$ é a corrente de descarga, $Z_{\mathrm{s}}$ é a impedância variável entre 1000 e $3000 \Omega$ e Z representa a impedância equivalente do circuito. 


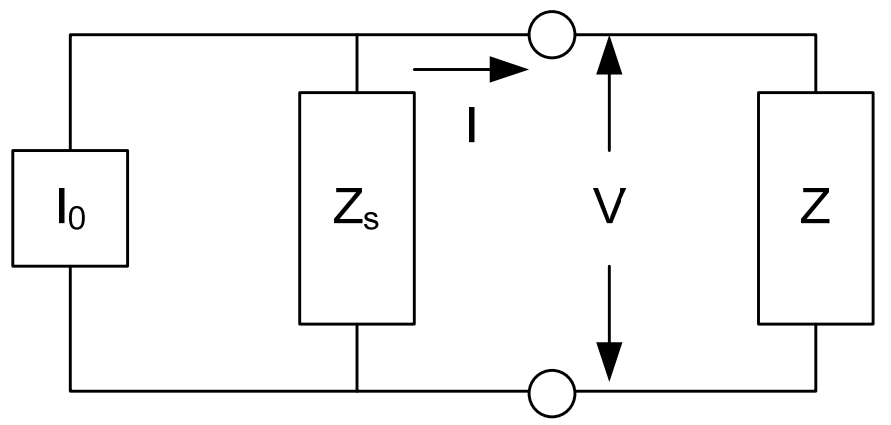

Figura 3.3 - Equivalente de Norton para caracterizar descargas atmosféricas.

\subsubsection{2 - CHAVEAMENTOS}

Surtos de chaveamento ocorrem em sistemas de potência como resultado de mudanças na configuração elétrica do sistema. Tais mudanças são principalmente associadas com operações de chaveamento e eventos de falta. Estas sobretensões geralmente apresentam magnitudes de crista que variam de 1 a 3 p.u. para surtos fase-terra e 2 a 4 p.u. para surtos fase-fase, sendo que valores maiores algumas vezes são encontrados como resultado de condições de ressonância do sistema (CHOWDHURI, 2001).

Surtos associados com o chaveamento de linhas de transmissão incluem aqueles que são gerados pela energização da linha, intertravamento, iniciação de falta, desenergização, eliminação da falta, etc. Durante a operação de energização, por exemplo, fechar um disjuntor no instante de tensão de crista do sistema resulta em uma onda de surto viajante de 1 p.u. pela linha de transmissão, sendo refletida no terminal remoto que estará na situação de terminal aberto. A reflexão interage com a onda vinda na fase sob consideração tanto quanto as ondas viajantes nas fases adjacentes. Sendo assim, ao mesmo tempo, as ondas estarão sendo atenuadas e modificadas pelas perdas na linha. Conseqüentemente, é difícil predizer precisamente a forma de onda resultante sem empregar sofisticadas ferramentas 
computacionais como, por exemplo, o TNA (Transient Network Analyzer) ou programas digitais, como o programa EMTP (Eletromagnetic Transients Program).

\subsection{2 - TRANSITÓRIOS MEIO-RÁPIDOS}

São transitórios causados por mudanças estruturais abruptas e anormais, tais como curtos-circuitos no sistema elétrico.

A maioria ocorre nas LTs expostas devido a:

- rompimento de isolação;

- sal nos isoladores;

- pássaros e causas mecânicas.

Por ordem de gravidade podem ser divididas em:

- Curto-Circuito nas três fases;

- Curto-Circuito de duas fases;

- Curto-Circuito fase-Terra.

No curto-circuito metálico (ou sólido), simétrico (ou equilibrado) nas três fases, a capacidade de transmissão é reduzida a zero. A Figura 3.4 ilustra um exemplo de falta simétrica, em que $Z_{\mathrm{f}}$ representa a impedância de falta.

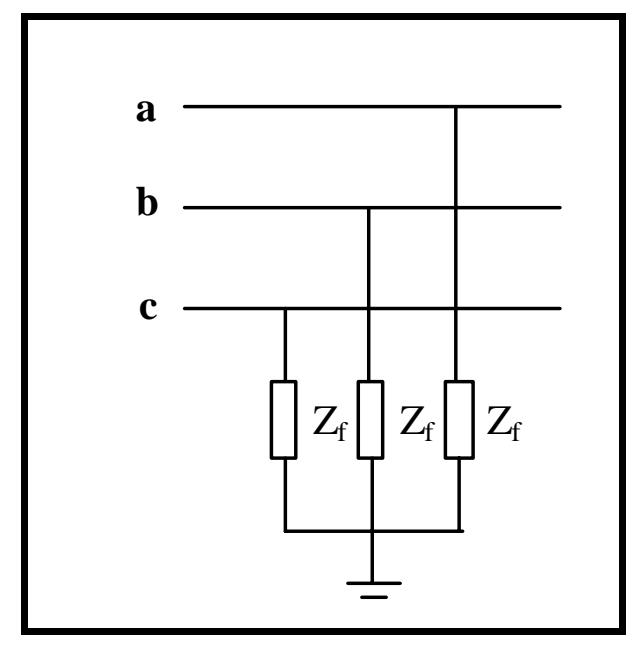

Figura 3.4 - Esquema de um curto-circuito trifásico 
A Figura 3.5 ilustra à esquerda, um curto-circuito bifásico com o envolvimento do terra e à direita, um curto-circuito bifásico sem o envolvimento do terra.

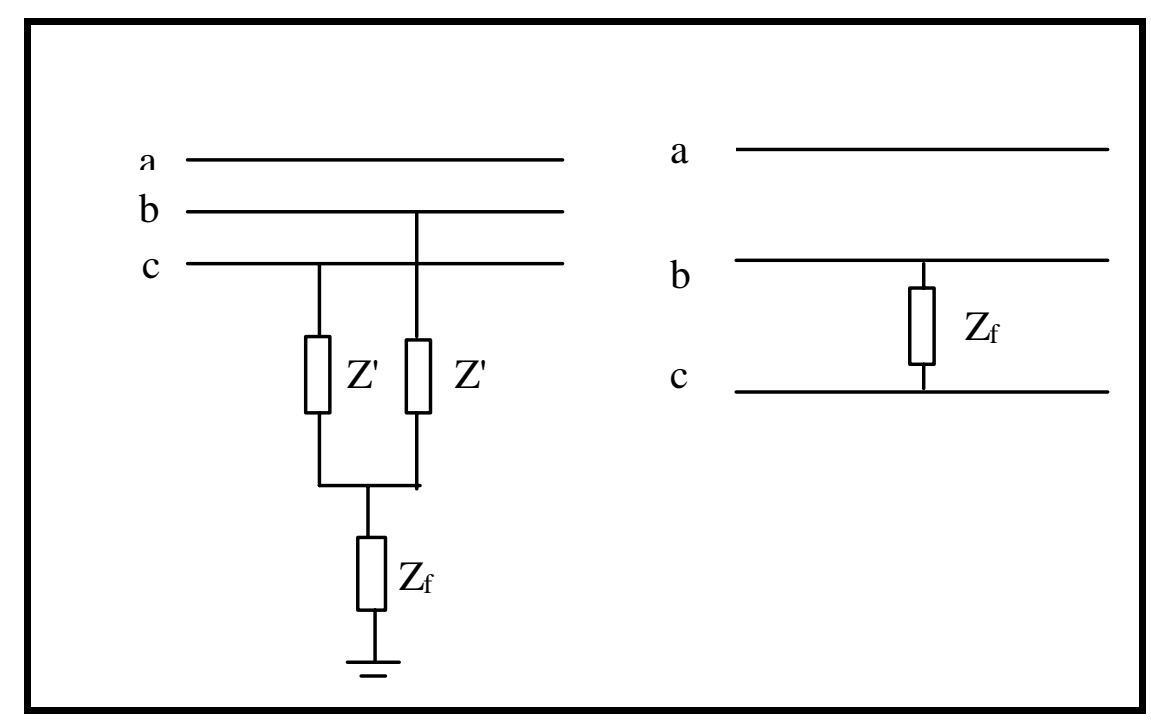

Figura 3.5 - Esquema de curto-circuito bifásico com e sem o envolvimento do terra Já a Figura 3.6 apresenta um curto-circuito fase terra.

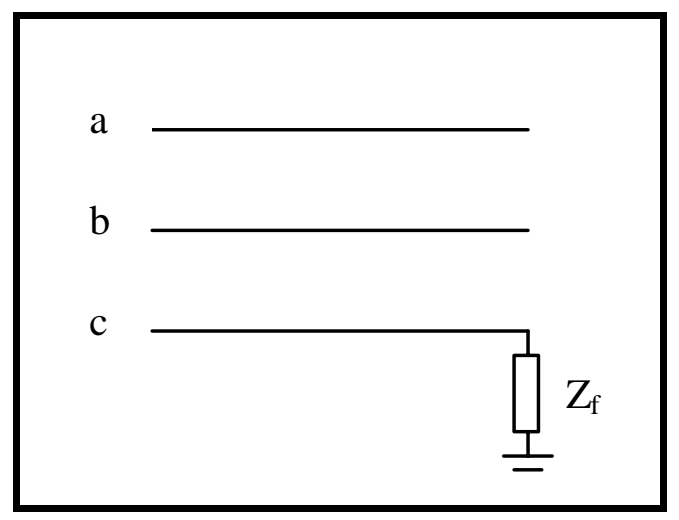

Figura 3.6 - Esquema de curto-circuito fase terra

Os transitórios meio rápidos também são de natureza puramente elétrica e os primeiros 10 ciclos das correntes de curto-circuito (CC) são os de maior importância prática.

As correntes de CC podem atingir valores muito altos e, se persistirem, podem causar danos térmicos ao equipamento e darão origem a oscilações 
mecânicas no gerador. Deve-se então eliminar a falta o mais rápido possível, isolando a menor parte possível do sistema.

\subsection{3 - TRANSITÓRIOS LENTOS}

Se a parte faltosa não for desligada, a situação pode evoluir para o tipo mais perigoso de situação transitória, ou seja, oscilações mecânicas nos rotores das máquinas síncronas.

Esses transitórios eletromecânicos podem tirar algumas ou todas as máquinas do sincronismo. Diz-se que o sistema atingiu o seu limite de estabilidade transitória (ELGERD, 1981).

Após essa breve descrição de transitórios eletromagnéticos em sistemas elétricos de potência, a próxima seção apresenta uma descrição da linha piloto utilizada no estudo.

\section{2 - LINHA PILOTO}

Nesta seção são descritas algumas informações importantes a respeito da linha em análise que são úteis para o entendimento dos esquemas apresentados para a aplicação de curtos-circuitos, bem como para apresentação das diferentes estruturas que constituem a linha, foco principal das simulações no software FLUX ${ }^{\circledR}$, abordado no Capítulo 4.

É importante colocar que a linha modelada e em análise possui $8,7 \mathrm{~km}$ de extensão, com estruturas de diferentes geometrias e distâncias entre fases que podem variar de $3 \mathrm{~m}$, como no caso da estrutura classificada como "HS" (CPFL, 1984d), e até 0,74 m, como a estrutura "A" (CPFL, 1984a) ou "B" (CPFL, 1984b). Estas possuem as mesmas distâncias diferindo apenas no número de cruzetas, uma e duas respectivamente. 
A linha foi escolhida para este estudo por ser uma linha curta, o que reduziria os custos de uma possível repotenciação e de estudos necessários ao reprojeto da nova configuração de $69 \mathrm{kV}$, dado que os custos são calculados por quilômetro.

Em uma das extremidades da linha, tem-se uma PCH (Pequena Central Hidrelétrica), localizada na cidade de Salto Grande - SP, referenciada no trabalho como USG e na outra extremidade a subestação de Souzas, denominada SOZ.

Como a linha possui uma miscelânea de tipos de estruturas ao longo de sua extensão, algumas figuras ilustrativas são necessárias para verificar as diferenças em suas geometrias.

A Figura 3.7 apresenta uma estrutura do tipo "G" (CPFL, 1970), com 1,5 m de distância tanto entre as fases $A$ e $B$ quanto entre as fases B e C. A referência do projeto desta estrutura pode ser encontrado em CPFL (1970).

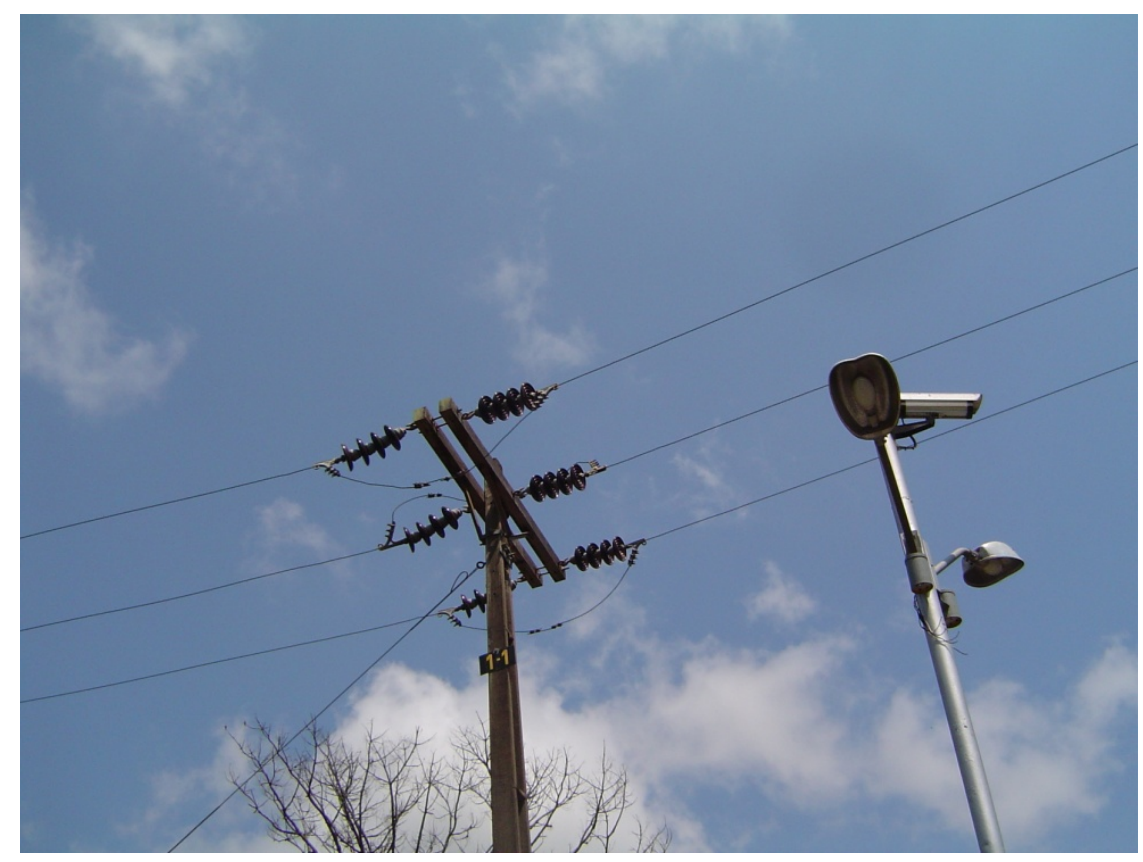

Figura 3.7 - Estrutura do Tipo "G" 
A Figura 3.8 apresenta uma estrutura do tipo "A", com 1,5 m de distância entre as fases $A$ e $B$ e $0,74 \mathrm{~m}$ entre as fases $B$ e C (CPFL, 1984a), sendo considerada a estrutura mais crítica em relação ao $\mathrm{NBI}$, pois possui o menor espaçamento entre fases das estruturas existentes na linha.

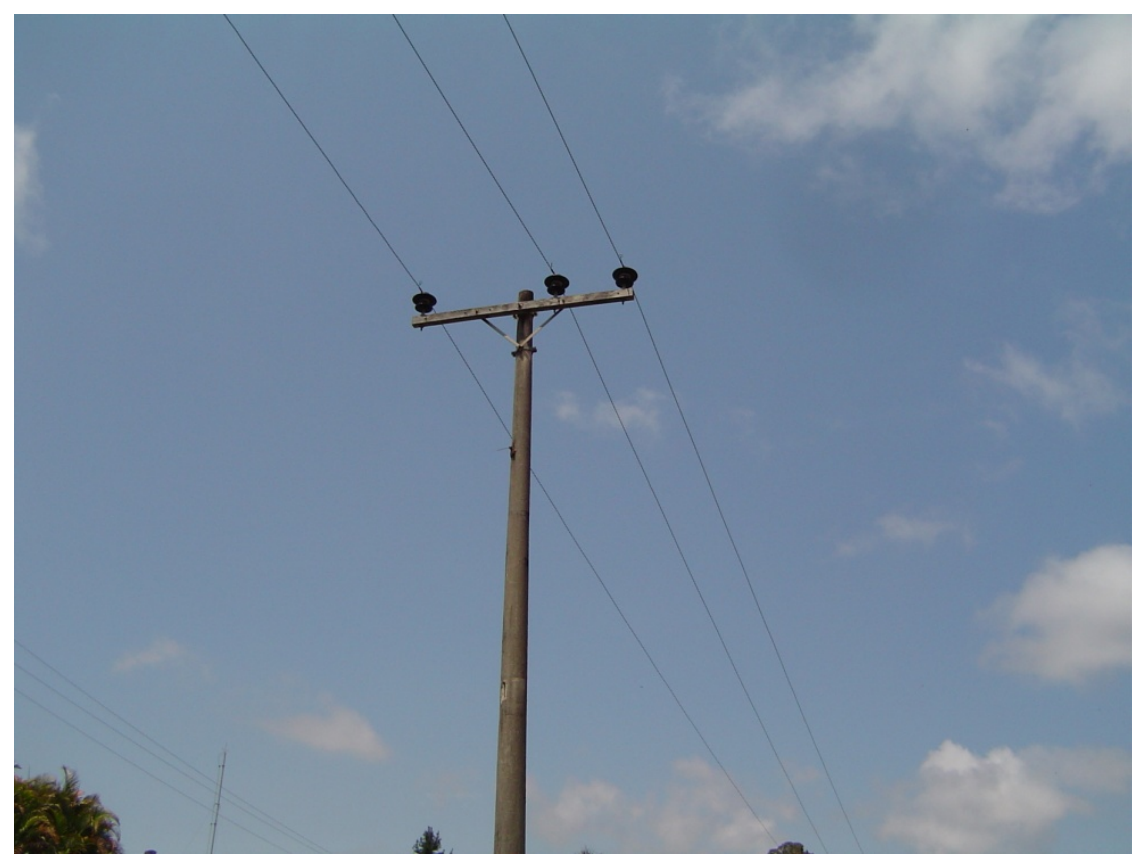

Figura 3.8 - Estrutura do Tipo "A"

A Figura 3.9 apresenta uma estrutura do tipo "B", com as mesmas características de isolação da estrutura anterior, porém com cruzeta dupla, uma vez que esta é utilizada na quebra de esforços mecânicos (CPFL, 1984b).

Pode-se verificar na Figura 3.10, uma estrutura do tipo "E" com dimensões diferentes das anteriores, sendo que o condutor central está localizado no alto do poste e, as fases ao lado, localizam-se um pouco abaixo na cruzeta (CPFL, 1984c). 


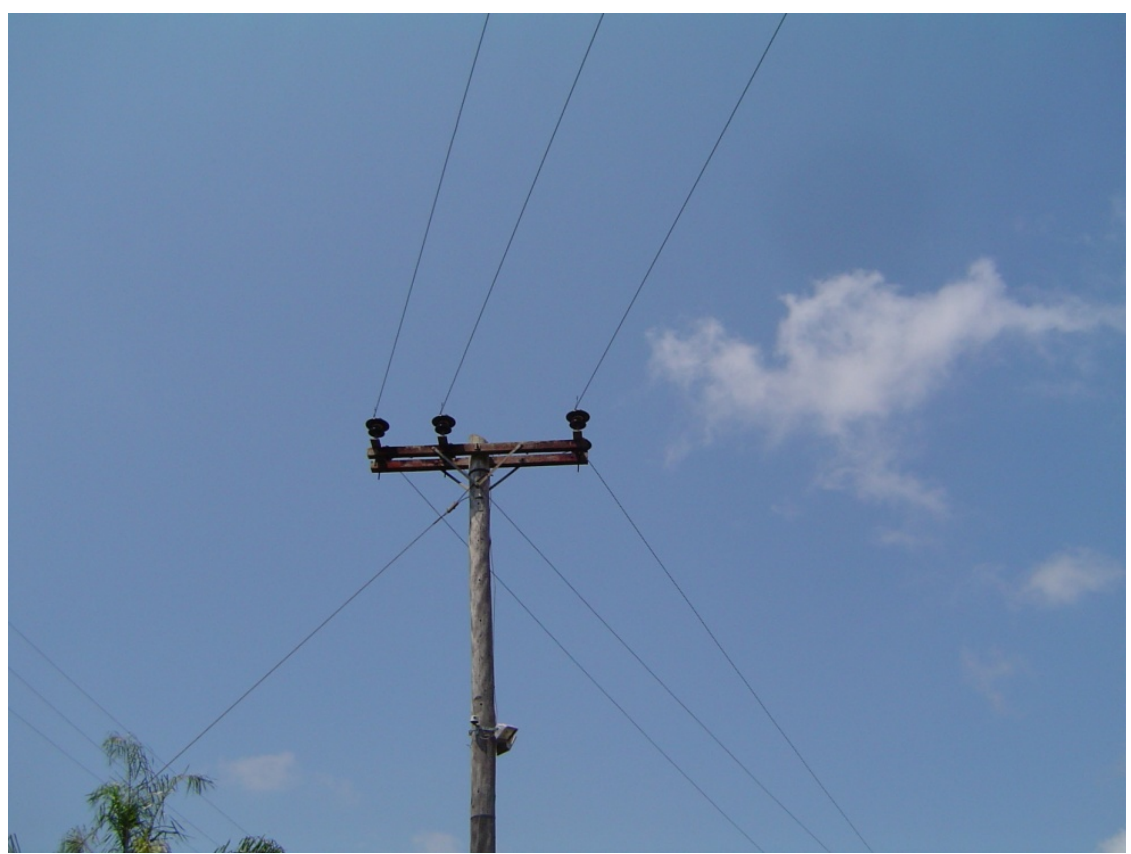

Figura 3.9 - Estrutura do Tipo "B"

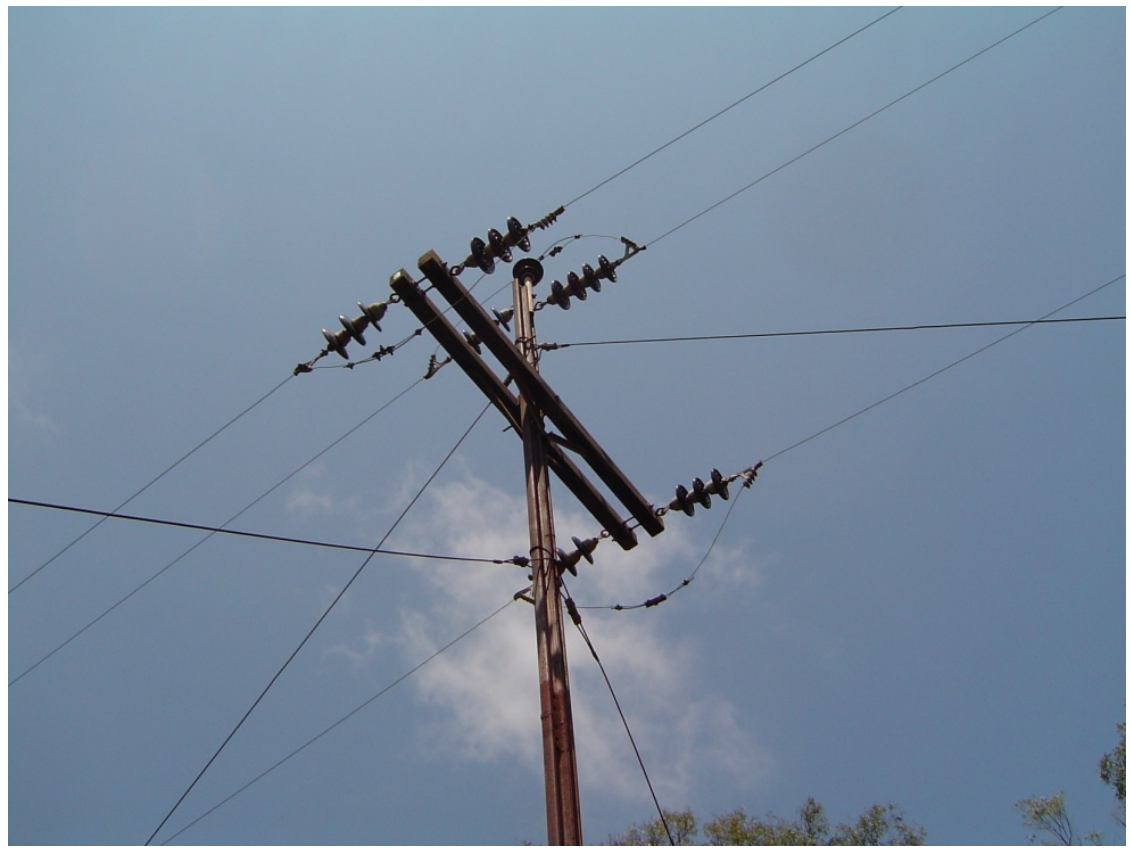

Figura 3.10 - Estrutura do Tipo "E"

Na Figura 3.11 tem-se uma estrutura que apresenta um espaçamento bem maior do que as anteriores e com uma cadeia de isoladores em suspensão adequada para a classe de $69 \mathrm{kV}$ e espaçamento de $3 \mathrm{~m}$ entre as fases (CPFL, 1984d). 
A estrutura apresentada na Figura 3.12 apresenta dimensões semelhantes à mostrada na figura anterior, porém, os isoladores dessa estrutura são da classe de 34,5 kV (CPFL, 1984e).

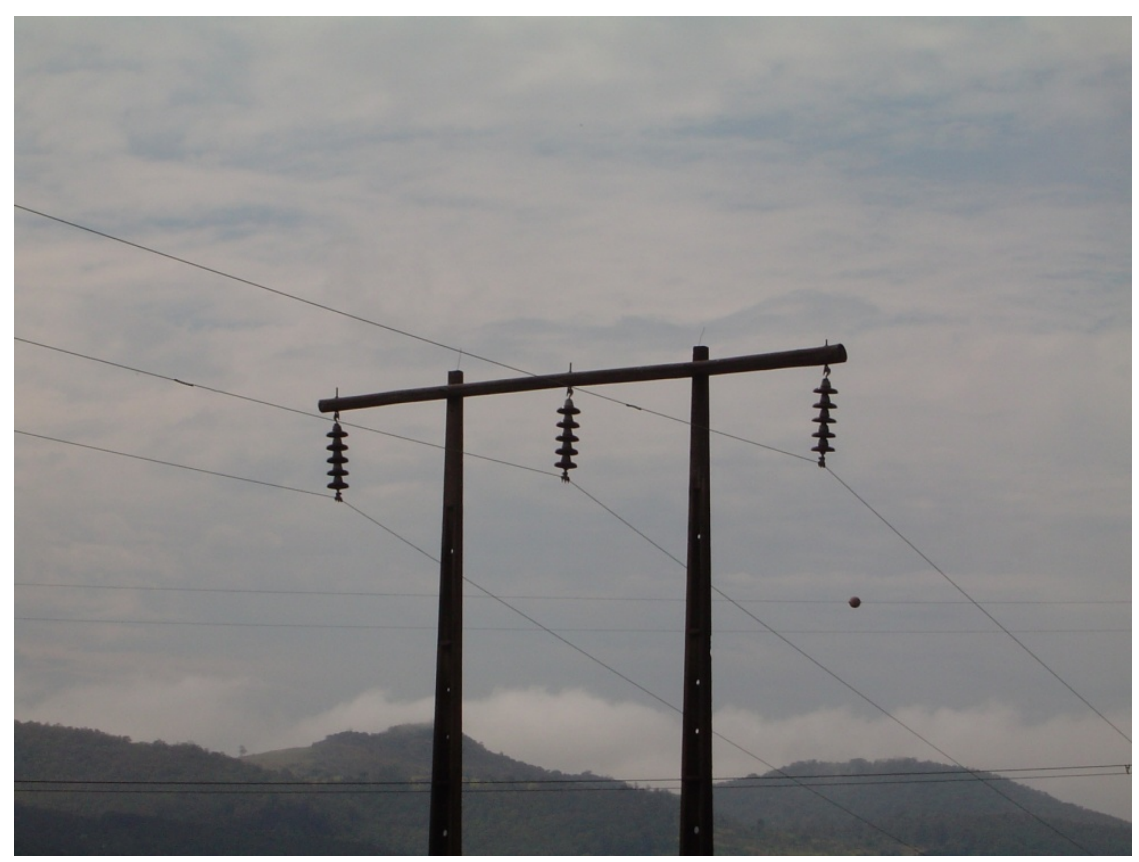

Figura 3.11 - Estrutura do Tipo "HS"

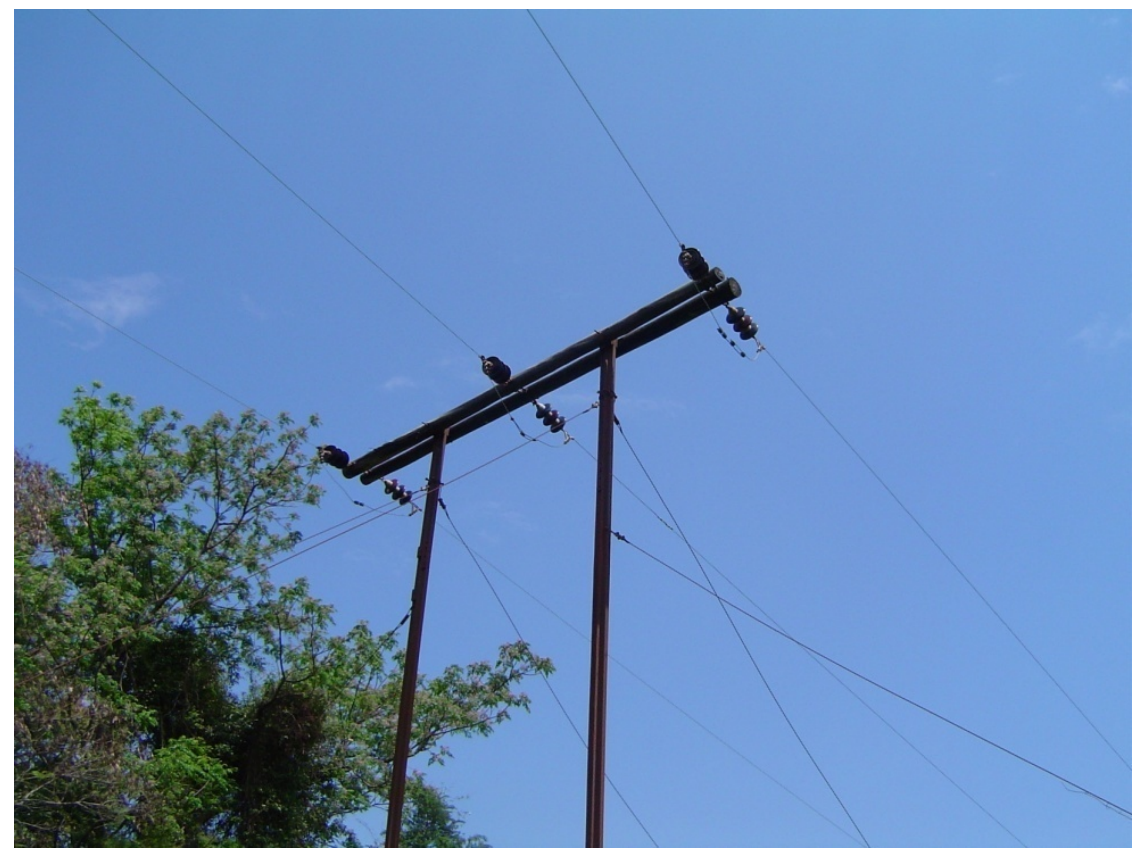

Figura 3.12 - Estrutura do Tipo "HT" 
Pode-se notar, pelas fotos apresentadas que algumas estruturas pertencentes à linha são mais robustas com relação à isolação, como as estruturas do tipo "HT", "HS" e "E". Estas estruturas apresentam um maior espaçamento entre as fases e isoladores mais robustos do que os do tipo pino, encontrados nas estruturas tipo "A" e "B". Essas são algumas das informações que são utilizadas na modelagem da linha, que é abordada na próxima seção.

\section{3 - MODELAGEM DA LINHA}

Neste item, os parâmetros de entrada dos componentes da interface gráfica ATPDraw para o software ATP, bem como as configurações do modelo são apresentadas. Seguem abaixo os componentes configurados:

- Rotina LCC - Line/Cable Constants;

- Transformador e fontes equivalentes de tensão (subestação e usina geradora);

- Modelagem de curto-circuito.

Alguns aspectos com relação à escolha do modelo matemático para representação da linha de transmissão no modelo computacional devem ser observados.

Os modelos de seção PI nominal aproximados são freqüentemente usados para linhas de transmissão curtas (até $15 \mathrm{~km}$ ), em que o tempo de viagem da onda de tensão é menor que o tempo de integração da solução. No entanto, tais modelos são impróprios para linhas de transmissão com grandes comprimentos (superiores a $15 \mathrm{~km}$ ) e, nestes casos, a teoria de ondas viajantes é usada no desenvolvimento de modelos mais realísticos (WATSON e ARRILLAGA, 2003). Para auxiliar a escolha do modelo da linha de transmissão empregado neste trabalho, foi utilizado o fluxograma da Figura 3.13, o qual aponta o modelo computacional mais adequado, 
baseando-se na disponibilidade de informações sobre o comprimento e geometria da linha.

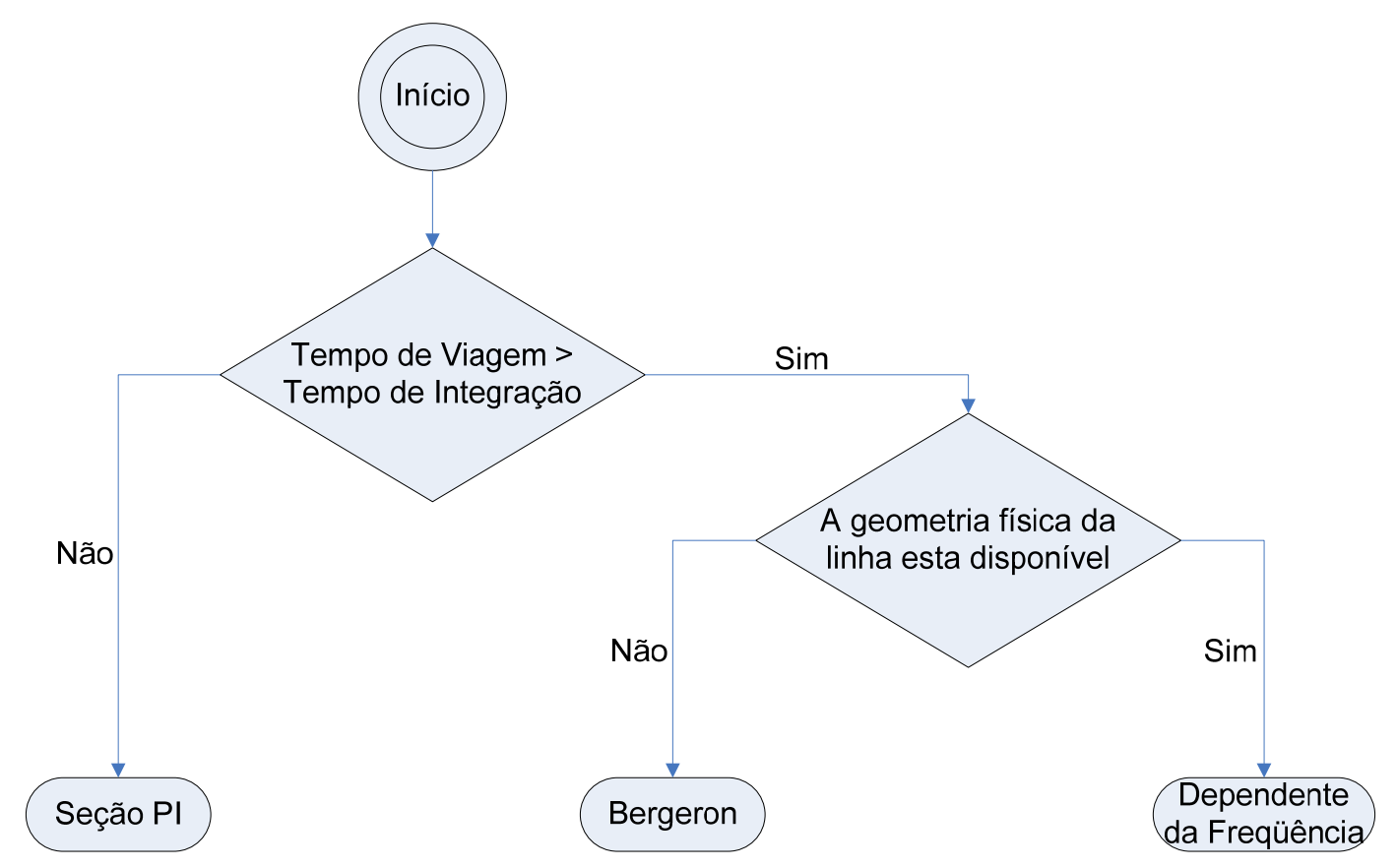

Figura 3.13 - Fluxograma para escolha do modelo computacional de linhas de transmissão (WATSON e ARRILLAGA, 2003)

Os parâmetros das linhas de transmissão com retorno pelo terra são altamente dependentes da freqüência, sendo que a modelagem precisa dessa dependência da freqüência sobre toda a faixa de freqüência dos sinais é de essencial importância para a correta simulação das condições transitórias eletromagnéticas (MARTI, 1982).

Ainda com respeito à modelagem, no trabalho apresentado por SEMLYEN (1975), tem-se que os modelos que assumem parâmetros constantes não podem adequadamente simular a resposta da linha sob uma larga faixa de freqüências que estão presentes nos sinais durante condições transitórias. Na maioria dos casos, a representação de parâmetros-constantes produz uma ampliação das harmônicas mais altas dos sinais e, como conseqüência, uma distorção das formas de onda e magnitude exagerada dos picos. Sendo assim, as rotinas descritas no trabalho evitam uma série de dificuldades numéricas encontradas nas formulações 
anteriores. Estas rotinas são generalizadas e não têm problemas de instabilidade numérica. Nos testes executados pelo autor, sob uma larga variedade de tamanhos de linha (5 a 500 milhas) para os modos de seqüência zero e positiva, a mesma rotina poderia precisamente modelar os diferentes tamanhos de linha e sob toda a faixa de freqüência, de 0 até $10^{6} \mathrm{~Hz}$. Isto é obtido sem intervenção de usuário, isto é, o usuário destas rotinas não tem que fazer julgamento de valores para forçar um melhor desempenho em certas freqüências ou tamanhos de linha.

Um fator a ser considerado entre as duas abordagens mencionadas é que, em simulações de transitórios, a representação dependente da freqüência de linhas de transmissão requer apenas de 10 a $30 \%$ mais tempo computacional que a simulação considerando parâmetros constantes.

No EMTP, linhas polifásicas são primeiramente desacopladas através de matrizes de transformação modal, para que cada modo possa ser estudado separadamente como um circuito monofásico. Matrizes de transformação independentes da freqüência são assumidas nessas composições. Este procedimento é exato no caso de configurações de linhas balanceadas e ainda muito preciso para linhas transpostas. Entretanto, nos casos mais gerais de linhas desbalanceadas, linhas não-transpostas, as matrizes de transformação modal são dependentes da freqüência. Todavia, ainda é possível neste caso obter uma aproximação razoavelmente boa sob o pressuposto de matrizes de transformação constante (MARTI, 1982).

Em GOMEZ (2007), é analisado o desempenho de três diferentes modelos de linha de transmissão existentes no ATP, para um estudo estatístico de sobretensões de chaveamento, utilizando o método de Monte Carlo. Os modelos no domínio do tempo, Bergeron, Semlyen e JMarti, são comparados com um método no 
domínio da freqüência baseado na transformada numérica de Laplace e no princípio da superposição. O estudo mostra que o modelo JMarti representa melhor a linha de transmissão frente a transitórios eletromagnéticos de alta freqüência.

Uma maneira mais eficiente de computar transitórios de chaveamento em sistemas de transmissão para coordenação do isolamento é obter a probabilidade de distribuição das sobretensões de chaveamento. Para este propósito, o método Monte Carlo é geralmente aplicado, o qual consiste em realizar várias simulações de chaveamento com tempos de chaveamento aleatórios para cada fase.

Embora o modelo Bergeron seja capaz de reproduzir a freqüência natural da linha, este não é suficiente para conseguir uma boa aproximação da sobretensão máxima, e então este valor é superestimado. Por outro lado, modelos de linha dependentes da freqüência (Semlyen e JMarti) são capazes de reproduzir não somente a freqüência natural da linha de transmissão, mas também a distorção e atenuação devido ao efeito pelicular, e, conseqüentemente, os resultados são mais próximos daqueles pelo método proposto.

O modelo JMarti considera que a matriz de transformação modal é constante para todas as faixas de freqüência do estudo, o que em geral não é verdade, mas ainda é uma aproximação boa o suficiente para linhas de transmissão balanceadas ou aproximadamente balanceadas. Entretanto, se a linha não é transposta e também uma configuração assimétrica da torre é considerada, o desempenho do modelo é questionável.

O modelo matemático a ser utilizado na modelagem da linha depende do tipo de simulação a ser realizada, seja ele em regime permanente ou transitório, como nas situações de curto-circuito, chaveamento e descargas atmosféricas. 
No caso de transitórios que envolvem altas freqüências no seu sinal de tensão, cabe adiantar que a utilização do modelo PI causa uma superestimação da onda de tensão, evidenciando a necessidade de um modelo que considere a impedância da linha para as várias faixas de freqüência que constituem o transitório, como é o caso do modelo JMarti.

Dispondo-se do software ATP através da interface gráfica ATPDraw, foi realizada a representação computacional da linha através da rotina LCC. Esta rotina considera as distâncias entre fases, altura de meio vão, parâmetros do condutor, resistividade do solo e, de acordo com o modelo matemático disponível, calcula os parâmetros elétricos de seqüência dos trechos de linha inseridos no programa.

A modelagem matemática da linha foi realizada dispondo do modelo $\mathrm{PI}$. Contudo, os estudos a serem reportados também contemplam a utilização de outro modelo matemático para a simulação da linha, o modelo JMarti. Cabe justificar que tal modelo foi empregado, visto que este é mais adequado para representar a linha frente a situações de transitórios eletromagnéticos que possuem componentes de alta freqüência em seu sinal.

A linha foi modelada, como se pode observar na Figura 3.14, com oito componentes LCC, cada um representando um trecho em específico. Vale destacar que foram feitas aproximações quanto às distâncias entre condutores, uma vez que a linha apresenta estruturas diversificadas. Estas aproximações foram feitas considerando sempre a estrutura mais problemática quanto às distâncias entre condutores e entre o condutor e o solo. Tratam-se como estruturas problemáticas as mais baixas e as que apresentam distâncias menores entre os condutores, podendo ter a isolação comprometida após a elevação da classe de tensão operativa da linha. 
Das estruturas encontradas sobre o sistema de $34,5 \mathrm{kV}$ em análise, cabe afirmar que a mais problemática é a do tipo "A", por apresentar as distâncias mais críticas entre as fases. Sendo assim, os estudos que são apresentados e comentados no próximo capítulo com relação à aplicação do software $F L U X^{\circledR}$, estão focados neste tipo de estrutura, visto que, caso a mesma não venha a apresentar problemas para uma futura repotenciação, as demais também não serão contrárias a esta situação.

Como mostra a Figura 3.14, os curtos-circuitos foram todos aplicados entre o Trecho 8 e SOZ, e medidos entre o Trecho 1 e USG. Esta configuração foi utilizada em todas as simulações, pois representou os maiores picos de tensão atingidos quando comparados aos picos observados nos curtos-circuitos aplicados entre 0 Trecho 1 e USG, e medidos entre Trecho 8 e SOZ.

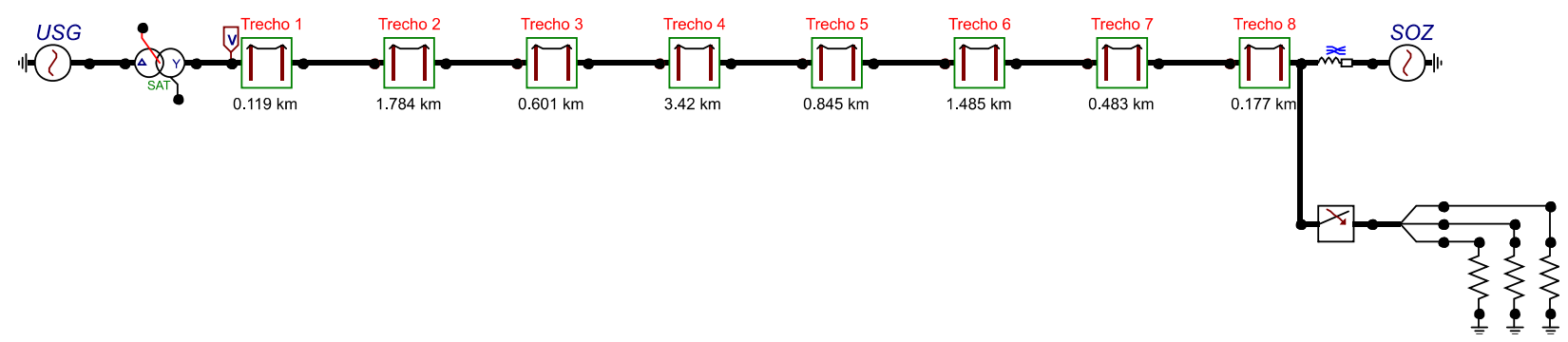

Figura 3.14 - Modelo da Linha Souzas - Salto Grande no software ATPDraw

Ressalta-se que para cada transitório foram registrados os picos de tensão para as fases A, B e C, negativos e positivos e os valores de tensão nas demais fases no mesmo instante de tempo que ocorreram os picos.

Para visualizar de maneira mais clara como os valores de tensão foram registrados, a Figura 3.15 mostra um exemplo de transitório em que a linha tracejada indica o instante no tempo em que os valores de tensão das três fases foram registrados. 


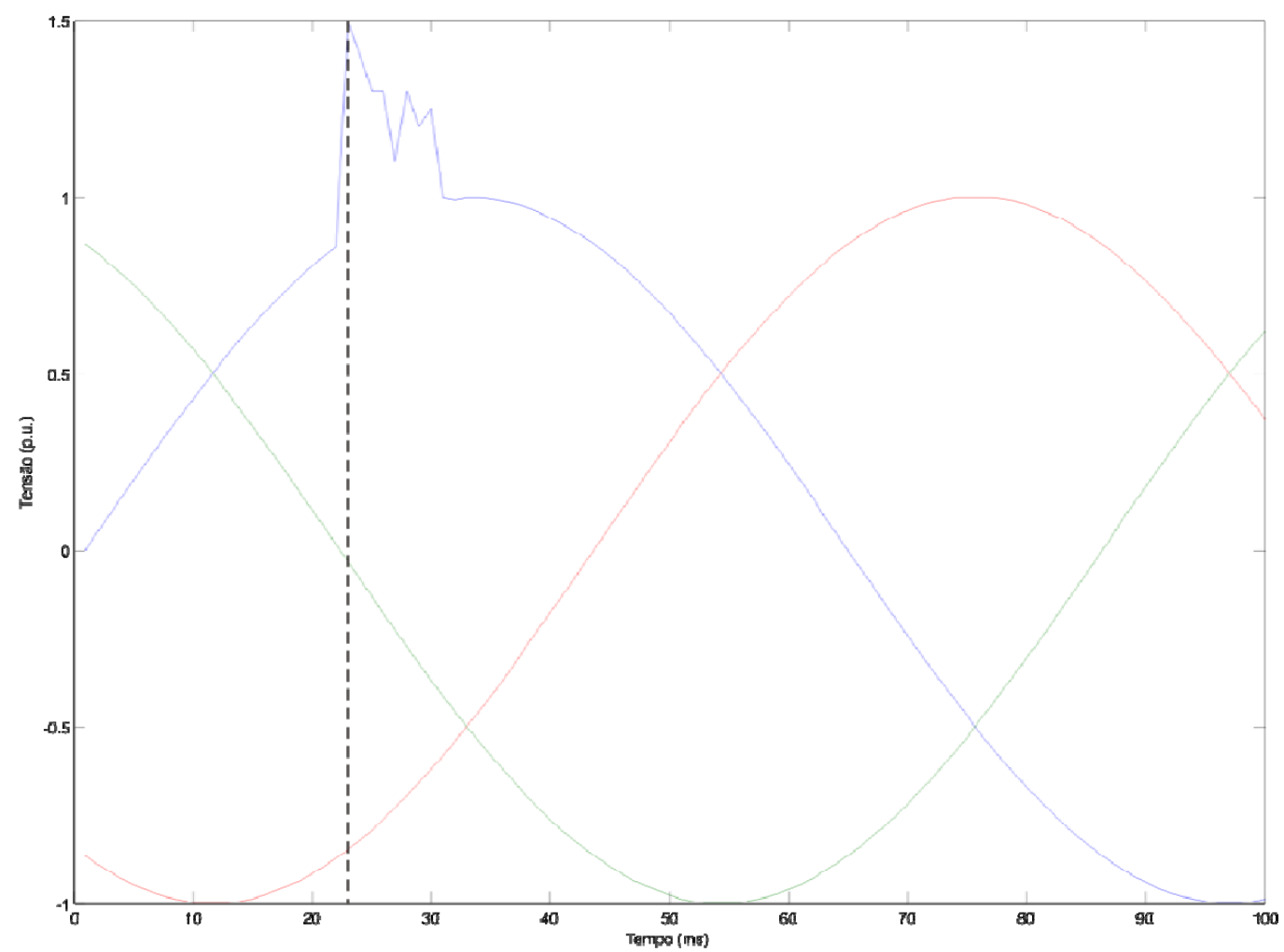

Figura 3.15 - Exemplo de transitório monofásico

Além dos curtos-circuitos entre as fases, também foram simuladas descargas atmosféricas diretas sobre a linha em estudo. A Figura 3.16 ilustra a implementação de descargas atmosféricas na interface ATPDraw em que pode ser observado um "splitter" empregado para selecionar as fases de forma individual, uma fonte de corrente "Heidler" e uma resistência em paralelo, representando o canal de ionização do ar (DIESENDORF, 1974).

De acordo com DIESENDORF (1974), 65\% das descargas atmosféricas possuem uma corrente igual ou inferior a $10 \mathrm{kA}$, com um tempo de subida de 1,2 $\mu \mathrm{s}$ e um tempo de descida de $50 \mu \mathrm{s}$. Portanto, estes valores foram adotados nas simulações das descargas atmosféricas sobre a linha em análise.

Uma situação de descarga atmosférica foi aplicada entre o Trecho 4 e o Trecho 5, conforme ilustra a Figura 3.16, sendo que o transitório pode ser observado na Figura 3.17, considerando os trechos da linha modelados utilizando o modelo PI. 
Na Figura 3.18, os trechos foram modelados com o modelo JMarti, exceto o Trecho 1 e Trecho 8 que permaneceram modelados com o modelo PI por representarem distâncias pequenas.

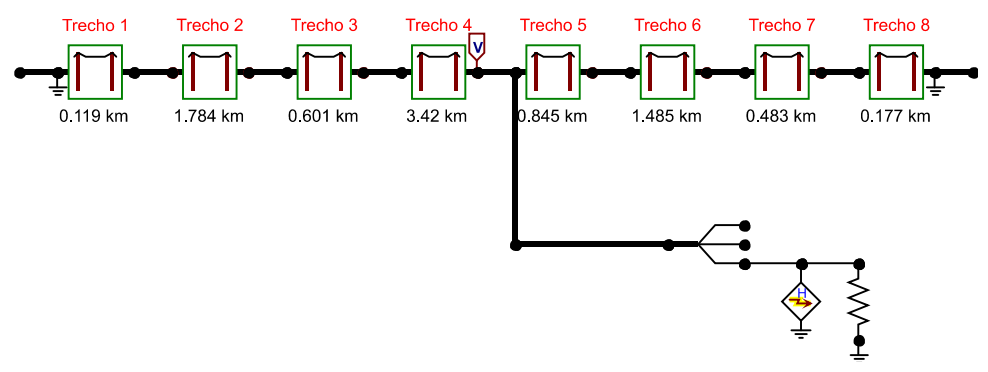

Figura 3.16 - Diagrama representativo do sistema elétrico simulado, considerando situações de descargas atmosféricas.

Ressalta-se que as duas descargas analisadas apresentam a mesma intensidade de corrente e foram aplicadas no mesmo ponto da linha. Na Figura 3.17 pode-se notar que a fase $\mathrm{C}$, em preto, praticamente atinge o valor de 2,8 $\mathrm{MV}$ e a fase $A$, em vermelho, chega a 1,9 MV. Na Figura 3.18 a fase $C$ atinge um pico de 2,1 MV e a fase A menos de $1 \mathrm{MV}$.

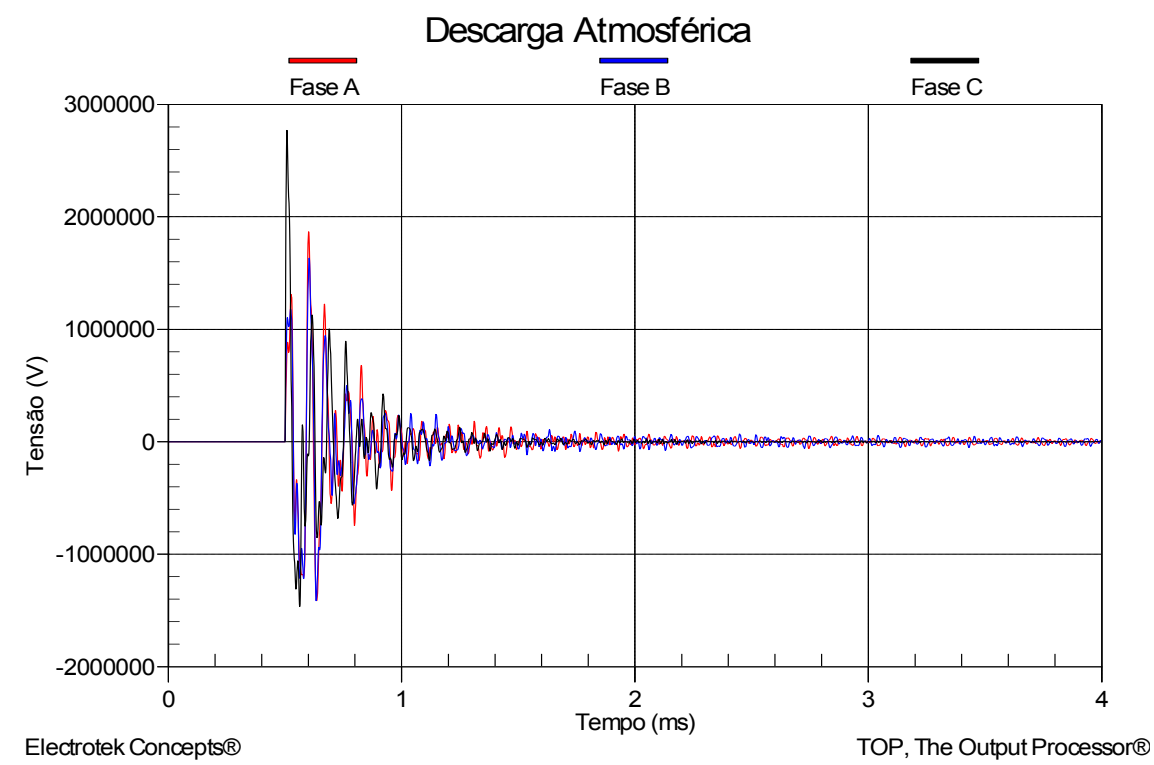

Figura 3.17 - Descarga atmosférica aplicada entre o Trecho 4 e o Trecho 5, com corrente de 10 kA, considerando o modelo PI.

Nota-se que as formas de onda da Figura 3.17, em que se utilizou o modelo PI na representação matemática da linha, possuem picos de tensão mais elevados 
que as formas de onda da tensão na Figura 3.18, representada pelo modelo JMarti, reforçando a necessidade de se utilizar o modelo adequado nas simulações para cada tipo de transitório.

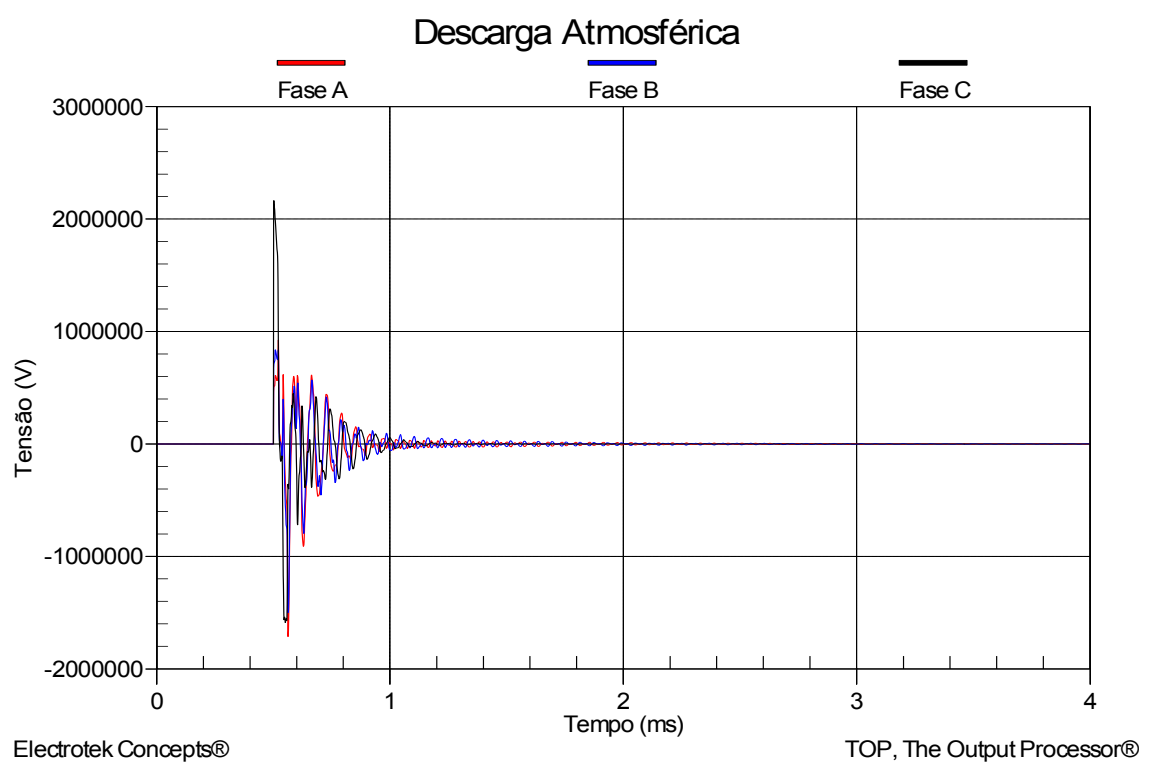

Figura 3.18 - Descarga atmosférica aplicada entre o Trecho 4 e o Trecho 5, com corrente de 10 $\mathrm{kA}$, considerando o modelo JMarti.

\subsection{1 - INTERFACE ATPDRAW}

O software ATP permite a possibilidade da utilização de seu componente LCC através da interface gráfica do ATPDraw, conforme ilustra a Figura 3.19. 


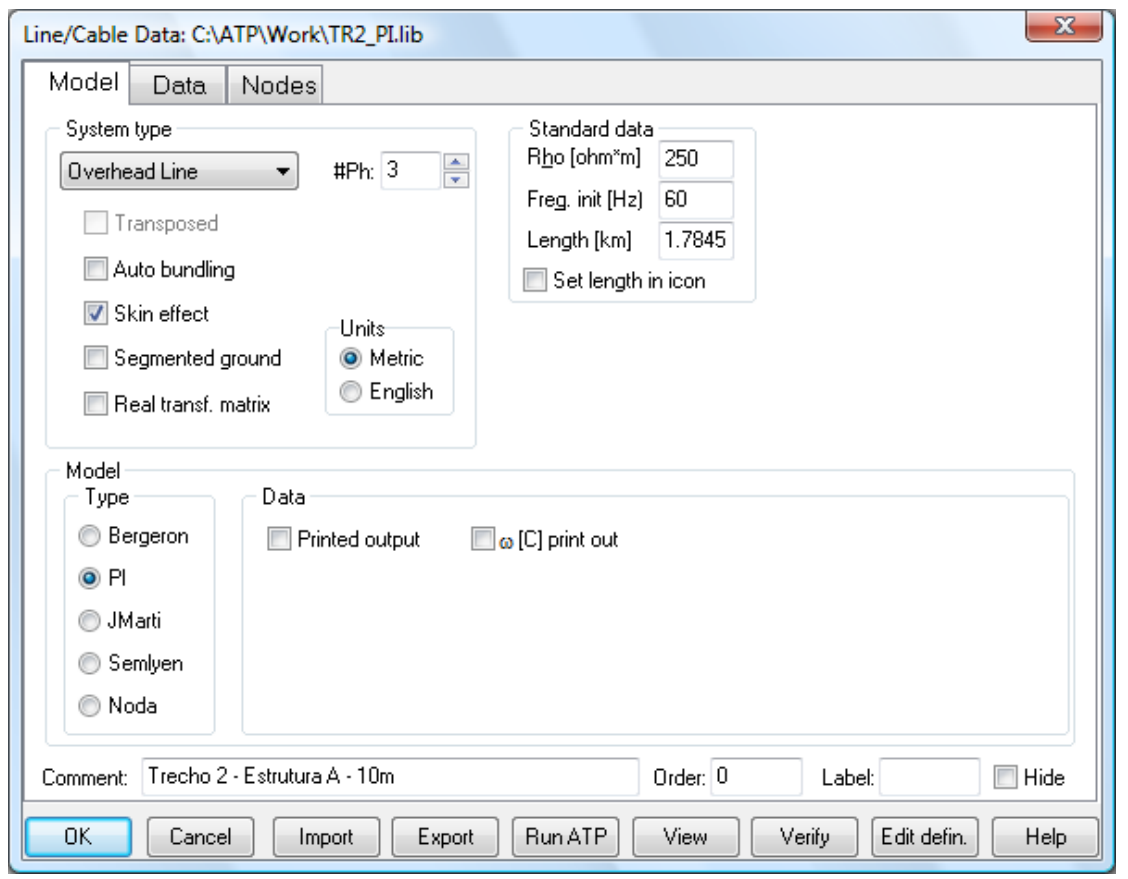

Figura 3.19 - Tela inicial do componente LCC

Na Figura 3.19, pode-se analisar a tela de seleção do modelo matemático que é utilizado pelo software para os cálculos dos parâmetros elétricos da linha. Nesta tela, pode-se também inserir o valor da resistividade do solo, a freqüência, o comprimento da linha e o tipo de sistema em implementação, como por exemplo, uma linha trifásica aérea, motivo em estudo.

A Figura 3.20 ilustra o procedimento da entrada dos dados que representam os condutores do sistema em análise. Por ela, pode-se configurar o raio interno e externo do condutor, sua resistência (FUCHS, 1979), as distâncias horizontais (CPFL, 1970, 1984a, 1984b, 1984c, 1984d, 1984e) e as alturas dos condutores tanto na torre quanto no meio vão em relação ao solo. 


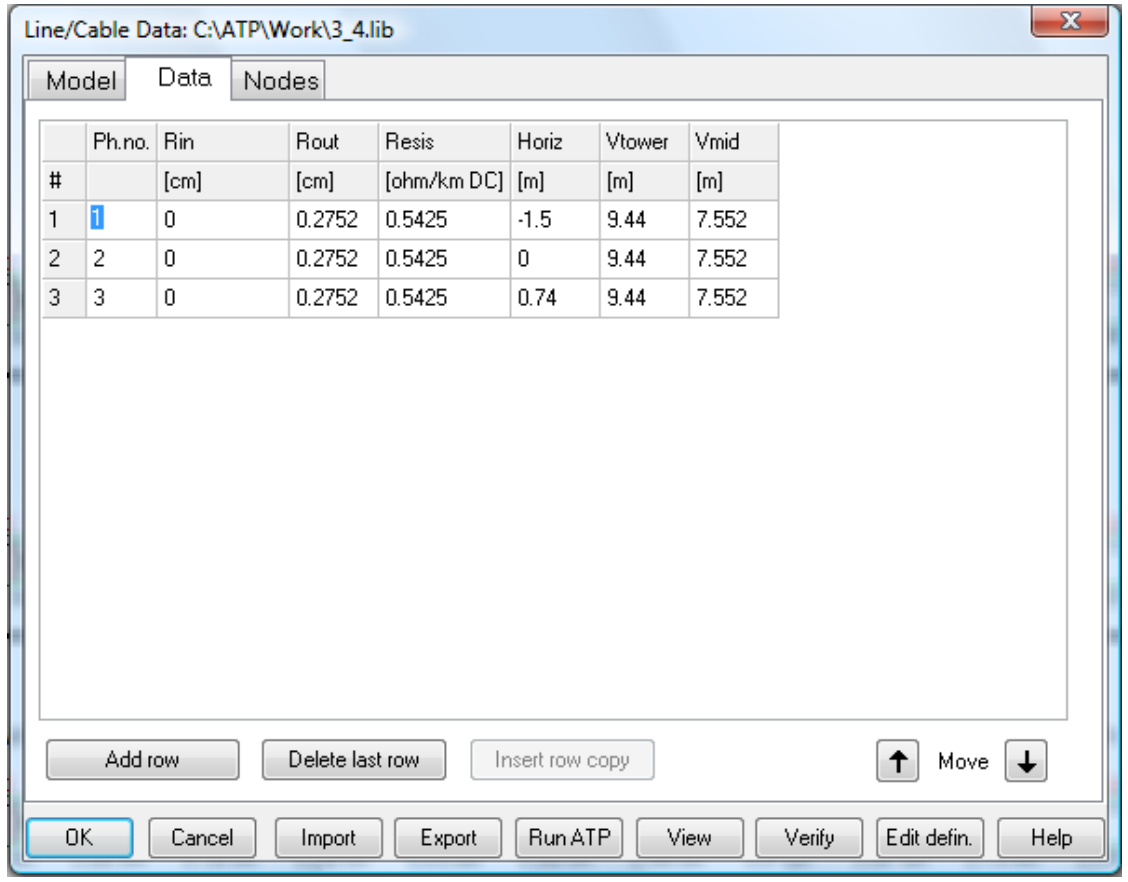

Figura 3.20 - Tela para a entrada dos dados representando os condutores do sistema simulado

Como pode ser notado na Figura 3.14, em um dos extremos da linha existe o equivalente da Usina de Salto Grande juntamente com um transformador e, no outro extremo, o equivalente da Subestação de Souzas.

Na interface ATPDraw, o transformador foi parametrizado com ligação delta no lado de baixa tensão (USG) e estrela no lado de alta tensão (Linha). Utilizou-se também uma impedância de 8,52\% (base de 4,5 MVA) e uma relação de transformação de 2.200/34.500 nas simulações da rede 34,5 kV e 2.200/69.000 nas simulações da nova classe de $69 \mathrm{kV}$.

A fonte equivalente de tensão da USG foi configurada com tensão de fase de $1.796 \mathrm{~V}$, uma vez que a entrada de tensão do componente equivalente de tensão dá-se pela tensão de fase do sistema, o que equivale a uma tensão de linha de 2.200 V, correspondente à tensão de geração, sendo a freqüência do sistema também configurada de acordo com a geração em $60 \mathrm{~Hz}$.

Os valores da impedância de curto-circuito para a classe de 34,5 kV e 69 kV, que foram calculados a partir das potências de curto-circuito de SOZ, são 
apresentados na Tabela 3.1. Nesta, Ro e R+ representam as resistências equivalentes, e L0 e L+ as indutâncias equivalentes de sequência zero e positiva, respectivamente.

Tabela 3.1 - Impedância de curto-circuito de SOZ

\begin{tabular}{c|c|c}
\hline Parâmetro & Classe de $34,5 \mathrm{kV}$ & Classe de $69 \mathrm{kV}$ \\
\hline $\mathrm{R}_{0}$ & $0,7329 \Omega$ & $3,01 \Omega$ \\
\hline $\mathrm{L}_{0}$ & $19,4 \mathrm{mH}$ & $41,76 \mathrm{mH}$ \\
\hline $\mathrm{R}_{+}$ & $0,5995 \Omega$ & $3,25 \Omega$ \\
\hline $\mathrm{L}_{+}$ & $13,915 \mathrm{mH}$ & $36,89 \mathrm{mH}$ \\
\hline
\end{tabular}

A partir dos componentes LCC, dos equivalentes e do transformador configurados, pode-se submeter a linha às situações de curtos-circuitos monofásicos, bifásicos e trifásicos, a fim de verificar os máximos picos de tensão provocados pelos distúrbios aplicados.

Para realizar estas simulações de curtos-circuitos via a interface ATPDraw, utilizou-se uma chave trifásica, um componente chamado "splitter", usado para ligar separadamente cada uma das fases às impedâncias de falta.

Através da chave trifásica, pode-se conectar, em paralelo, a linha e uma impedância de curto-circuito. Pode-se configurar o instante de tempo em que a chave irá abrir ou fechar, com controle individual para cada fase.

Os procedimentos anteriormente descritos foram utilizados na configuração da linha e na geração dos distúrbios. Os valores de tensão registrados após a simulação desses distúrbios são apresentados na seção a seguir.

\section{4 - RESULTADOS DAS SIMULAÇÕES REALIZADAS}

Inicialmente, a impedância de falta dos curtos-circuitos aplicados na linha foi variada em $10 \Omega$ e $0,01 \Omega$, bem como o ponto de incidência da falta, considerandose três pontos ao longo da linha. Estes pontos são: entre a USG e o Trecho 1, entre 
o Treco 4 e o Trecho 5 e entre o Trecho 8 e a SOZ. Para se ter uma idéia precisa da distância, o ponto entre o Trecho 4 e o Trecho 5 está a 5944 m da USG e 2890 m da SOZ, como pode ser visto na Figura 3.14.

Os curtos-circuitos são aplicados após quase um ciclo de regime permanente, com uma duração aproximada de sete ciclos. Após este tempo, a falta é eliminada, sem considerar a atuação dos equipamentos de proteção instalados na linha.

Utilizando-se essas duas diferentes impedâncias de falta, três diferentes pontos de incidência de falta, e ainda, registrando os transitórios em três pontos ao longo da linha, foi amostrado um total de 198 simulações de curtos-circuitos na linha piloto.

A partir desses 198 registros percebeu-se que os transitórios que apresentavam os picos de tensão mais elevados eram provenientes de curtoscircuitos aplicados entre o Trecho 8 e a SOZ com impedância de falta de 0,01 $\Omega$ e medidos entre a USG e o Trecho 1.

Assim, todas as simulações de transitórios foram refeitas, dessa vez, com impedância de falta de $0,01 \Omega$, aplicando-se os curtos-circuitos entre o Trecho 8 e a SOZ e observados entre a USG e o Trecho 1.

Com esta metodologia, foram construídas a Tabela 3.2, Tabela 3.3, Tabela 3.4 e Tabela 3.5. As duas primeiras estão relacionadas à classe de $34,5 \mathrm{kV}$, e as duas últimas, à classe de $69 \mathrm{kV}$. Para cada classe de tensão, uma tabela contém os picos positivos e outra, os picos negativos de tensão.

\subsection{1 - CLASSE DE TENSÃO DE 34,5 KV}

Nessa seção são apresentadas as tabelas com os valores máximos de tensão, positivos e negativos, dos transitórios observados no sistema de $34,5 \mathrm{kV}$. 
A Tabela 3.2 e Tabela 3.3 foram construídas a partir de transitórios como os que podem ser observados na Figura 3.21, Figura 3.22, Figura 3.23, Figura 3.24 e Figura 3.25 .

A Figura 3.21 mostra a forma de onda da tensão nas três fases devido a uma falta trifásica com impedância de curto de $0,01 \Omega$, envolvendo o terra, aplicada próxima à Subestação de Souzas e medida próxima à Usina de Salto Grande.

Na Figura 3.22 observa-se a forma de onda da tensão nas três fases devido a uma falta trifásica com impedância de curto de $0,01 \Omega$, sem o terra, aplicada próxima à Subestação de Souzas e medida próxima à Usina de Salto Grande.

A Figura 3.23 ilustra a forma de onda da tensão nas três fases devido a uma falta bifásica entre as fases B e C com impedância de curto de $0,01 \Omega$, envolvendo o terra, aplicada próxima à Subestação de Souzas e medida próxima à Usina de Salto Grande.

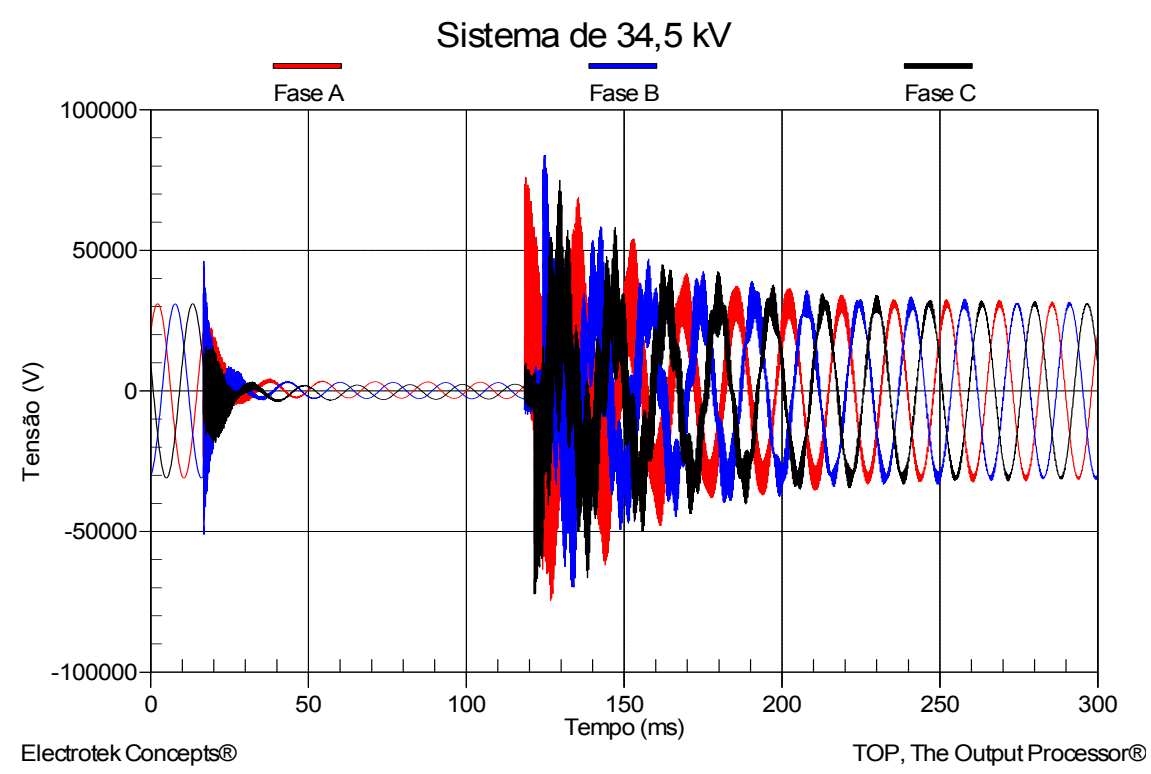

Figura 3.21 - Forma de onda da tensão devido a uma falta trifásica envolvendo o terra.

Na Figura 3.24 observa-se a forma de onda da tensão nas três fases devido a uma falta bifásica entre as fases B e C com impedância de curto de $0,01 \Omega$, sem o 
terra, aplicada próxima à Subestação de Souzas e medida próxima à Usina de Salto Grande.

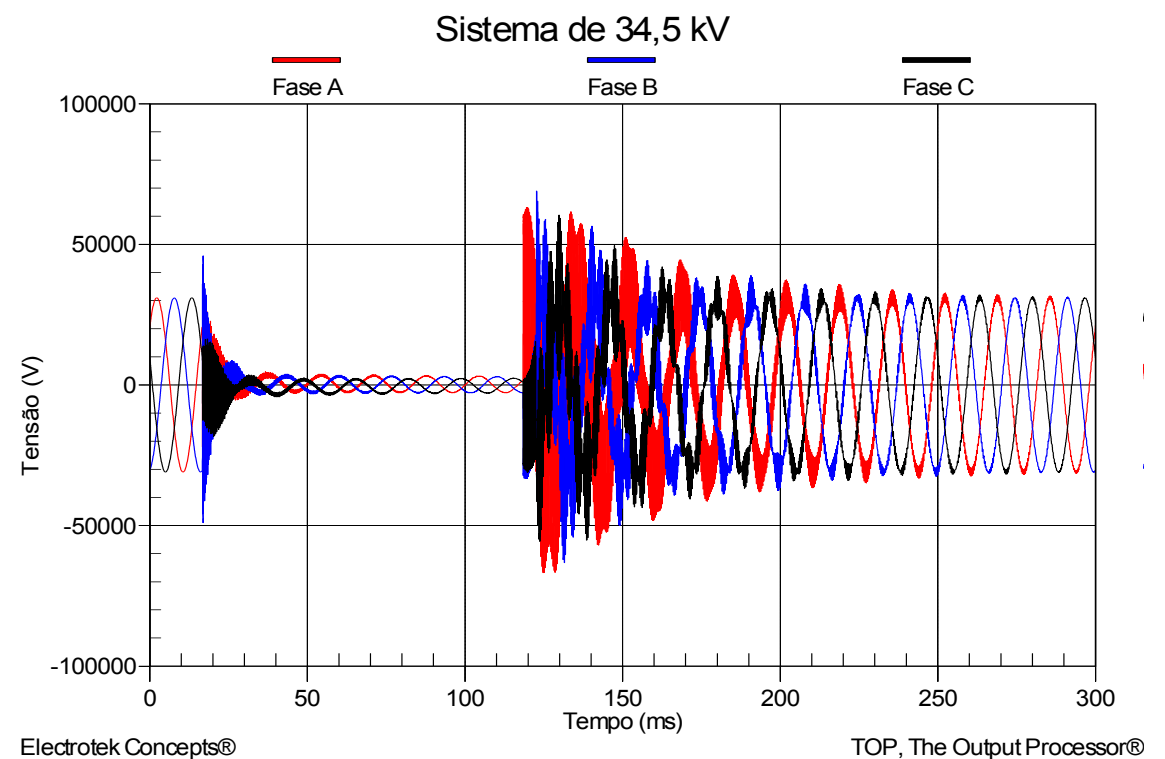

Figura 3.22 - Forma de onda da tensão devido a uma falta trifásica sem o terra.

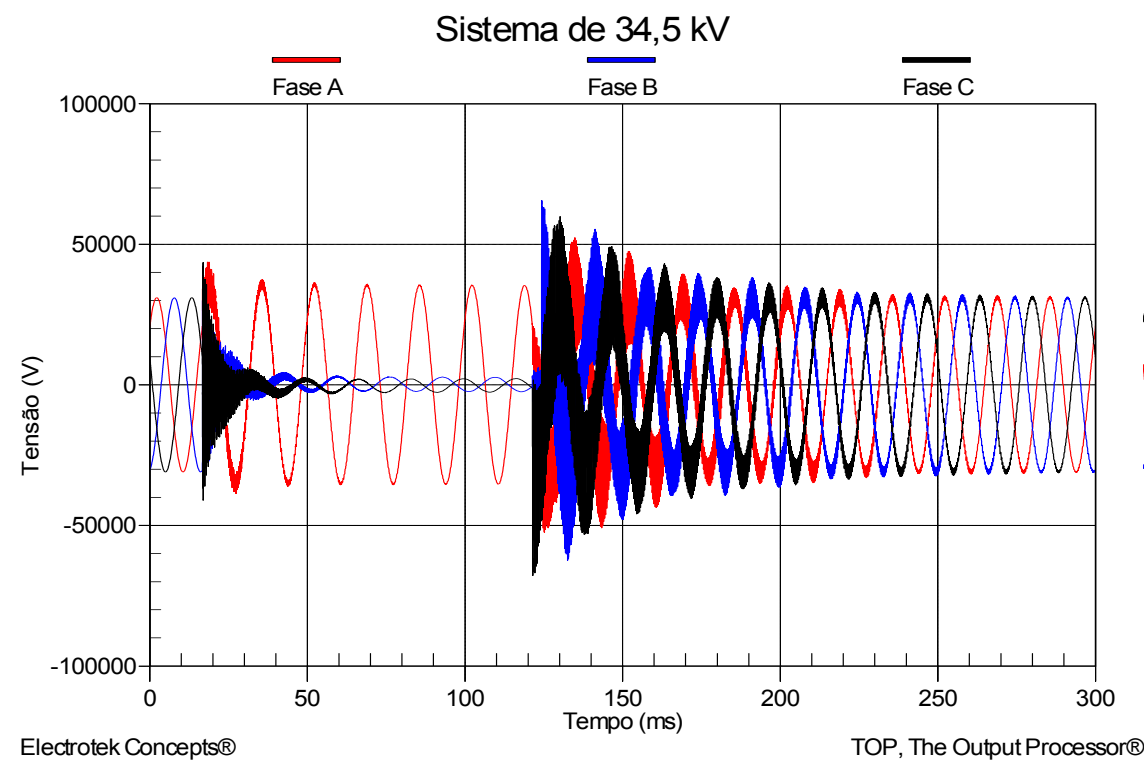

Figura 3.23 - Forma de onda da tensão devido a uma falta bifásica entre as fases B e C envolvendo o terra.

A Figura 3.25 ilustra a forma de onda da tensão nas três fases devido a uma falta na fase $C$ com impedância de curto de $0,01 \Omega$, aplicada próxima à Subestação de Souzas e medida próxima à Usina de Salto Grande. 


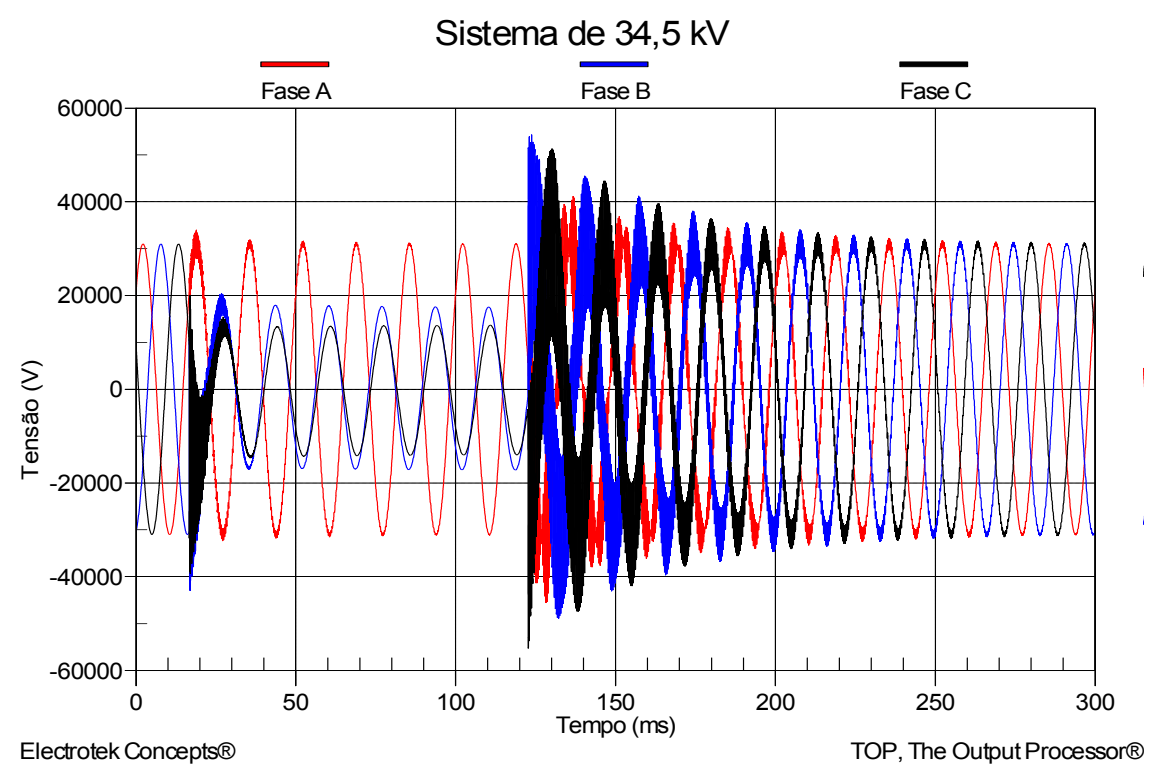

Figura 3.24 - Forma de onda da tensão devido a uma falta bifásica entre as fases B e C sem o terra.

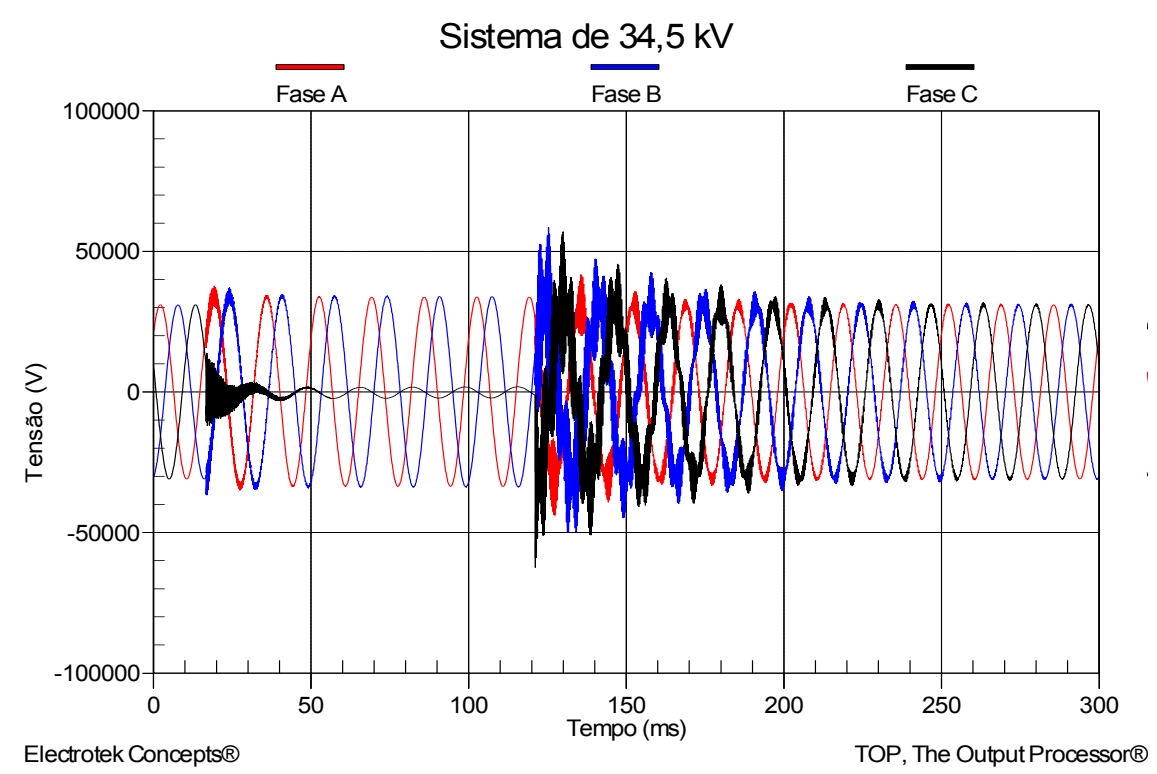

Figura 3.25 - Forma de onda da tensão devido a uma falta na fase C.

Na Tabela 3.2 podem ser observados todos os tipos de curtos-circuitos na linha para a classe de $34,5 \mathrm{kV}$. Para cada situação, três registros de tensão foram considerados, sendo um registro para o pico positivo de tensão ocorrido na fase $A$, e os valores instantâneos das tensões nas fases $\mathrm{B}$ e $\mathrm{C}$, respectivamente. O mesmo foi realizado para as fases $\mathrm{B}$ e $\mathrm{C}$, ou seja, foi também armazenado o pico de tensão da 
fase $B$ e considerados os valores instantâneos de tensão das fases $A$ e $C$, bem como o pico de tensão da fase $C$ e os valores de tensão das fases $A$ e B no mesmo instante de tempo.

Tabela 3.2 - Valores de tensão para picos positivos: classe de $34,5 \mathrm{kV}$

\begin{tabular}{l|r|r|r}
\hline Tipo de Falta (Fase) & Fase A (V) & Fase B (V) & Fase C (V) \\
\hline ABC-T (A) & $70.197,3$ & $10.403,3$ & $10.036,9$ \\
\hline ABC-T (B) & $-32.358,7$ & $53.730,0$ & $-32.493,4$ \\
\hline ABC-T (C) & $-937,4$ & $19.159,5$ & $57.733,9$ \\
\hline ABC (A) & $57.846,4$ & $-28.374,3$ & $-28.474,6$ \\
\hline ABC (B) & $-9.625,2$ & $69.494,1$ & $-21.105,7$ \\
\hline ABC (C) & $-5.888,0$ & $-1.155,1$ & $50.871,9$ \\
\hline AB-T (A) & $63.803,2$ & $13.897,6$ & $-148,5$ \\
\hline AB-T (B) & $7.316,3$ & $62.424,9$ & $-10.933,6$ \\
\hline AB-T (C) & $-794,0$ & $17.234,8$ & $38.362,5$ \\
\hline AB (A) & $56.033,4$ & $-13.364,7$ & $-19.966,4$ \\
\hline AB (B) & $-18.211,2$ & $41.907,2$ & $-3.872,4$ \\
\hline AB (C) & $-20.709,6$ & $-5.898,4$ & $38.868,1$ \\
\hline BC-T (A) & $40.046,3$ & $-2.350,8$ & $-1.4430,2$ \\
\hline BC-T (B) & $-18.621,7$ & $57.570,3$ & $-28.300,9$ \\
\hline BC-T (C) & $-812,9$ & $-5.584,3$ & $53.088,4$ \\
\hline BC (A) & $38.588,2$ & $1.526,8$ & $-11.955,8$ \\
\hline BC (B) & $-10.776,5$ & $55.878,5$ & $-36.394,3$ \\
\hline BC (C) & $-3.072,5$ & $15.561,2$ & $46.761,6$ \\
\hline CA-T (A) & $65.651,8$ & $2.348,9$ & $13.044,6$ \\
\hline CA-T (B) & $13.631,7$ & $42.528,7$ & $5.220,3$ \\
\hline CA-T (C) & $-16.799,1$ & $-4.339,9$ & $45.411,0$ \\
\hline CA (A) & $51.070,7$ & $-1.974,5$ & $-48.335,9$ \\
\hline CA (B) & $-22.840,6$ & $46.355,7$ & $12.437,7$ \\
\hline CA (C) & $-23.094,6$ & $-14.254,0$ & $37.011,0$ \\
\hline A-T (A) & $58.223,9$ & $-11.629,1$ & $-7.456,0$ \\
\hline A-T (B) & $-12.137,8$ & $46.870,3$ & $-14.065,5$ \\
\hline A-T (C) & $-8.513,6$ & $-7.254,0$ & $38.874,0$ \\
\hline B-T (A) & $38.260,5$ & $11.900,5$ & $-24,9$ \\
\hline B-T (B) & $-8.399,6$ & $58.946,6$ & $-12.393,2$ \\
\hline B-T (C) & $5.625,5$ & $1.643,1$ & $41.723,2$ \\
\hline C-T (A) & $37.450,3$ & $-8.565,8$ & $5.613,7$ \\
\hline C-T (B) & $-28.157,9$ & $38.928,1$ & $-13.288,2$ \\
\hline C-T (C) & $-12.396,9$ & $-5.576,4$ & $44.590,0$ \\
\hline & & & \\
\hline
\end{tabular}


Utilizando-se do mesmo raciocínio aplicado para a construção da Tabela 3.2, foi realizada uma análise considerando os picos de tensão negativos e, através deles, foi gerada a Tabela 3.3.

Tabela 3.3 - Valores de tensão para picos negativos: classe de 34,5 kV

\begin{tabular}{|l|l|l|l|}
\hline Tipo de Falta (Fase) & Fase A (V) & Fase B (V) & Fase C (V) \\
\hline
\end{tabular}

\begin{tabular}{r|r|r|r}
\hline ABC-T (A) & $-61.190,4$ & $20.014,2$ & $-14.040,2$ \\
\hline ABC-T (B) & $-1.392,1$ & $-42.046,9$ & $37.317,7$ \\
\hline ABC-T (C) & $-18.221,2$ & $-21.661,4$ & $-72.552,7$ \\
\hline ABC (A) & $-59.830,6$ & $15.136,8$ & $-16.607,1$ \\
\hline ABC (B) & $-4.590,5$ & $-45.615,4$ & $27.880,4$ \\
\hline ABC (C) & $-15.957,8$ & $16.463,2$ & $-47.589,4$ \\
\hline AB-T (A) & $-54.311,1$ & $-15.956,2$ & $-3.616,3$ \\
\hline AB-T (B) & $4.208,7$ & $-48.563,6$ & $10.864,3$ \\
\hline AB-T (C) & $-3.577,5$ & $-5.608,8$ & $-52.370,8$ \\
\hline AB (A) & $-36.772,1$ & $30.674,8$ & $-3.498,8$ \\
\hline AB (B) & $49.102,4$ & $-51.640,9$ & $3.445,0$ \\
\hline AB (C) & $14.670,0$ & $-4.750,5$ & $-57.999,5$ \\
\hline BC-T (A) & $-57.328,2$ & $17.166,0$ & $-11.357,2$ \\
\hline BC-T (B) & $-3.949,1$ & $-43.150,9$ & $19.508,5$ \\
\hline BC-T (C) & $5.133,0$ & $-12.176,1$ & $-65.820,3$ \\
\hline BC (A) & $-56.528,3$ & $4.628,5$ & $-11.177,6$ \\
\hline BC (B) & $8.104,6$ & $-43.604,5$ & $26.655,0$ \\
\hline BC (C) & $1.672,7$ & $49.950,3$ & $-51.791,7$ \\
\hline CA-T (A) & $-50.256,5$ & $10.459,6$ & $-2.134,5$ \\
\hline CA-T (B) & $-6.922,2$ & $-41.861,4$ & $-18.148,9$ \\
\hline CA-T (C) & $-126,2$ & $20.700,7$ & $-63.083,5$ \\
\hline CA (A) & $-46.113,3$ & $21.174,2$ & $14.786,8$ \\
\hline CA (B) & $11.778,6$ & $-38.257,3$ & $11.362,0$ \\
\hline CA (C) & $21.032,4$ & $-6.595,2$ & $-52.110,0$ \\
\hline A-T (A) & $-40.413,8$ & $17.889,0$ & $5.006,6$ \\
\hline A-T (B) & $3.011,3$ & $-35.682,8$ & $19.635,1$ \\
\hline A-T (C) & $18.480,4$ & $-21.276,8$ & $-49.678,9$ \\
\hline B-T (A) & $-50.595,3$ & $1.754,2$ & $-306,7$ \\
\hline B-T (B) & $-4.028,3$ & $-44.803,3$ & $16.011,4$ \\
\hline B-T (C) & $8.466,1$ & $-11.971,3$ & $-37.186,5$ \\
\hline C-T (A) & $-42.484,0$ & $10.888,4$ & $12.107,0$ \\
\hline C-T (B) & $1.404,0$ & $-44.513,7$ & $-29.808,1$ \\
\hline C-T (C) & $10.620,3$ & $8.842,4$ & $-58.476,0$ \\
\hline & & & \\
\hline & & & \\
\hline & &
\end{tabular}




\subsection{2 - CLASSE DE TENSÃO DE $69 \mathrm{KV}$}

Conforme seção anterior são apresentadas a seguir as tabelas com os valores máximos de tensão, positivos e negativos, desta vez, dos transitórios observados no sistema de $69 \mathrm{kV}$.

A Tabela 3.4 e a Tabela 3.5 seguem o mesmo princípio de construção da Tabela 3.2 e Tabela 3.3, respectivamente. Contudo, os distúrbios foram aplicados na linha de 69 kV e, alguns dos transitórios utilizados para a construção da Tabela 3.4 e a Tabela 3.5 podem ser observados na Figura 3.26, Figura 3.27, Figura 3.28, Figura 3.29 e Figura 3.30 .

A Figura 3.26 apresenta a forma de onda da tensão nas três fases devido a uma falta trifásica com impedância de curto de $0,01 \Omega$, envolvendo o terra, aplicada próxima à Subestação de Souzas e medida próxima à Usina de Salto Grande.

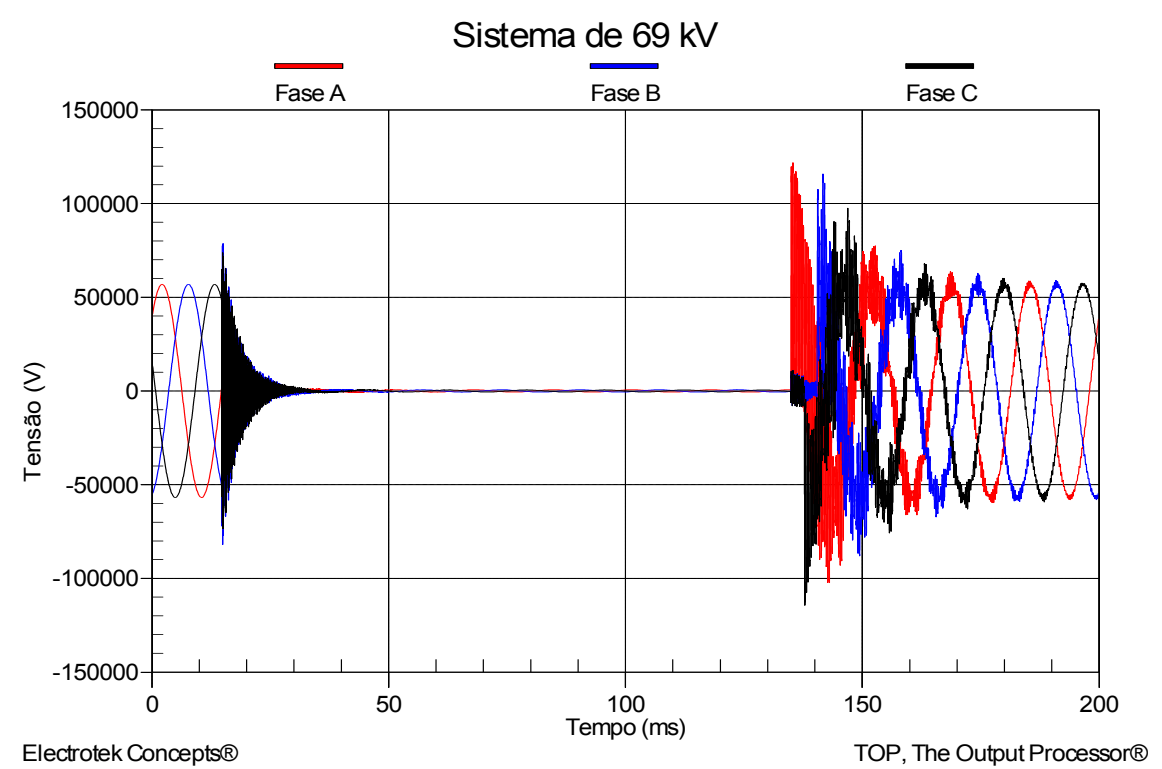

Figura 3.26 - Forma de onda da tensão devido a uma falta trifásica envolvendo o terra.

Na Figura 3.27 observa-se a forma de onda da tensão nas três fases devido a uma falta trifásica com impedância de curto de $0,01 \Omega$, sem o terra, aplicada próxima à Subestação de Souzas e medida próxima à Usina de Salto Grande. 


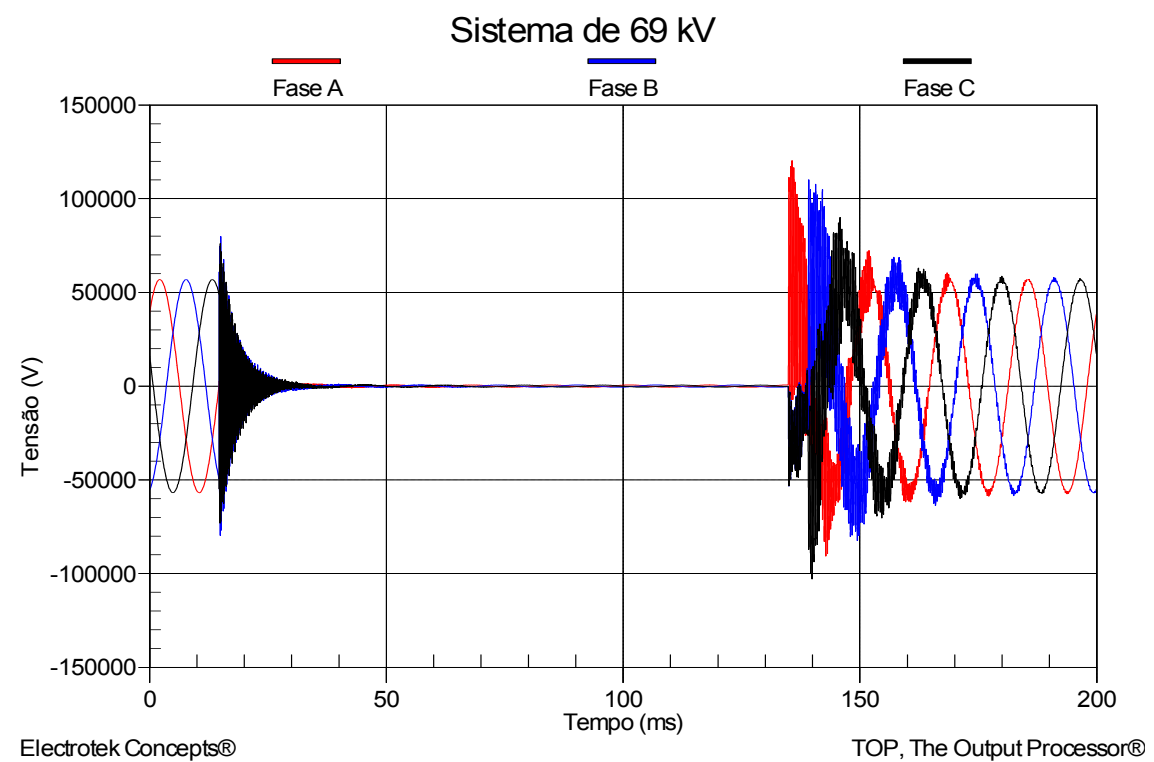

Figura 3.27 - Forma de onda da tensão devido a uma falta trifásica sem o terra.

A Figura 3.28 ilustra a forma de onda da tensão nas três fases devido a uma falta bifásica entre as fases B e C com impedância de curto de $0,01 \Omega$, envolvendo o terra, aplicada próxima à Subestação de Souzas e medida próxima à Usina de Salto Grande.

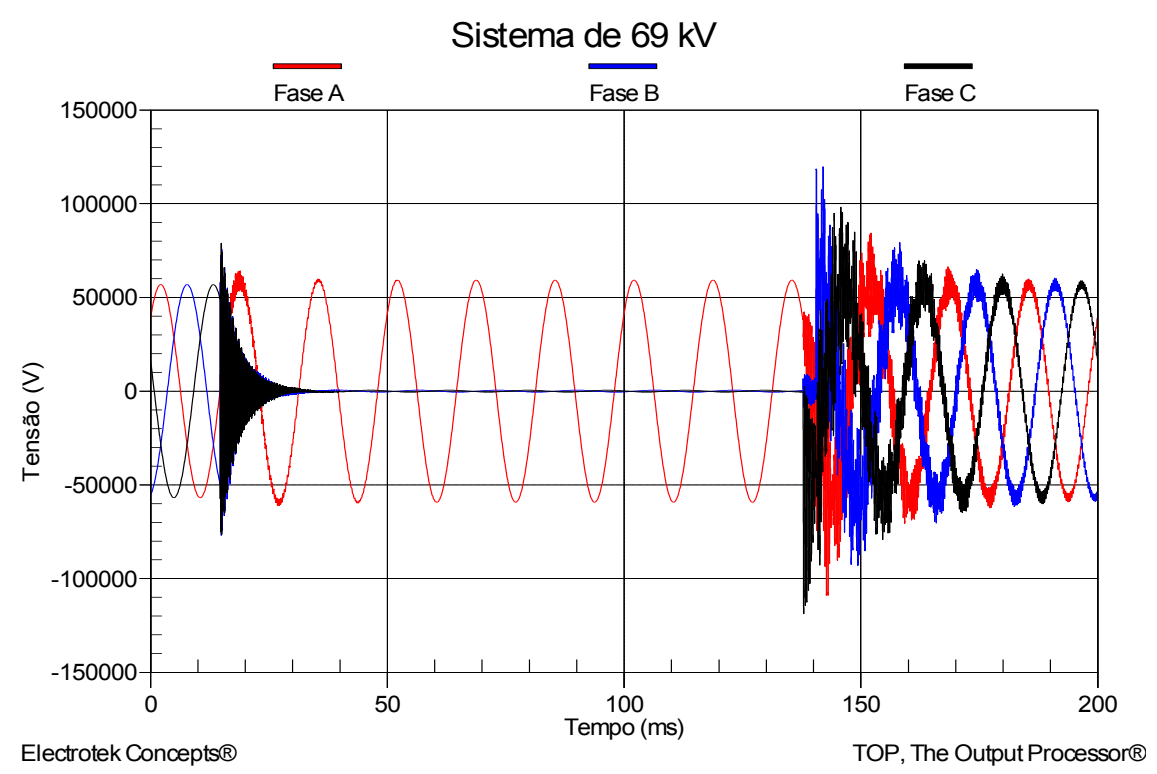

Figura 3.28 - Forma de onda da tensão devido a uma falta bifásica entre as fases B e C envolvendo o terra. 
A Figura 3.29 demonstra a forma de onda da tensão nas três fases devido a uma falta bifásica entre as fases B e C com impedância de curto de $0,01 \Omega$, sem o terra, aplicada próxima à Subestação de Souzas e medida próxima à Usina de Salto Grande.

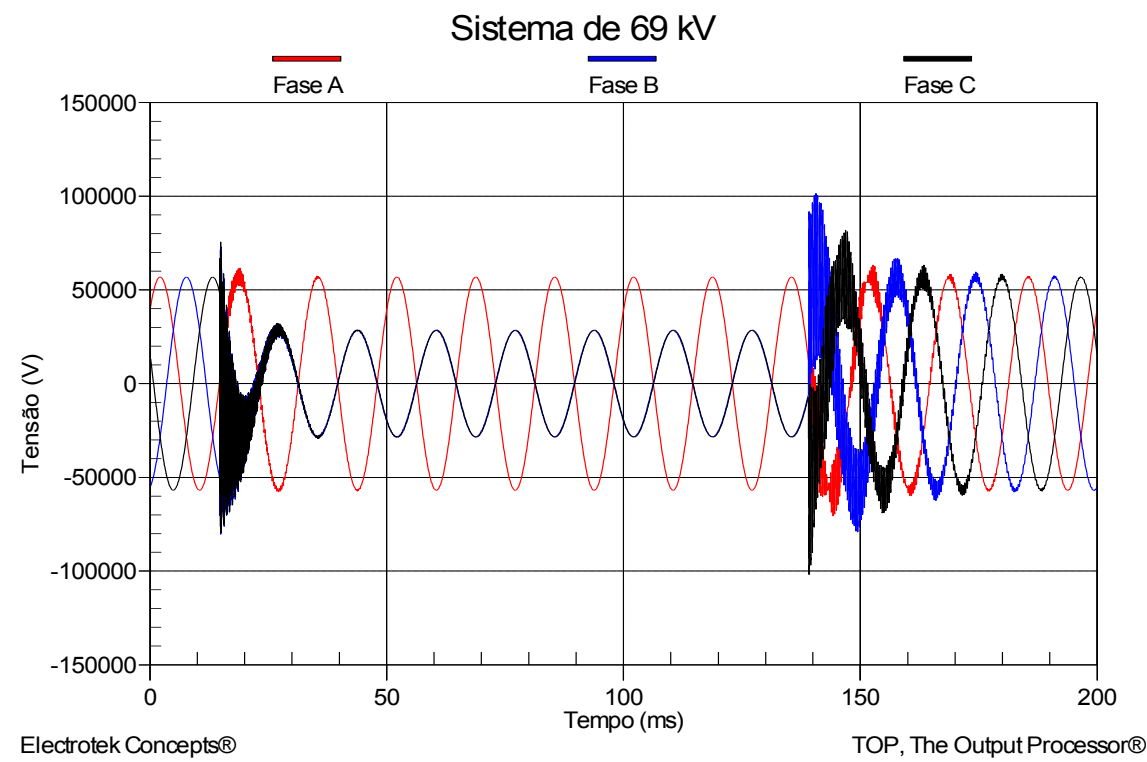

Figura 3.29 - Forma de onda da tensão devido a uma falta bifásica entre as fases B e C sem o terra.

A Figura 3.30 apresenta a forma de onda da tensão nas três fases devido a uma falta na fase $\mathrm{C}$ com impedância de curto de $0,01 \Omega$, aplicada próxima à Subestação de Souzas e medida próxima à Usina de Salto Grande.

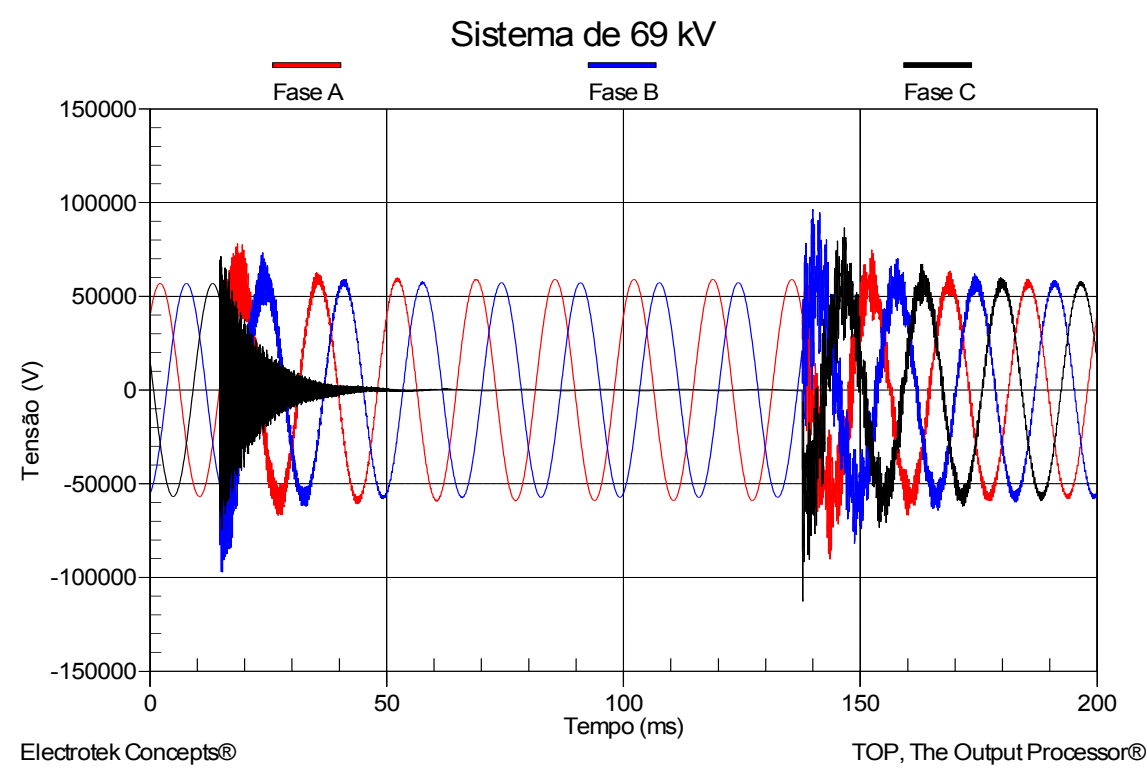

Figura 3.30 - Forma de onda da tensão devido a uma falta na fase C. 
Tabela 3.4 - Valores de tensão para picos positivos: classe de $69 \mathrm{kV}$ \begin{tabular}{l|l|l|l} 
Tipo de Falta (Fase) & Fase A (V) & Fase B (V) & Fase C (V) \\
\hline
\end{tabular}

\begin{tabular}{l|r|r|r}
\hline ABC-T (A) & $121.799,2$ & $10.667,3$ & $10.546,2$ \\
\hline ABC-T (B) & $-74.636,1$ & $115.964,5$ & $-9.013,0$ \\
\hline ABC-T (C) & $-15.850,9$ & $-36.835,6$ & $97.539,3$ \\
\hline ABC (A) & $120.288,6$ & $-45.233,3$ & $-45.510,5$ \\
\hline ABC (B) & $-22.996,0$ & $110.099,6$ & $-83.949,4$ \\
\hline ABC (C) & $-35.789,2$ & $-37.758,7$ & $90.233,3$ \\
\hline AB-T (A) & $116.041,7$ & $9.050,7$ & $-5.713,2$ \\
\hline AB-T (B) & $22.279,6$ & $120.361,1$ & $-20.193,1$ \\
\hline AB-T (C) & $-11.285,0$ & $9.748,2$ & $97.593,7$ \\
\hline AB (A) & $100.908,5$ & $-63.406,2$ & $-12.438,7$ \\
\hline AB (B) & $-41.898,0$ & $80.544,2$ & $-34.844,1$ \\
\hline AB (C) & $-21.320,0$ & $-44.713,6$ & $72.353,0$ \\
\hline BC-T (A) & $84.643,7$ & $-2.509,4$ & $-16.539,6$ \\
\hline BC-T (B) & $-39.142,1$ & $119.721,5$ & $10.838,3$ \\
\hline BC-T (C) & $-23.793,5$ & 309,8 & $98.276,8$ \\
\hline BC (A) & $63.448,3$ & $-29.969,8$ & $-29.113,1$ \\
\hline BC (B) & $-40.951,2$ & $101.609,4$ & $-66.297,3$ \\
\hline BC (C) & $-20.198,3$ & $-57.427,9$ & $81.935,5$ \\
\hline CA-T (A) & $119.311,8$ & $-20.333,9$ & $9.910,8$ \\
\hline CA-T (B) & $15.663,9$ & $110.408,6$ & $-16.248,7$ \\
\hline CA-T (C) & $-16.651,3$ & $-5.363,1$ & $100.113,8$ \\
\hline CA (A) & $103.414,9$ & $1.229,7$ & $-82.722,9$ \\
\hline CA (B) & $-51.798,7$ & $71.679,9$ & $-16.391,7$ \\
\hline CA (C) & $-67.117,7$ & $-1.836,7$ & $70.489,7$ \\
\hline A-T (A) & $113.929,4$ & $-27.225,1$ & $-11.987,6$ \\
\hline A-T (B) & $-17.066,1$ & $76.507,3$ & $-19.470,9$ \\
\hline A-T (C) & $-49.642,9$ & $8.546,0$ & $76.009,8$ \\
\hline B-T (A) & $84.281,0$ & $41.386,5$ & $15.481,5$ \\
\hline B-T (B) & $-11.809,4$ & $111.855,4$ & $-27.652,7$ \\
\hline B-T (C) & $-2.411,5$ & $-28.668,9$ & $92.260,9$ \\
\hline C-T (A) & $78.197,6$ & $-17.779,7$ & $24.012,9$ \\
\hline C-T (B) & $-12.142,8$ & $96.431,5$ & $-28.050,9$ \\
\hline C-T (C) & $-20.108,0$ & $-20.647,9$ & $86.830,6$ \\
\hline & & & \\
\hline
\end{tabular}


Tabela 3.5 - Valores de tensão para picos negativos: classe de $69 \mathrm{kV}$ \begin{tabular}{l|l|l|l} 
Tipo de Falta (Fase) & Fase A (V) & Fase B (V) & Fase C (V) \\
\hline
\end{tabular}

\begin{tabular}{l|r|r|r}
\hline ABC-T (A) & $-102.282,0$ & $28.440,5$ & $12.627,4$ \\
\hline ABC-T (B) & $30.589,1$ & $-88.148,5$ & $28.449,9$ \\
\hline ABC-T (C) & $55.112,2$ & $-2.893,0$ & $-114.264,0$ \\
\hline ABC (A) & $-90.556,9$ & $82.802,2$ & $-20.916,7$ \\
\hline ABC (B) & $-18.968,9$ & $-82.544,5$ & $48.730,8$ \\
\hline ABC (C) & $-101.533,0$ & $19.113,5$ & $-102.771,0$ \\
\hline AB-T (A) & $-24.137,3$ & $-94.326,2$ & $-29.240,2$ \\
\hline AB-T (B) & $12.923,6$ & $-7.290,2$ & $-104.221,0$ \\
\hline AB-T (C) & $-73.782,2$ & $15.900,5$ & $45.006,6$ \\
\hline AB (A) & $92.153,1$ & $-99.569,2$ & $12.284,7$ \\
\hline AB (B) & $30.932,1$ & $42.040,9$ & $-84.870,2$ \\
\hline AB (C) & $-109.074,0$ & $28.992,7$ & $-20.011,9$ \\
\hline BC-T (A) & $5.850,7$ & $-93.200,3$ & $23.528,8$ \\
\hline BC-T (B) & $22.942,9$ & $-7.955,6$ & $-118.786,0$ \\
\hline BC-T (C) & $-70.612,4$ & $47.023,6$ & $14.531,8$ \\
\hline BC (A) & $-313,0$ & $-80.221,8$ & $75.350,7$ \\
\hline BC (B) $(8.284,0$ & $91.872,0$ & $-101.955,0$ \\
\hline BC (C) & $-102.543,0$ & 368,9 & $-1.586,6$ \\
\hline CA-T (A) & $12.604,6$ & $-90.059,0$ & $13.853,9$ \\
\hline CA-T (B) & $-1.288,8$ & $12.128,4$ & $-119.661,0$ \\
\hline CA-T (C) & $-86.381,3$ & $59.208,1$ & $23.210,7$ \\
\hline CA (A) & $55.023,6$ & $-63.388,1$ & $9.177,9$ \\
\hline CA (B) & $100.658,1$ & $-8.084,8$ & $-89.427,2$ \\
\hline CA (C) & $-87.104,1$ & $10.286,6$ & $29.235,4$ \\
\hline A-T (A) & $4.435,0$ & $-68.843,0$ & $30.130,2$ \\
\hline A-T (B) & $31.866,9$ & $6.724,3$ & $-89.095,2$ \\
\hline A-T (C) & $-87.381,0$ & $16.710,2$ & $-3.484,3$ \\
\hline B-T (A) & $21.761,6$ & $-87.799,6$ & $19.831,2$ \\
\hline B-T (B) & $19.649,7$ & $-37.337,9$ & $-79.599,3$ \\
\hline B-T (C) & $-90.268,5$ & $29.941,8$ & $-386,5$ \\
\hline C-T (A) & $-23.680,4$ & $-97.165,4$ & $-65.159,6$ \\
\hline C-T (B) & $27.440,8$ & $12.109,4$ & $-112.644,0$ \\
\hline C-T (C) & & & \\
\hline & &
\end{tabular}

A Tabela 3.2, Tabela 3.3, Tabela 3.4 e Tabela 3.5 foram geradas para a posterior aplicação dos valores de tensão (obtidos dispondo do software ATP) no software baseado na teoria de elementos finitos, FLUX ${ }^{\circledR}$, que é detalhado no Capítulo 4. 


\subsection{3 - DESCARGAS ATMOSFÉRICAS}

Cabe colocar que a realização das simulações relacionadas com as descargas atmosféricas também foi contemplada no escopo do trabalho dispondo-se do software ATPDraw. Para representar o amortecimento sofrido pelo surto, a simulação da descarga foi realizada retirando-se o equivalente que representa a SOZ e a USG, aterrando as extremidades, conforme o exemplo da Figura 3.16.

Destaca-se que nas simulações contemplando situações de descargas atmosféricas, foi utilizado o modelo JMarti para representar os trechos da linha em estudo. Já o modelo da forma de onda da descarga atmosférica toma como base um tempo de alcance do valor máximo de $1,2 \mu \mathrm{s}$, de descida um valor médio de $50 \mu \mathrm{s}$, uma corrente de descarga de 10 kA e 2,5 kA, uma impedância do canal de ionização do ar de $1 \mathrm{k} \Omega$ e $3 \mathrm{k} \Omega$, sendo os pontos entre os Trechos 1 e 2, Trechos 4 e 5 e Trecho 7 e 8 utilizados tanto como pontos de incidência da descarga quanto pontos de medição.

Na Tabela 3.6 estão os valores máximos de tensão de cada fase, sejam eles positivos e negativos, para cada tipo de descarga atmosférica direta simulada, bem como a impedância do canal de ionização, a corrente da descarga, o ponto de incidência da falta e o ponto de medição. É importante destacar que as extremidades da linha estão aterradas, pois dessa maneira, é possível analisar somente o comportamento da descarga atmosférica sobre a linha em análise.

Contudo, vale frisar que é possível analisar os valores das descargas atmosféricas juntamente com os valores de operação da linha em regime permanente. Como o interesse dessa simulação é o de analisar o comportamento da linha, durante as simulações, as extremidades foram aterradas, desconsiderando as fontes equivalentes de tensão. 
Sendo assim, não foi necessária a realização de simulações para as duas classes de tensão em análise.

A partir da Tabela 3.6, pode-se notar que os casos que apresentam maior pico de tensão durante as descargas atmosféricas diretas aplicadas na linha são os casos de corrente de descarga de $10 \mathrm{kA}$ e canal de ionização de $3 \mathrm{k} \Omega$. A sobretensão provocada pela descarga é diretamente proporcional à intensidade da corrente, ou seja, quanto maior a corrente da descarga, maiores serão os picos de tensão medidos na linha. Uma resistência maior, representada pelo canal de ionização em paralelo à linha, faz com que uma maior parcela da corrente percorra a mesma, causando também uma maior sobretensão.

As simulações de descargas atmosféricas são ilustradas numa seqüência de três figuras, mostrando as tensões trifásicas entre os Trechos 1 e 2, entre os Trechos 4 e 5 e, entre os Trechos 7 e 8.

Na Figura 3.31 observa-se a forma de onda da tensão nas três fases devido a uma descarga atmosférica direta de $10 \mathrm{kA}$, com impedância paralela de $3 \mathrm{k} \Omega$, aplicada entre os Trechos 4 e 5, e medida entre os Trechos 1 e 2.

A Figura 3.32 apresenta a forma de onda da tensão nas três fases devido a uma descarga atmosférica direta de $10 \mathrm{kA}$, com impedância paralela de $3 \mathrm{k} \Omega$, aplicada entre os Trechos 4 e 5, e medida no mesmo ponto.

A Figura 3.33 ilustra a forma de onda da tensão nas três fases devido a uma descarga atmosférica direta de $10 \mathrm{kA}$, com impedância paralela de $3 \mathrm{k} \Omega$, aplicada entre os Trechos 4 e 5, e medida entre os Trechos 7 e 8.

A impedância de $3 \mathrm{k} \Omega$ representa o canal de ionização do ar. Os máximos valores de tensão atingidos por cada fase estão apresentados na Tabela 3.6. 
Tabela 3.6 - Valores máximos de tensão observados durante situações de descargas atmosféricas diretas sobre o sistema em análise

\begin{tabular}{|c|c|c|c|c|c|}
\hline $\begin{array}{c}\text { Amplitude / } \\
\text { Canal } \\
\text { ionização } \\
\end{array}$ & $\begin{array}{l}\text { Ponto de } \\
\text { incidência }\end{array}$ & $\begin{array}{l}\text { Ponto de } \\
\text { Medição }\end{array}$ & Fase A (V) & Fase B (V) & Fase C (V) \\
\hline $10 \mathrm{kA} / 1 \mathrm{k} \Omega$ & Trecho 1 - 2 & Trecho 1 - 2 & $924.621,84$ & $597.092,76$ & $626.533,01$ \\
\hline $10 \mathrm{kA} / 1 \mathrm{k} \Omega$ & Trecho $1-2$ & Trecho $4-5$ & $129.226,12$ & $-110.117,08$ & $-114.721,39$ \\
\hline $10 \mathrm{kA} / 1 \mathrm{k} \Omega$ & Trecho 1 - 2 & Trecho $7-8$ & $-138.414,89$ & $116.208,45$ & $117.741,75$ \\
\hline $10 \mathrm{kA} / 1 \mathrm{k} \Omega$ & Trecho $4-5$ & Trecho 1 - 2 & $-50.085,46$ & $-65.172,64$ & $-68.717,13$ \\
\hline $10 \mathrm{kA} / 1 \mathrm{k} \Omega$ & Trecho $4-5$ & Trecho $4-5$ & $1.598 .270,09$ & $995.574,14$ & $1.063 .100,45$ \\
\hline $10 \mathrm{kA} / 1 \mathrm{k} \Omega$ & Trecho $4-5$ & Trecho $7-8$ & $234.328,67$ & $167.157,31$ & $168.886,98$ \\
\hline $10 \mathrm{kA} / 1 \mathrm{k} \Omega$ & Trecho 7 - 8 & Trecho 1 - 2 & $17.050,70$ & $-14.689,50$ & $-14.423,48$ \\
\hline $10 \mathrm{kA} / 1 \mathrm{k} \Omega$ & Trecho $7-8$ & Trecho $4-5$ & $-304.760,23$ & $-246.833,73$ & $-245.004,69$ \\
\hline $10 \mathrm{kA} / 1 \mathrm{k} \Omega$ & Trecho $7-8$ & Trecho 7 - 8 & $1.581 .994,59$ & $735.001,53$ & $788.228,61$ \\
\hline $10 \mathrm{kA} / 3 \mathrm{k} \Omega$ & Trecho 1 - 2 & Trecho 1 - 2 & $1.030 .913,75$ & $789.271,30$ & $827.045,02$ \\
\hline $10 \mathrm{kA} / 3 \mathrm{k} \Omega$ & Trecho $1-2$ & Trecho $4-5$ & $130.899,92$ & $-112.113,60$ & $-116.944,21$ \\
\hline $10 \mathrm{kA} / 3 \mathrm{k} \Omega$ & Trecho 1 - 2 & Trecho $7-8$ & $-24.654,55$ & $-25.267,80$ & $-22.432,34$ \\
\hline $10 \mathrm{kA} / 3 \mathrm{k} \Omega$ & Trecho $4-5$ & Trecho 1 - 2 & $77.323,39$ & $-89.846,70$ & $-94.601,25$ \\
\hline $10 \mathrm{kA} / 3 \mathrm{k} \Omega$ & Trecho $4-5$ & Trecho 4 - 5 & $1.915 .371,07$ & $1.435 .133,42$ & $1.535 .858,53$ \\
\hline $10 \mathrm{kA} / 3 \mathrm{k} \Omega$ & Trecho $4-5$ & Trecho 7 - 8 & $278.222,10$ & \begin{tabular}{|l|}
$220.752,86$ \\
\end{tabular} & $213.391,43$ \\
\hline $10 \mathrm{kA} / 3 \mathrm{k} \Omega$ & Trecho 7 - 8 & Trecho 1 - 2 & $-20.510,38$ & $-19.493,01$ & $-19.030,03$ \\
\hline $10 \mathrm{kA} / 3 \mathrm{k} \Omega$ & Trecho $7-8$ & Trecho $4-5$ & $-334.708,08$ & $-265.133,34$ & $-261.884,12$ \\
\hline $10 \mathrm{kA} / 3 \mathrm{k} \Omega$ & Trecho $7-8$ & Trecho $7-8$ & $1.851 .839,44$ & $1.070 .474,95$ & $1.151 .437,93$ \\
\hline $2,5 \mathrm{kA} / 1 \mathrm{k} \Omega$ & Trecho 1 - 2 & Trecho 1 - 2 & $231.155,53$ & $149.273,13$ & $156.633,26$ \\
\hline $2,5 \mathrm{kA} / 1 \mathrm{k} \Omega$ & Trecho 1 - 2 & Trecho $4-5$ & $32.306,53$ & $-27.529,27$ & $-28.680,35$ \\
\hline $2,5 \mathrm{kA} / 1 \mathrm{k} \Omega$ & Trecho 1 - 2 & Trecho 7 - 8 & $-5.821,02$ & $-5.940,16$ & $-5.325,40$ \\
\hline $2,5 \mathrm{kA} / 1 \mathrm{k} \Omega$ & Trecho $4-5$ & Trecho 1 - 2 & $-12.521,36$ & $-16.293,16$ & $-17.179,28$ \\
\hline $2,5 \mathrm{kA} / 1 \mathrm{k} \Omega$ & Trecho $4-5$ & Trecho $4-5$ & $399.567,50$ & $248.893,48$ & $265.775,11$ \\
\hline $2,5 \mathrm{kA} / 1 \mathrm{k} \Omega$ & Trecho 4 - 5 & Trecho 7 - 8 & $58.582,17$ & $41.789,33$ & $42.221,74$ \\
\hline $2,5 \mathrm{kA} / 1 \mathrm{k} \Omega$ & Trecho 7 - 8 & Trecho 1 - 2 & $4.262,68$ & $-3.672,38$ & $-3.605,87$ \\
\hline $2,5 \mathrm{kA} / 1 \mathrm{k} \Omega$ & Trecho $7-8$ & Trecho 4 - 5 & $-76.190,06$ & $-61.708,43$ & $-61.251,17$ \\
\hline $2,5 \mathrm{kA} / 1 \mathrm{k} \Omega$ & Trecho $7-8$ & Trecho 7 - 8 & $395.498,59$ & $183.750,42$ & $197.057,21$ \\
\hline $2,5 \mathrm{kA} / 3 \mathrm{k} \Omega$ & Trecho 1 - 2 & Trecho 1 - 2 & $950.602,02$ & $-593.908,67$ & $-624.040,59$ \\
\hline $2,5 \mathrm{kA} / 3 \mathrm{k} \Omega$ & Trecho 1 - 2 & Trecho $4-5$ & $537.177,35$ & $-388.685,63$ & $-397.447,76$ \\
\hline $2,5 \mathrm{kA} / 3 \mathrm{k} \Omega$ & Trecho 1 - 2 & Trecho $7-8$ & $38.919,92$ & $26.616,73$ & $27.216,97$ \\
\hline $2,5 \mathrm{kA} / 3 \mathrm{k} \Omega$ & Trecho $4-5$ & Trecho 1 - 2 & $586.929,09$ & $-442.799,09$ & $-451.877,48$ \\
\hline $2,5 \mathrm{kA} / 3 \mathrm{k} \Omega$ & Trecho $4-5$ & Trecho $4-5$ & $478.842,85$ & $-421.152,20$ & $-406.293,57$ \\
\hline $2,5 \mathrm{kA} / 3 \mathrm{k} \Omega$ & Trecho $4-5$ & Trecho $7-8$ & $69.555,56$ & $-56.390,22$ & $-56.104,05$ \\
\hline $2,5 \mathrm{kA} / 3 \mathrm{k} \Omega$ & Trecho $7-8$ & Trecho 1 - 2 & $950.602,02$ & $-593.908,67$ & $-624.040,59$ \\
\hline $2,5 \mathrm{kA} / 3 \mathrm{k} \Omega$ & Trecho 7 - 8 & Trecho $4-5$ & $537.177,35$ & $-388.685,63$ & $-397.447,76$ \\
\hline $2,5 \mathrm{kA} / 3 \mathrm{k} \Omega$ & Trecho $7-8$ & Trecho $7-8$ & $38.919,92$ & $26.616,73$ & $27.216,97$ \\
\hline
\end{tabular}




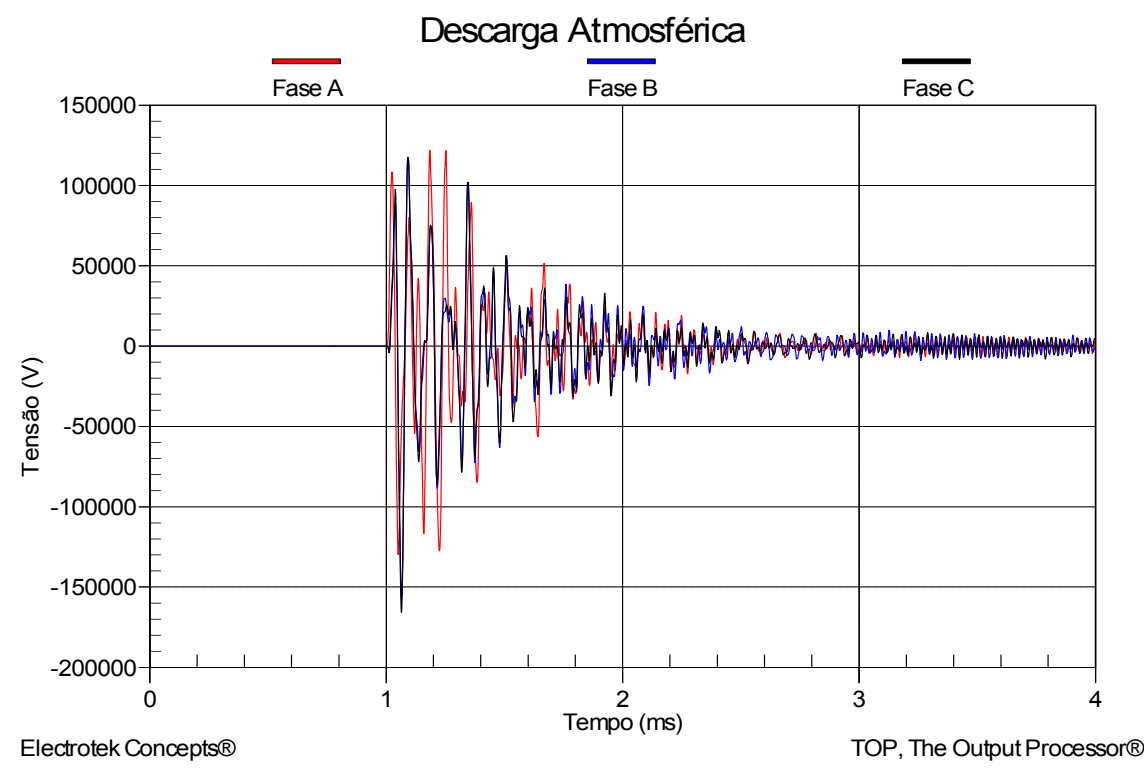

Figura 3.31 - Forma de onda da tensão nas três fases devido a uma descarga atmosférica direta de $10 \mathrm{kA}$, com impedância paralela de $3 \mathrm{k} \Omega$, aplicada entre os Trechos 4 e 5, e medida entre os Trechos 1 e 2.

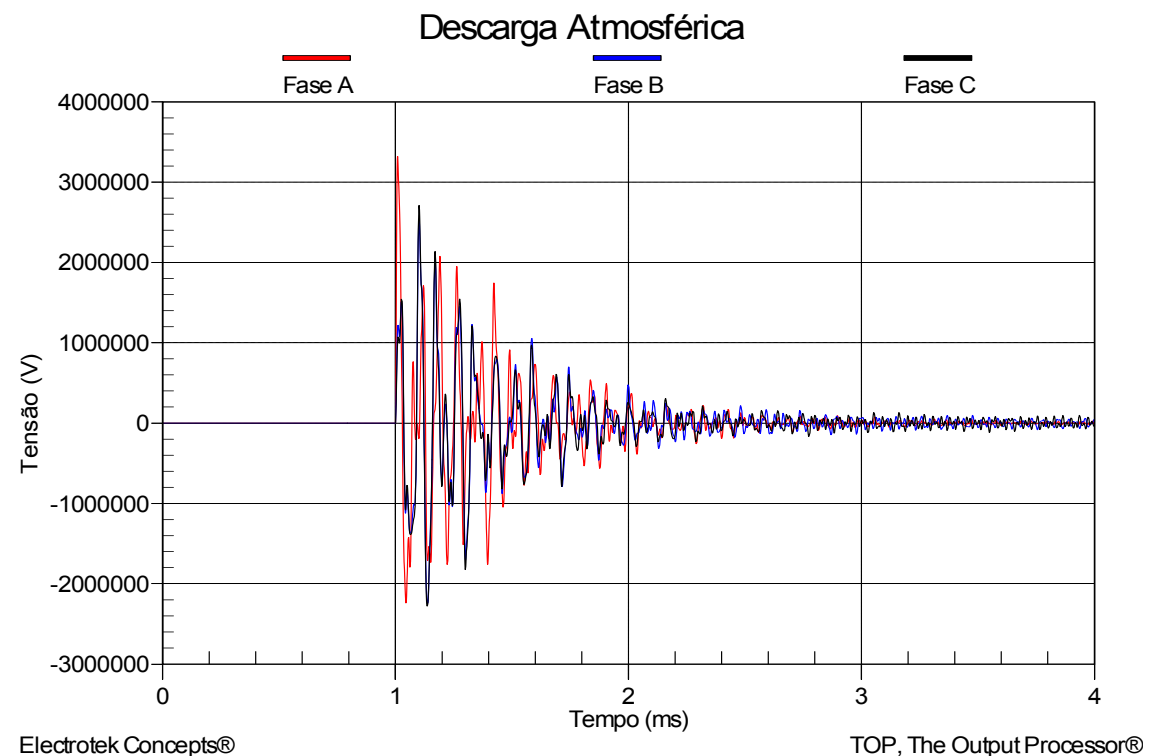

Figura 3.32 - Forma de onda da tensão nas três fases devido a uma descarga atmosférica direta de $10 \mathrm{kA}$, com impedância paralela de $3 \mathrm{k} \Omega$, aplicada entre os Trechos 4 e 5 , e medida no mesmo ponto. 


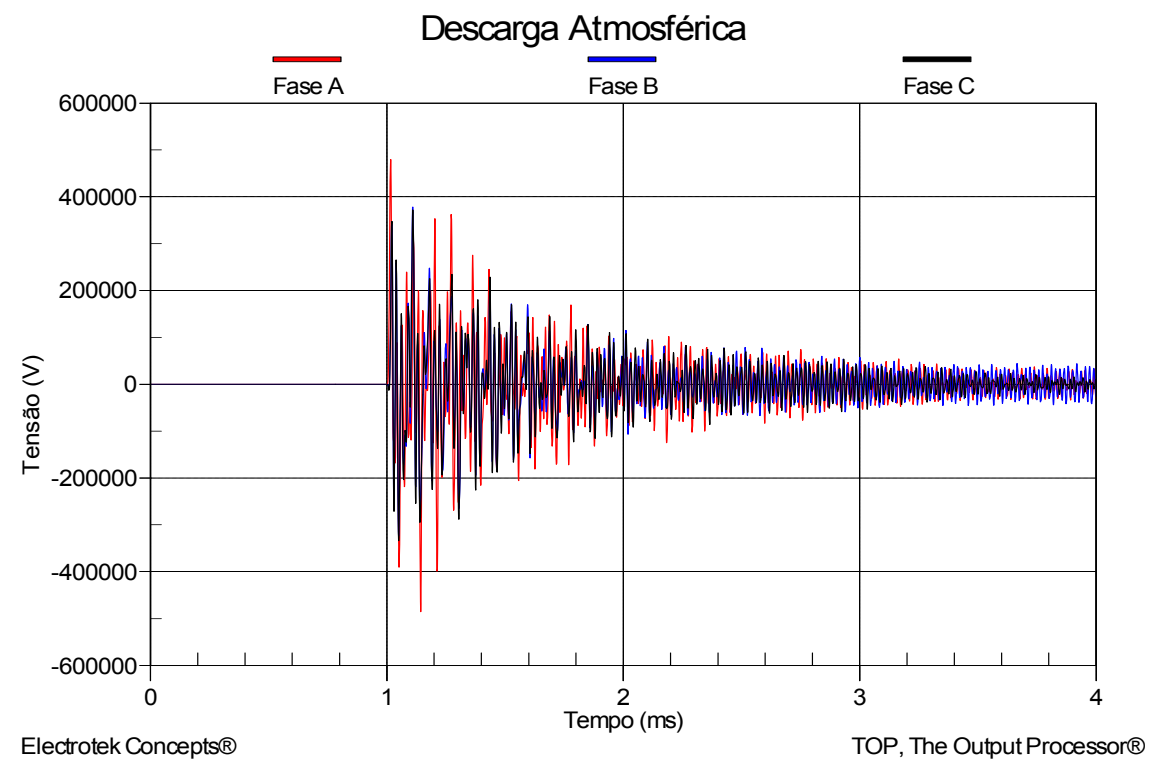

Figura 3.33 - Forma de onda da tensão nas três fases devido a uma descarga atmosférica direta de $10 \mathrm{kA}$, com impedância paralela de $3 \mathrm{k} \Omega$, aplicada entre os Trechos 4 e 5, e medida entre os Trechos 7 e 8.

É importante colocar que as estruturas da classe de $34,5 \mathrm{kV}$ ou $69 \mathrm{kV}$ não estão preparadas para transitórios dessa magnitude, provocados por descargas atmosféricas.

Assim, para melhorar o NBI destas estruturas frente a descargas atmosféricas, devem-se instalar equipamentos como cabos-guarda para proteger a linha, ou então, instalar pára-raios ao longo da linha que funcionariam como válvulas de escape para as correntes de descarga.

Portanto, como os surtos de tensão provocados por descargas atmosféricas são muito elevados para a classe de tensão de operação da linha, apenas os valores de tensão registrados a partir de curtos-circuitos serão utilizados no software FLUX $^{\circledR}$.

No próximo capítulo, os valores de tensão obtidos na Tabela 3.4 e Tabela 3.5 são utilizados no software $\mathrm{FLUX}^{\circledast}$ para gerar as figuras contendo as linhas equipotenciais de campo elétrico e, posteriormente, avaliar o NBI das estruturas da linha piloto. 


\section{Capítulo 4 Simulações Computacionais Espaciais via Software FLUX ${ }^{\circledR}$}

Para a continuidade das simulações computacionais e objetivando a análise do NBI das estruturas, foi proposta uma série de simulações dispondo-se do software $F L U X^{\circledR}$, contemplando as estruturas existentes ao longo da linha, para avaliar as linhas equipotenciais em torno de cada uma delas.

As sobretensões evidenciadas são utilizadas nesta seção. Elas foram obtidas a partir das simulações computacionais de curtos-circuitos executadas via software ATP e apresentadas no capítulo anterior. As simulações realizadas no software FLUX ${ }^{\circledR}$ com modelo baseado na teoria de elementos finitos são apresentadas neste capítulo.

Diante deste panorama geral, é proposta uma análise das regiões de concentração do campo elétrico nas estruturas da linha, considerando os isoladores cerâmicos tipo pino, estruturas e cruzetas de madeira.

Ressalta-se que apesar dessa linha apresentar diversos padrões de estruturas e isoladores, os estudos inicialmente foram realizados somente sobre as estruturas do tipo "A" e isoladores cerâmicos do tipo pino.

\section{1 - MÉTODO DE ELEMENTOS FINITOS}

Antes de abordar as simulações realizadas, uma breve introdução do MEF (método de elementos finitos) é evidenciada nesta subseção.

A distribuição do campo elétrico nos isoladores de alta tensão e, ao redor deles, é um aspecto muito importante no seu projeto. Além disso, o conhecimento do 
campo elétrico também pode ser útil para a deteç̧ão de defeitos nos isoladores (VASSILIKI et al., 2006).

A teoria de Maxwell permite descrever o conjunto dos fenômenos eletromagnéticos e, a partir das equações de Maxwell, consideradas como postulados, todas as leis clássicas podem ser deduzidas e outros fenômenos previstos. A aplicação deste conjunto de equações de maneira analítica é restrita a casos particulares, e até mesmo inexplicáveis em outros. Este fato foi um dos que contribuíram para que alguns problemas em eletromagnetismo fossem modelados e estudados por circuitos elétricos equivalentes como, por exemplo, o estudo de máquinas elétricas.

Como fato, tem-se que a geometria e a distribuição das grandezas eletromagnéticas nos casos reais, a interface entre meios com características diferentes e os fenômenos não lineares, ocasionam certa complexidade na resolução e no entendimento de certos problemas. Em conseqüência, torna-se necessário recorrer aos métodos numéricos, utilizando técnicas de discretização. Estes métodos transformam as equações de derivadas parciais em sistemas de equações algébricas cuja solução fornece uma aproximação dos campos eletromagnéticos.

Com o advento dos computadores digitais, métodos numéricos puderam ser usados para resolver problemas de eletromagnetismo, tais como o cálculo dos campos elétricos e das linhas de potencial entre um conjunto de isoladores (RASOLONJANAHARY et al., 1992; SEBESTYÉN, 2002). Entre eles, o MEF (VLASTOS; GUBANSKI, 1991) é um dos mais utilizados, pois se adapta facilmente às geometrias complexas. Este é baseado em uma discretização do domínio geométrico estudado e dos campos escalares e vetoriais incógnitos. 
A precisão da solução obtida fornece uma aproximação das grandezas locais que são os campos magnéticos e elétricos. Estas grandezas são exploradas para determinar as grandezas globais, tais como fluxo magnético, corrente, tensões, etc.

Cabe colocar que o MEF pertence a uma classe de modernas técnicas aplicadas em análises numéricas. É um método de análise numérica de modelos matemáticos de problemas físicos em meios contínuos. Esses modelos são, tradicionalmente, determinados através de equações diferenciais ou equações integrais com suas respectivas condições de contorno. Antes do aparecimento do MEF, a análise dos meios contínuos era efetuada por resolução direta dos sistemas de equações diferenciais parciais que regem o fenômeno, tendo em consideração as necessárias condições de contorno. Assim, o MEF é uma análise matemática que consiste na divisão do domínio de integração em um número finito de pequenas regiões básicas, denominadas elementos finitos, mantendo as mesmas propriedades do meio original (ZIENKIEWICZ e TAYLOR, 2000).

O MEF transforma o meio contínuo em discreto. A essa divisão do domínio dá-se o nome de "malha" (grid em inglês). A malha é formada por elementos compostos de arestas (faces) e nós (pontos de interseção das arestas), tal como mostrado na Figura 4.1. Sendo assim, ao invés de se buscar uma função admissível que satisfaça as condições de contorno para todo o domínio, essas funções agora devem ser definidas em cada elemento.

Como pode ser observado na Figura 4.1, o sistema é dividido em subsistemas de geometria simples (por exemplo, triângulos e/ou retângulos para análise bidimensional), os quais são chamados de elementos finitos. Dentro de cada elemento, os valores dos campos são calculados por meio de funções de 
interpolação. A forma da interpolação nos elementos é definida pelos valores dos campos e, algumas vezes, por suas derivadas nos pontos nodais. As derivadas dos campos são obtidas derivando as funções de interpolação enquanto as equações de campo são aproximadas pela minimização das equações integrais obtidas pelos princípios variacionais, ou ainda aplicando o método dos resíduos ponderados nas equações diferenciais e condições de contorno (AREND, 2009).

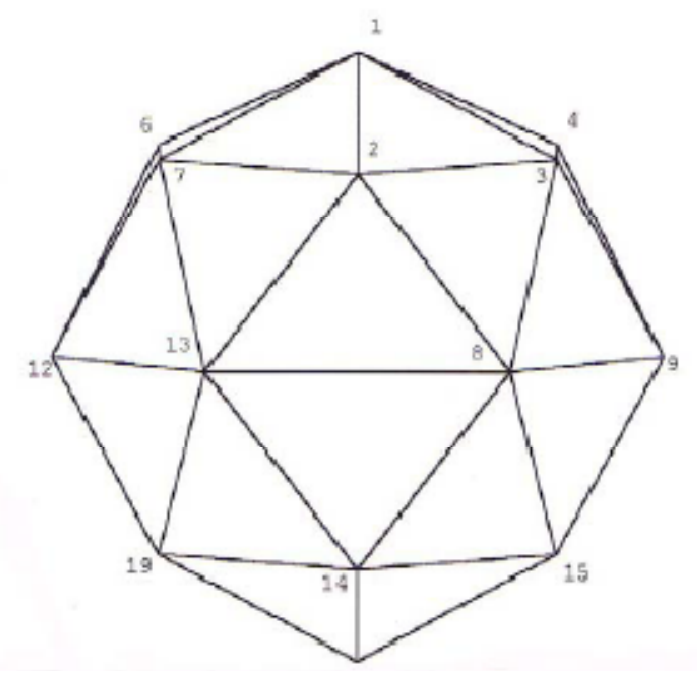

Figura 4.1 - Exemplo de malha de elementos finitos

\section{2 - APLICAÇÕES DO MEF EM SISTEMAS ELÉTRICOS DE POTÊNCIA}

Nesta seção são apresentados alguns exemplos da utilização do MEF em análise de campos elétricos em SEPs, bem como na análise de seus elementos, como, por exemplo, em desempenho de isoladores, análise daqueles com defeitos, etc.

Em QUEIROZ, NERI e COSTA (2006) são realizadas simulações em isoladores poliméricos com tensão nominal de $69 \mathrm{kV}$ a fim de verificar as áreas com maior concentração de campo elétrico, dentro ou fora dos dispositivos, e desenvolver uma metodologia para o estudo do comportamento elétrico dos isoladores. As simulações foram realizadas no software Femlab (FEMLAB, 2004), 
tanto para isoladores perfeitos, quanto para isoladores com defeitos previamente observados. Segundo os autores, as determinações do campo elétrico e de potenciais elétricos são importantes na caracterização dos pontos críticos de degradação. Altas concentrações de campos elétricos podem provocar descargas parciais desgastando o material e ocasionando um envelhecimento precoce do isolador. O Femlab é um software desenvolvido para modelagem e simulação de processos físicos que podem ser descritos por equações diferenciais parciais. Apresenta uma interface gráfica que permite a visualização dos desenhos em escala e a caracterização das superfícies e dos contornos com os valores desejados. O programa faz uso do MEF e das equações diferenciais parciais para calcular os resultados que, podem ser observados em forma de linhas equipotenciais ou, por mapa de cores. Para a resolução de problemas utilizando o software é necessário definir a geometria da região onde o problema deve ser resolvido, indicando-se as condições de contorno e as características elétricas da região. O programa discretiza a região e realiza os cálculos de campo e potenciais elétricos. Considerando os resultados obtidos nas simulações, os autores concluíram que a presença de corpos condutores no interior do isolador causa uma forte intensificação do campo elétrico, contudo, esta ocorrência é incomum nos isoladores. Embora a simulação não tenha apresentado grandes concentrações de campo elétrico, este defeito pode evoluir para situações extremas, devido à carbonização de uma micro-região, causada pelas descargas elétricas ou pela presença de solução aquosa. A presença das descargas ou da solução aquosa no interior do isolador promovendo uma intensificação do campo elétrico fornece condições favoráveis à ocorrência do processo de trilhamento (tracking). 
Em PIHLER e TICAR (2005), são apresentados os resultados de uma pesquisa teórica sobre o comportamento de um sistema de transmissão de energia elétrica em média tensão com condutores revestidos. A pesquisa foi realizada com base nos cálculos computadorizados de campos elétricos. Foram verificadas medidas de descarga parcial para determinar se elas são mais intensas quando o condutor isolado está em uma braçadeira de metal ou plástico ou quando o isolador é de vidro ou porcelana. Segundo os autores, no caso do cálculo do campo elétrico na proximidade imediata do condutor com uma braçadeira de metal, melhores resultados são obtidos com o uso de um isolador de porcelana. No caso de uma braçadeira de material isolante, a magnitude do campo elétrico diminui cerca de cinco vezes em relação ao caso anterior. Nos sistemas com uma braçadeira isolada, o isolador de vidro apresenta magnitude de campo elétrico até duas vezes maior do que no caso da porcelana.

Em SALARI, MPALANTINOS e SILVA (2009), realiza-se uma análise comparativa de métodos em 2-D e 3-D (dimensões) para calcular o campo eletromagnético produzido por linhas de transmissão operando na freqüência do sistema. O estudo foca no efeito da catenária de cabos e no efeito de cargas elétricas e correntes presentes nos elementos da torre. Tais cálculos do campo elétrico na superfície dos cabos foram considerados observando-se os campos elétricos e magnéticos próximos à superfície da terra. São mostrados os resultados para uma típica linha trifásica de $138 \mathrm{kV}$, bem como o intervalo adequado de aplicação para uma modificada e rápida solução em 2-D. Segundo os autores, dos resultados obtidos, calculados na freqüência do sistema, os efeitos da catenária dos cabos e os efeitos de cargas e correntes presentes nos elementos da torre na variação do campo eletromagnético ao longo de uma seção da linha ficam claros. 
Para cálculos em pontos onde os cabos estão em sua altura mínima (para terreno plano), como esperado, os resultados obtidos com uma metodologia tradicional em 2-D são satisfatoriamente precisos. Ao longo do vão das linhas e para pontos suficientemente distantes das torres (no mínimo uma vez a altura da torre), uma metodologia em 2-D modificada demonstrou ser razoavelmente precisa. Para analisar todos os pontos ao longo de todas as seções da linha, particularmente próximo das torres, um método em 3-D é inevitável. Vale colocar que, apesar da sobrecarga computacional, o método em 3-D é perfeitamente possível de ser aplicado pelos computadores pessoais atuais.

O campo elétrico produzido por linhas aéreas é freqüentemente calculado com o uso de métodos numéricos através de um computador. Entretanto, o cálculo analítico oferece a vantagem de que leva a uma expressão matemática, que permite o cálculo direto do campo elétrico. Em TZINEVRAKIS, TSANAKAS e MIMOS (2007) é desenvolvido um método para obter fórmulas analíticas da intensidade do campo elétrico produzido por linhas contendo um único circuito. Este método é baseado na análise da intensidade do campo elétrico através da soma de duas expansões multipolares e no uso de números complexos duplos para a simplificação das expressões matemáticas. Devido à assimetria de cargas nos condutores, eles são analisados através de seus componentes simétricos. Utilizando este método, é dada a fórmula analítica precisa da intensidade do campo elétrico para linhas contendo um único circuito com condutores em arranjo triangular, que é válido em qualquer ponto na vizinhança destas linhas. Através da fórmula precisa, é obtida uma fórmula aproximada mais simples, a qual fornece, segundo os autores, o campo elétrico com precisão excepcional para cálculos a baixas alturas ou para longas distâncias da linha. 
Em VASSILIKI et al. (2006) é apresentado um estudo para o cálculo de potenciais e de campos elétricos aplicável em isoladores utilizados para a suspensão de linhas de transmissão aéreas de $400 \mathrm{kV}$. É utilizado o software OPERA (VECTOR FIELDS, 2004a; VECTOR FIELDS, 2004b), baseado no MEF, para realizar as análises dos isoladores. Foram analisados dois tipos de cadeias de isoladores, sendo a primeira composta por isoladores de porcelana e a segunda por isoladores de vidro. Segundo os autores, os níveis de campo elétrico obtidos para a cadeia de isoladores de vidro são maiores do que para os isoladores de porcelana. As características dielétricas da porcelana são tais que este tipo de cadeia de isoladores oferece uma distribuição suave do campo elétrico ao longo dela. Os maiores níveis de campo elétrico obtidos para os isoladores de vidro são, entretanto, ainda sustentáveis devido à maior força dielétrica do vidro.

A seguir, são apresentados os procedimentos quanto à modelagem no software $F_{L U X}{ }^{\circledR}$ e a utilização dos resultados obtidos com as simulações de transitórios eletromagnéticos.

\section{3 - MODELAGEM E SIMULAÇÃO DAS ESTRUTURAS ESTUDADAS NO SOFTWARE FLUX ${ }^{\circledR}$}

Os valores de tensão obtidos nas simulações de curtos-circuitos na linha USG - SOZ demonstrados nas tabelas do Capítulo 3 foram utilizados na realização das simulações usando o software FLUX ${ }^{\circledR}$.

Para entender melhor as etapas da simulação no software $\mathrm{FLUX}^{\circledR}$, um fluxograma foi desenvolvido e é apresentado na Figura 4.2. A primeira fase se destina a realizar a modelagem em escala real dos componentes que deverão compor o ambiente da simulação. Esta modelagem foi realizada no espaço bidimensional (2D). Em seguida deve-se gerar a malha de elementos finitos, que 
deve ser feita primeiramente nos pontos, depois nas linhas, e por fim nas faces dos componentes modelados na etapa anterior. Nesta etapa, ressalta-se que, quanto mais fina a malha (grande número de elementos finitos), mais precisos serão os resultados da simulação. Em contrapartida, as simulações demandarão maior esforço computacional. Com a malha de elementos finitos gerada é realizada a atribuição de características físicas dos elementos, condutores e dielétricos, aplicação do potencial elétrico obtido com as simulações no software ATP e as características elétricas dos materiais. A partir de todos os componentes do ambiente de simulação configurados pode ser executada a solução do problema e os gráficos contendo o campo elétrico e as linhas equipotenciais são criados.

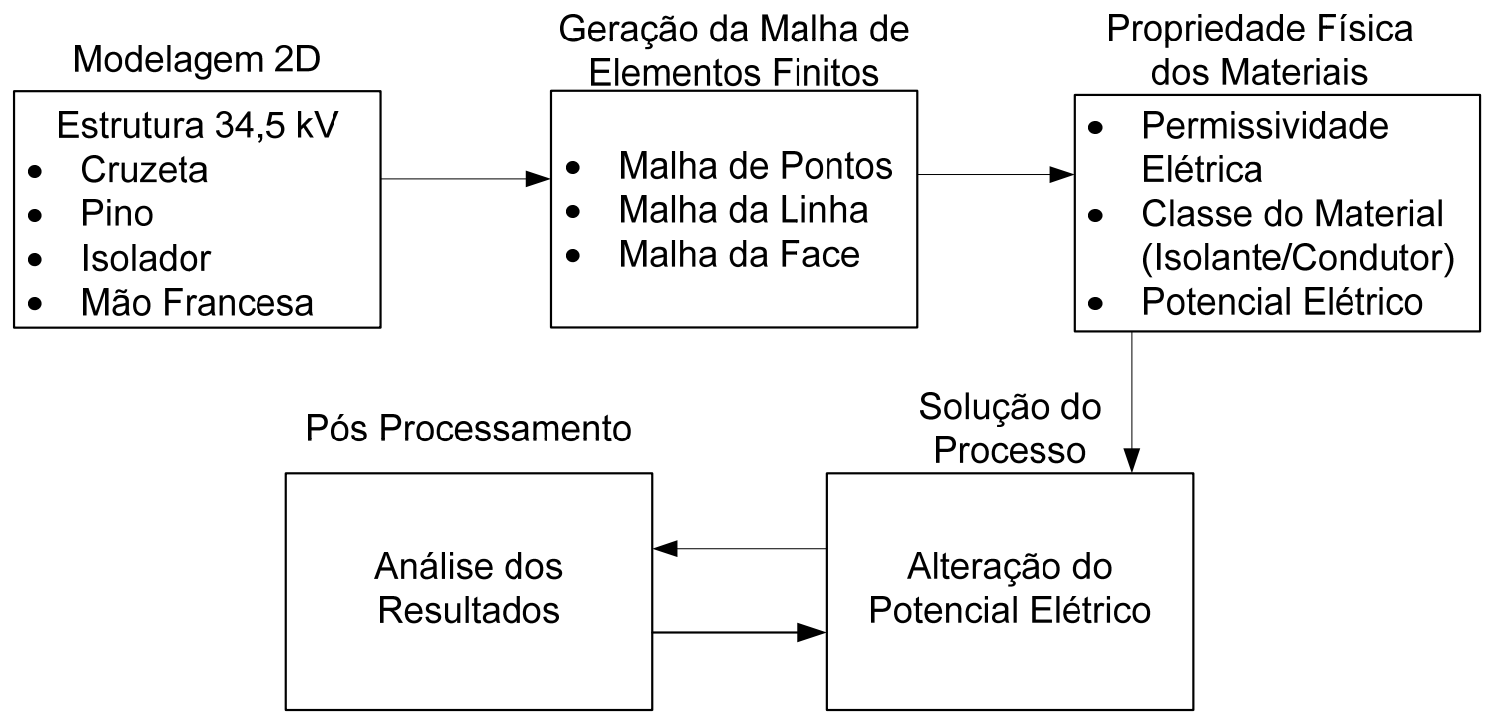

Figura 4.2 - Etapas para simulações no software FLUX ${ }^{\circledast}$

Como o objetivo deste estudo foi verificar a suportabilidade de tensão das estruturas da classe de $34,5 \mathrm{kV}$ operando na classe de $69 \mathrm{kV}$, inicialmente foi desenvolvido no ambiente do software de elementos finitos, o modelo da estrutura com distâncias mais críticas entre fases, neste caso, o da estrutura tipo "A", como pode ser observado na Figura 4.3. 


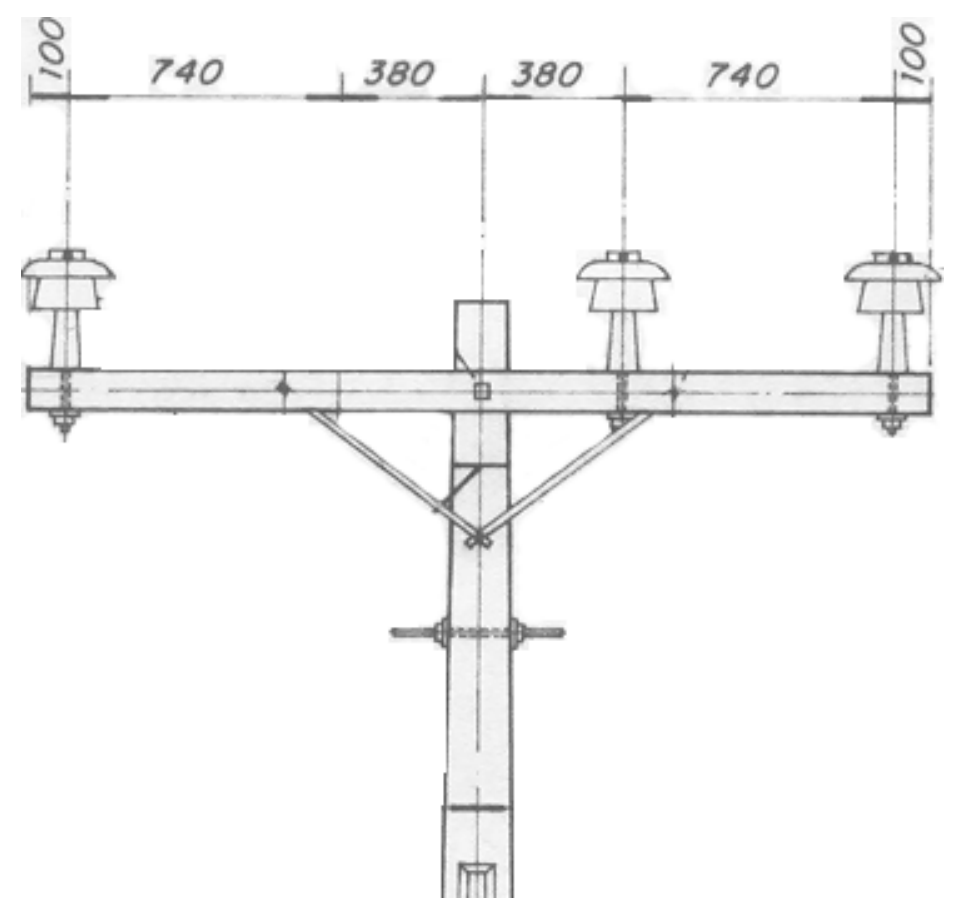

Figura 4.3 - Estrutura do tipo "A" (distâncias em mm)

De acordo com o projeto da estrutura "A", foi desenhado através do aplicativo CAD, disponível no software FLUX ${ }^{\circledR}$, o modelo desta estrutura, mantendo a escala real e modelando-se todos os seus componentes, desde o poste e a cruzeta, até os isoladores, os pinos e a mão francesa. $\mathrm{O}$ resultado parcial desta modelagem pode ser visto na Figura 4.4. 


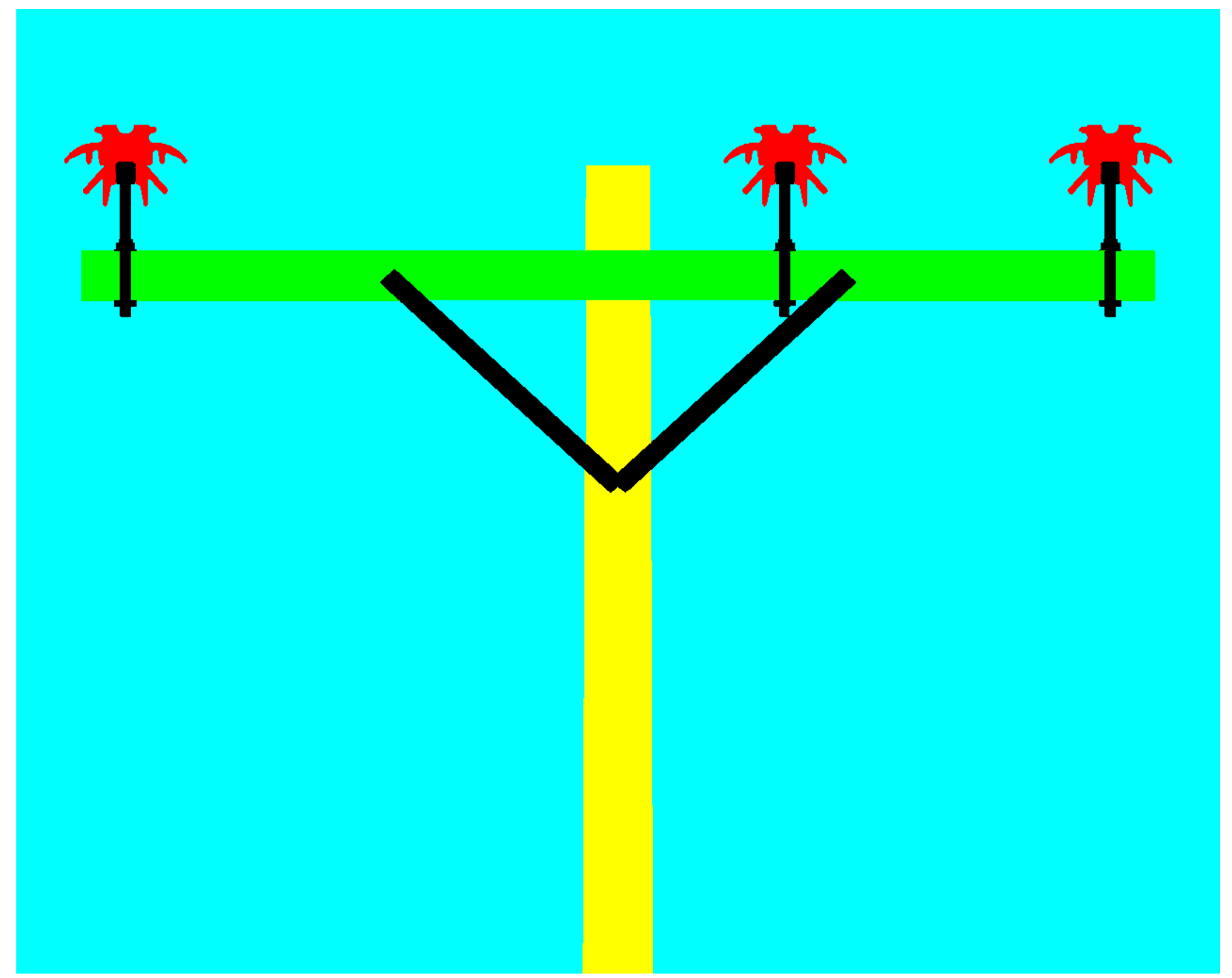

Figura 4.4 - Estrutura do tipo "A" modelada no software FLUX ${ }^{\circledR}$

Considerando-se o isolador mais à esquerda como sendo da fase "A", o do centro como da fase "B" e, o isolador localizado mais à direita, como da fase "C", foram aplicados os valores de tensão no condutor de cada fase (valores apresentados nas tabelas do Capítulo 3), realizando-se uma análise estática dos campos elétricos gerados pelos curtos-circuitos que provocaram os mais altos picos de tensão.

A partir do modelo criado no software $F L U X^{\circledR}$, é realizada a etapa de geração da malha de elementos finitos, utilizada para os cálculos das equações diferenciais que regem o fenômeno. 
O tamanho da malha depende do nível de precisão requerido e da geometria dos componentes modelados. Durante as simulações percebeu-se que quanto mais ângulos agudos no modelo criado, maior a necessidade de refinamento da malha. Para a estrutura em questão, a malha criada pode ser vista na Figura 4.5.

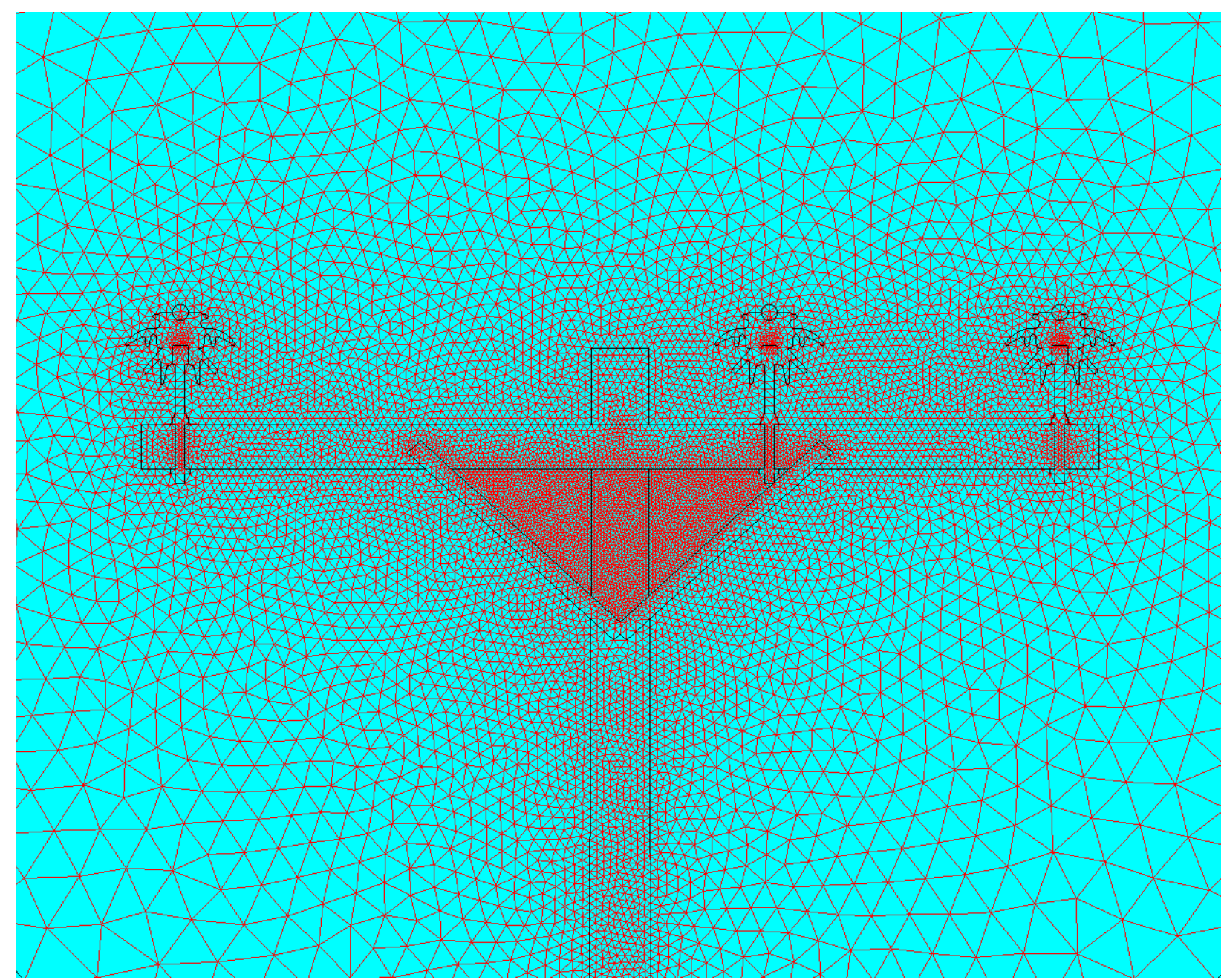

Figura 4.5 - Malha de elementos finitos gerada no software FLUX ${ }^{\circledR}$

Cabe lembrar que a permissividade de um material é usualmente dada com relação à do vácuo, denominando-se permissividade relativa, que é uma constante física que descreve como um campo elétrico afeta e é afetado por um meio. Esta constante é determinada pela habilidade de um material de polarizar-se em resposta a um campo elétrico aplicado. 
As permissividades relativas do ambiente simulado e dos materiais presentes na estrutura são apresentadas na Tabela 4.1 (SCHMIDT, 1979).

Tabela 4.1 - Permissividade relativa dos materiais utilizados na estrutura tipo " $A$ "

\begin{tabular}{c|c}
\hline Material & Permissividade Relativa (F/m) \\
\hline $\mathrm{Ar}$ & 1 \\
\hline Isolador Cerâmico & $5,4^{1}$ \\
\hline Cruzeta e Poste (Madeira) & $10-60$ \\
\hline Pino e Mão Francesa (Ferro) & 5000 \\
\hline
\end{tabular}

Admitindo-se que alguns parâmetros podem variar de acordo com alterações do ambiente como, por exemplo, a poluição, a umidade relativa do ar e a altitude, foram utilizadas sempre as condições mais conservadoras para a realização das simulações, ou seja, os menores valores para a característica de permissividade relativa dos materiais.

A Figura 4.6 apresenta o campo elétrico em cores para a estrutura tipo "A", para um curto-circuito trifásico terra, no momento em que a fase " $A$ " atinge seu pico positivo de tensão. Este corresponde ao caso ABC-T (A) da Tabela 3.4 que apresenta transitórios da classe de $69 \mathrm{kV}$. Como pode ser observado pela escala de cores alocada ao lado direito da Figura 4.6, quanto mais claro for o tom da cor, maiores serão as intensidades dos campos elétricos e, conseqüentemente, maiores as influências destes sobre qualquer material e/ou corpo colocado nas proximidades.

\footnotetext{
${ }^{1}$ Valor fornecido pela biblioteca de materiais do software FLUX ${ }^{\circledR}$
} 


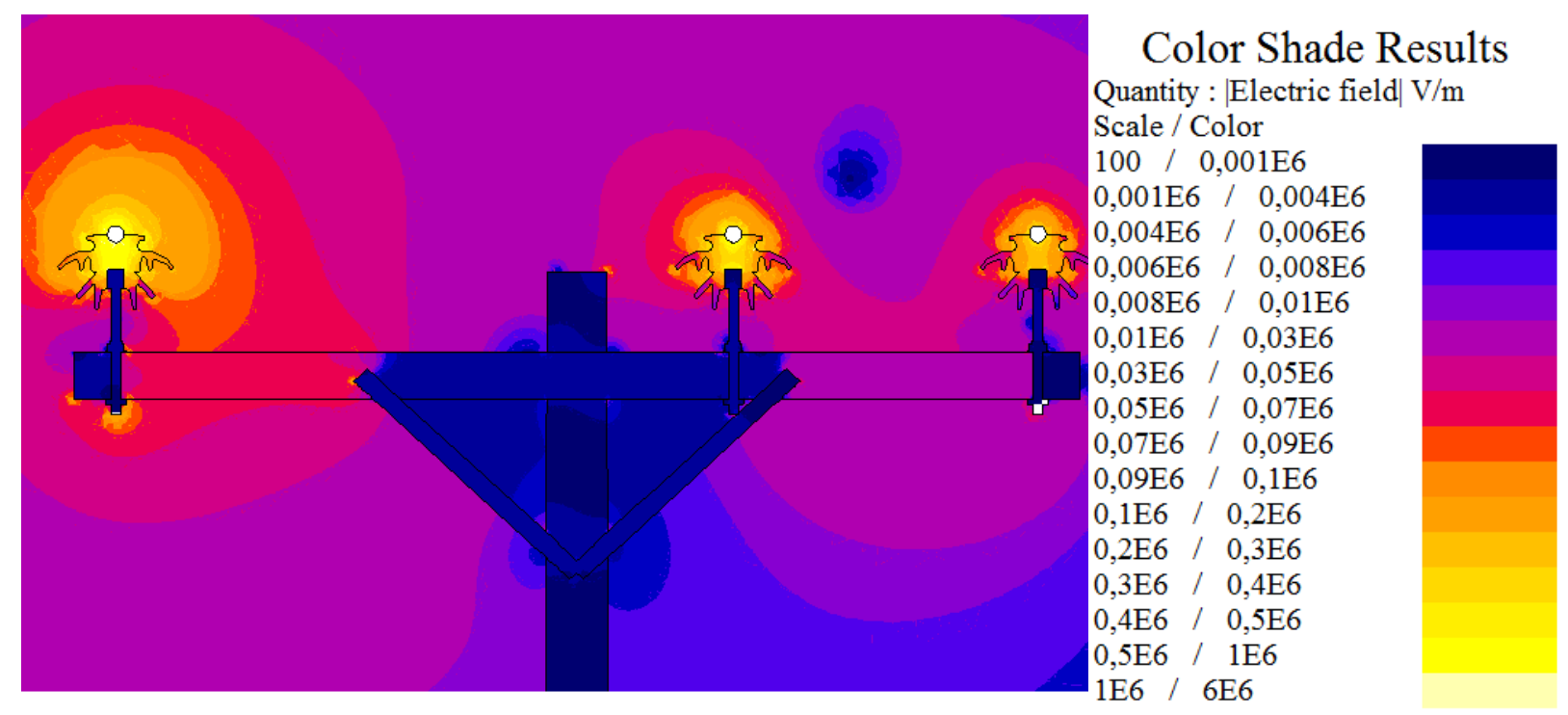

Figura 4.6 - Campo elétrico gerado por um curto-circuito trifásico terra com pico na fase "A"

Além da representação dos campos elétricos por um esquema de cores, tal como apresentado na Figura 4.6, o software FLUX ${ }^{\circledR}$ também disponibiliza os resultados na forma de linhas equipotenciais. Essa característica pode ser vista na Figura 4.7, em que se mostra o mesmo caso analisado na Figura 4.6. Ressalta-se que a apresentação dos resultados por meio de linhas equipotenciais, torna mais rápido o entendimento da interação dos campos elétricos na estrutura simulada. Para facilitar a visualização da propagação das linhas de potencial na Figura 4.7, optou-se por não enumerá-las, mas sim, apresentar o valor das linhas de interesse para o cálculo, descrevendo, na Tabela 4.2, o local onde elas se encontram. 


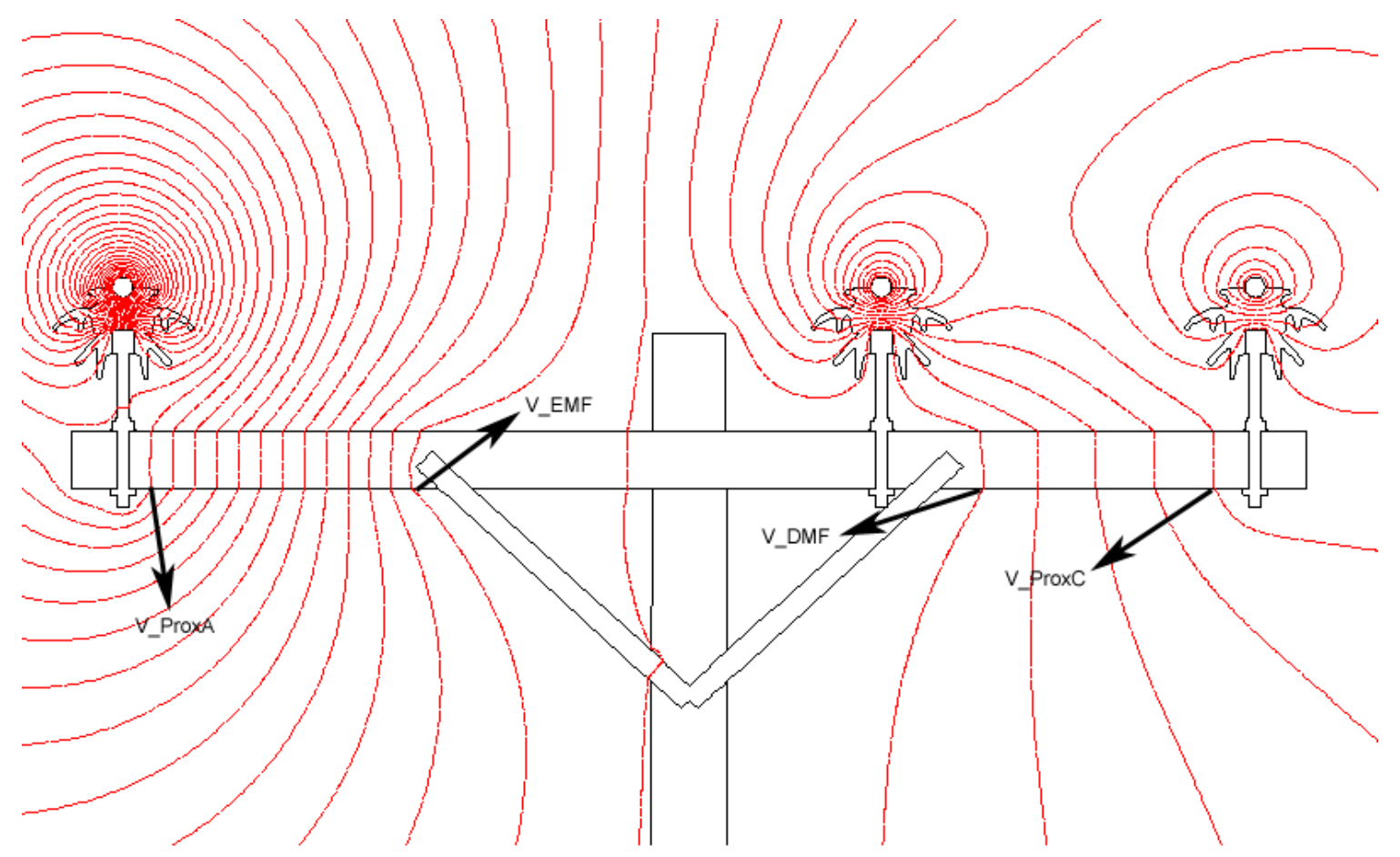

Figura 4.7 - Linhas de potencial elétrico geradas por um curto-circuito trifásico terra com pico na fase "A"

Tabela 4.2 - Valores das linhas de potencial para um curto-circuito trifásico terra com pico na fase "A"

\begin{tabular}{c|c}
\hline Linha de Campo & Potencial Elétrico \\
\hline Linha à direita mais próxima da fase A (V_ProxA) & $69,5 \mathrm{kV}$ \\
\hline Linha à esquerda mais próxima da mão francesa (V_EMF) & $42,8 \mathrm{kV}$ \\
\hline Linha à direita mais próxima da mão francesa (V_DMF) & $38,4 \mathrm{kV}$ \\
\hline Linha à esquerda mais próxima da fase C (V_ProxC) & $29,5 \mathrm{kV}$ \\
\hline
\end{tabular}

A Tabela 4.2 representa apenas um dos casos simulados no software FLUX ${ }^{\circledR}$. A partir dos vários casos de curtos-circuitos gerados pelo software ATP, foram construídas a Tabela 4.3 e a Tabela 4.4 para picos positivos e negativos de tensão, respectivamente.

Nota-se que, como relatado no Capítulo 3, existem três casos simulados no software FLUX ${ }^{\circledR}$ para cada tipo de curto-circuito.

A Tabela 4.3 e Tabela 4.4 apresentam os valores de tensão das linhas equipotenciais de interesse para a análise da diferença de potencial que a estrutura 
é submetida durante os curtos-circuitos aplicados. A variável DDP_AB é a diferença de potencial entre o ponto da cruzeta mais próximo ao pino do isolador da fase "A" e o ponto mais próximo à esquerda da mão francesa. Já a variável DDP_BC é a diferença de potencial entre o ponto da cruzeta mais próximo ao pino do isolador da fase "C" e o ponto mais próximo à direita da mão francesa. A distância entre V_ProxA e V_EMF pela cruzeta de madeira é a mesma entre V_DMF e V_ProxC e, mede aproximadamente $0,595 \mathrm{~m}$. Pela rigidez dielétrica da madeira da cruzeta utilizada nos estudos, parâmetro que indica qual o limite de tensão por unidade de espessura que o material pode suportar sem se romper (SCHMIDT, 1979), que é de 330 kV/m, é analisado então se a estrutura do tipo "A" suportará os níveis de tensão em que está sendo submetida para os casos de curtos-circuitos simulados no software ATPDraw.

Sendo assim, para a estrutura do tipo "A", considerada a mais crítica no sistema em análise, verificou-se para todos os valores de DDP_AB e DDP_BC se estes não excediam, simultaneamente, o valor de 196,35 kV. Este valor, tomado como referência, foi calculado multiplicando-se a distância de 0,595 m da cruzeta de madeira, pela sua rigidez dielétrica de $330 \mathrm{kV} / \mathrm{m}$ (valor este conservador). Conforme mostram a Tabela 4.3 e Tabela 4.4 , todas as situações simuladas via o software FLUX $^{\circledR}$ foram analisadas tomando como referência o valor de 196,35 kV. Como conclusão para a Tabela 4.3 e a Tabela 4.4, observa-se na coluna "condição", a designação "suportável", atestando que tal valor de referência não foi ultrapassado para as situações analisadas.

Ainda com relação a essas tabelas, observa-se que existem algumas células preenchidas com “-”, que representam os casos em que o software FLUX ${ }^{\circledR}$ não gerou linhas equipotenciais próximas aos pontos estudados. Isto ocorreu, por 
exemplo, nos casos AB (A) e C-T (A) da Tabela 4.3. Para o primeiro caso, quando existe uma grande diferença de potencial aplicada entre a fase $A$ e a fase $B$ comparada a uma menor diferença de potencial aplicada entre a fase $\mathrm{B}$ e a fase $\mathrm{C}, \mathrm{O}$ software $F L U X^{\circledR}$ concentra as linhas equipotenciais entre as fases $A$ e $B$, o que dificulta o posicionamento das linhas equipotenciais nos pontos onde foram realizados os estudos, tais como, o potencial elétrico de V_DMF e V_ProxC. 
Tabela 4.3 - Diferença de potencial elétrico para picos de tensão positivos

\begin{tabular}{|c|c|c|c|c|c|c|c|}
\hline Tipo de Falta & V_ProxA & V_EMF & DDP_AB & V_DMF & V_ProxC & DDP_BC & Condição \\
\hline ABC-T (A) & $69.510,0$ & $42.809,0$ & $26.701,0$ & $38.359,0$ & $29.458,0$ & $8.901,0$ & Suportável \\
\hline ABC-T (B) & $-11.737,0$ & $22.570,0$ & $34.307,0$ & $69.510,0$ & $76.185,0$ & $6.675,0$ & Suportável \\
\hline ABC-T (C) & $-554,4$ & $4.820,0$ & $5.374,4$ & $7.508,0$ & $39.758,0$ & $32.250,0$ & Suportável \\
\hline$A B C(A)$ & $45.646,0$ & $5.868,0$ & $39.778,0$ & $-4.075,0$ & $-20.649,0$ & $16.574,0$ & Suportável \\
\hline$A B C(B)$ & $34.420,0$ & $22.777,0$ & $11.643,0$ & $18.896,0$ & $-19.913,0$ & $38.809,0$ & Suportável \\
\hline$A B C(C)$ & $-10.880,0$ & $-3.200,0$ & $7.680,0$ & $-641,0$ & $32.636,0$ & $33.277,0$ & Suportável \\
\hline AB-T (A) & $63.686,0$ & $36.901,0$ & $26.785,0$ & $32.030,0$ & $19.855,0$ & $12.175,0$ & ável \\
\hline AB-T (B) & $40.244,0$ & $51.488,0$ & $11.244,0$ & $51.488,0$ & $26.189,0$ & $25.299,0$ & tável \\
\hline AB-T (C) & $13.756,0$ & $24.644,0$ & $10.888,0$ & $29.000,0$ & $52.953,0$ & $23.953,0$ & Supo \\
\hline$A B(A)$ & $36.826,0$ & $\begin{array}{l}676,7 \\
\end{array}$ & $36.149,3$ & - & - & - & ável \\
\hline$A B(B)$ & -8.83 & $8.303,0$ & $17.141,0$ & $10.752,0$ & & $17.141,0$ & ável \\
\hline$A B(C$ & -10.76 & -6.08 & $4.682,0$ & -3.7 & 22.0 & $25.753,0$ & ável \\
\hline BC-T & 43.15 & $18.874,0$ & $24.284,0$ & $16.850,0$ & 8,0 & $12.142,0$ & ivel \\
\hline$B C-T$ & $13.282,0$ & $41.878,0$ & $28.596,0$ & $41.878,0$ & 32.3 & $9.532,0$ & ável \\
\hline$B C-T$ & $4.282,0$ & \begin{tabular}{|l|}
$18.931,0$ \\
\end{tabular} & $14.649,0$ & \begin{tabular}{|l|}
$18.931,0$ \\
\end{tabular} & $48.227,0$ & $29.296,0$ & ável \\
\hline BC (A) & $21.410,0$ & $-1.010,0$ & $22.420,0$ & $-4.746,0$ & $-12.220,0$ & $7.474,0$ & avel \\
\hline $\mathrm{BC}(\mathrm{B})$ & $-4.171,0$ & $12.618,0$ & $16.789,0$ & $12.618,0$ & $-14.246,0$ & $26.864,0$ & avel \\
\hline$B C(C$ & $-11.437,0$ & $-8.650,0$ & $2.787,0$ & $-5.863,0$ & $24.796,0$ & $30.659,0$ & Supo \\
\hline CA-T (A) & $59.264,0$ & $28.542,0$ & $30.722,0$ & $25.748,0$ & $20.163,0$ & $5.585,0$ & Suportável \\
\hline CA-T & $35.680,0$ & $45.813,0$ & $10.133,0$ & $45.813,0$ & $25.547,0$ & $20.266,0$ & Suportável \\
\hline CA-T (C) & $5.533,0$ & $17.210,0$ & $11.677,0$ & $19.545,0$ & $47.569,0$ & $28.024,0$ & tável \\
\hline CA (A) & $41.988,0$ & $8.484,0$ & $33.504,0$ & $4.761,0$ & $-25.019,0$ & $29.780,0$ & tável \\
\hline $\mathrm{CA}(\mathrm{B})$ & $-11.050,0$ & $11.175,0$ & $22.225,0$ & $11.175,0$ & $3.766,0$ & $7.409,0$ & tável \\
\hline $\mathrm{CA}(\mathrm{C}$ & $-24.458,0$ & $-2.442,0$ & $22.016,0$ & \begin{tabular}{|r|}
309,9 \\
\end{tabular} & $25.079,0$ & $24.769,1$ & ável \\
\hline A-T (A) & $53.232,0$ & $19.355,0$ & $33.877,0$ & $13.709,0$ & $5.240,0$ & $8.469,0$ & tável \\
\hline A-T (B) & $8.362,0$ & $21.799,0$ & $13.437,0$ & $21.799,0$ & $8.362,0$ & $13.437,0$ & tável \\
\hline$A-T(C)$ & $-10.690,0$ & $6.900,0$ & $17.590,0$ & $11.926,0$ & $32.030,0$ & $20.104,0$ & Suportável \\
\hline$B-T(A)$ & $58.825,0$ & $45.064,0$ & $13.761,0$ & $45.064,0$ & $34.057,0$ & $11.007,0$ & Suportável \\
\hline B-T (B) & $18.384,0$ & $35.125,0$ & $16.741,0$ & $35.125,0$ & $15.594,0$ & $19.531,0$ & Suportável \\
\hline$B-T(C)$ & $6.400,0$ & $11.237,0$ & $4.837,0$ & $13.656,0$ & $40.261,0$ & $26.605,0$ & Suportável \\
\hline $\mathrm{C}-\mathrm{T}(\mathrm{A})$ & $40.765,0$ & $21.570,0$ & $19.195,0$ & - & - & - & Suportável \\
\hline $\mathrm{C}-\mathrm{T}(\mathrm{B})$ & $15.517,0$ & $30.455,0$ & $14.938,0$ & $30.455,0$ & $10.538,0$ & $19.917,0$ & Suportável \\
\hline C-T (C) & $-2.376,0$ & $8.371,0$ & $10.747,0$ & $8.371,0$ & $36.315,0$ & $27.944,0$ & Suportável \\
\hline
\end{tabular}


Tabela 4.4 - Diferença de potencial elétrico para picos de tensão negativos

\begin{tabular}{|c|c|c|c|c|c|c|c|}
\hline Tipo de Falta & V_ProxA & V_EMF & DDP_AB & V_DMF & V_ProxC & DDP_BC & Condição \\
\hline ABC-T (A) & $-46.070,0$ & $-14.697,0$ & $31.373,0$ & $-9.468,0$ & $-4.240,0$ & $5.228,0$ & Suportável \\
\hline ABC-T (B) & $-1.470,0$ & $-20.468,0$ & $18.998,0$ & $-20.468,0$ & $-3.844,0$ & $16.624,0$ & Suportável \\
\hline ABC-T (C) & $9.380,0$ & $-14.332,0$ & $23.712,0$ & $-17.719,0$ & $-51.594,0$ & $33.875,0$ & Suportável \\
\hline $\mathrm{ABC}(\mathrm{A})$ & $-29.881,0$ & $1.322,0$ & $31.203,0$ & $4.790,0$ & $11.724,0$ & $6.934,0$ & Suportável \\
\hline$A B C(B)$ & $-2.466,0$ & $-12.968,0$ & $10.502,0$ & $-15.593,0$ & $8.035,0$ & $23.628,0$ & Suportável \\
\hline$A B C(C)$ & $-920,3$ & $7.067,0$ & $7.987,3$ & $7.067,0$ & $-28.879,0$ & $35.946,0$ & Suportável \\
\hline AB-T $(A)$ & $-54.480,0$ & $-30.351,0$ & $24.129,0$ & & & & Suportável \\
\hline AB-T (B) & $-32.923,0$ & $-37.935,0$ & $5.012,0$ & $-37.935,0$ & $-12.873,0$ & $25.062,0$ & tável \\
\hline$A B-T(C)$ & $-11.676,0$ & $-25.734,0$ & $14.058,0$ & $-28.077,0$ & $-53.848,0$ & $25.771,0$ & Suportável \\
\hline$A B(A)$ & $-27.454,0$ & $-3.696,0$ & $23.758,0$ & $1.054,0$ & $15.308,0$ & $14.254,0$ & tável \\
\hline$A B(B)$ & $25.050,0$ & $-9.459,0$ & $34.509,0$ & $-13.294,0$ & $-20.963,0$ & $7.669,0$ & tável \\
\hline$A B(C)$ & $12.851,0$ & $5.236,0$ & $7.615,0$ & $2.698,0$ & $-27.760,0$ & $30.458,0$ & tável \\
\hline BC-T (A) & $-55.227,0$ & $-24.853,0$ & $30.374,0$ & & & & ável \\
\hline BC-T ( & $-17.326,0$ & $-31.333,0$ & $14.007,0$ & $-31.333,0$ & $-12.657,0$ & $18.676,0$ & ável \\
\hline $\mathrm{BC}-\mathrm{T}(\mathrm{C})$ & $-9.654,0$ & $-26.661,0$ & $17.007,0$ & $-29.496,0$ & $-60.676,0$ & $31.180,0$ & ável \\
\hline $\mathrm{BC}$ & $-22.381,0$ & $3.4 s$ & $25.879,0$ & $5.851,0$ & $8.203,0$ & $2.352,0$ & ável \\
\hline & $-10.214,0$ & $-13.325,0$ & $3.111,0$ & $-13.325,0$ & $17.788,0$ & $31.113,0$ & ável \\
\hline & - & - & - & 12.40 & $-26.361,0$ & $38.763,0$ & Supor \\
\hline CA-T (A) & $-56.232,0$ & $-29.475,0$ & $26.757,0$ & $-25.359,0$ & $-19.184,0$ & $6.175,0$ & tável \\
\hline CA-T (B) & $-14.202,0$ & $-28.750,0$ & $14.548,0$ & $-30.828,0$ & $-45.375,0$ & $14.547,0$ & ável \\
\hline CA-T (C) & $-15.547,0$ & $-23.454,0$ & $7.907,0$ & $-28.725,0$ & $-60.355,0$ & $31.630,0$ & ável \\
\hline CA (A) & $-26.689,0$ & $5.339,0$ & $32.028,0$ & $14.074,0$ & $16.986,0$ & $2.912,0$ & ável \\
\hline $\mathrm{CA}(\mathrm{B})$ & $13.579,0$ & $-7.734,0$ & $21.313,0$ & $-7.734,0$ & $-2.998,0$ & $4.736,0$ & ável \\
\hline $\mathrm{CA}(\mathrm{C})$ & $37.929,0$ & $3.714,0$ & $34.215,0$ & $-3.888,0$ & $-30.500,0$ & $26.612,0$ & Suportável \\
\hline$A-T(A)$ & $-39.404,0$ & $-13.810,0$ & $25.594,0$ & $-9.156,0$ & $2.476,0$ & $11.632,0$ & Suportável \\
\hline$A-T(B)$ & $-10.448,0$ & $-18.366,0$ & $7.918,0$ & $-18.366,0$ & $-551,5$ & $17.814,5$ & Suportável \\
\hline$A-T(C)$ & $4.045,0$ & $-10.469,0$ & $14.514,0$ & $-12.888,0$ & $-39.500,0$ & $26.612,0$ & Suportável \\
\hline B-T (A) & $-42.621,0$ & $-19.721,0$ & $22.900,0$ & $-15.557,0$ & $-13.476,0$ & $2.081,0$ & Suportável \\
\hline B-T (B) & $-7.819,0$ & $-25.349,0$ & $17.530,0$ & $-25.349,0$ & $-10.010,0$ & $15.339,0$ & Suportável \\
\hline $\mathrm{B}-\mathrm{T}(\mathrm{C})$ & $-13.102,0$ & $-28.981,0$ & $15.879,0$ & $-32.951,0$ & $-48.832,0$ & $15.881,0$ & Suportável \\
\hline C-T (A) & $-40.981,0$ & $-14.535,0$ & $26.446,0$ & $-9.727,0$ & $-7.323,0$ & $2.404,0$ & Suportável \\
\hline C-T (B) & $-49.399,0$ & $-64.096,0$ & $14.697,0$ & $-65.566,0$ & $-64.096,0$ & $1.470,0$ & Suportável \\
\hline C-T (C) & $-1.977,0$ & $-15.984,0$ & $14.007,0$ & $-18.786,0$ & $-52.407,0$ & $33.621,0$ & Suportável \\
\hline
\end{tabular}

A seguir, são apresentadas as figuras que apresentaram os maiores valores de tensão para os indicadores DDP_AB e DDP_BC, para picos positivos conforme a Tabela 4.3, e para picos negativos conforme a Tabela 4.4. Para facilitar a localização dos casos ilustrados nas tabelas, as linhas foram colocadas em negrito. 
A Figura 4.8 ilustra as linhas de potencial elétrico para um curto-circuito trifásico sem o envolvimento do terra, em uma estrutura do tipo $A$, com pico de tensão na fase $A$.

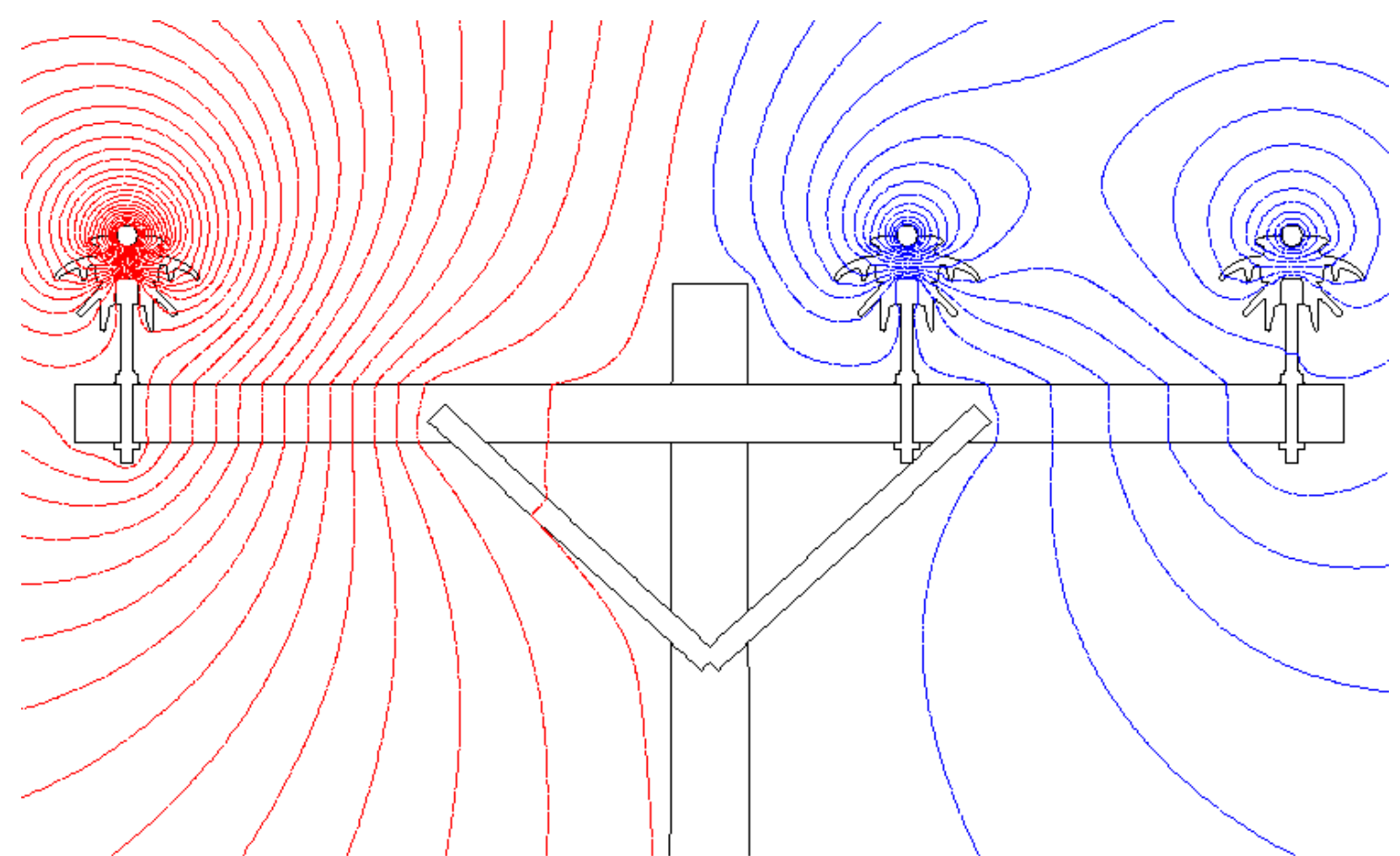

Figura 4.8 - Linhas de potencial elétrico gerado por um curto-circuito trifásico sem o envolvimento do terra com pico na fase $A$

A Tabela 4.5 apresenta os indicadores utilizados na Tabela 4.3 para um curto-circuito trifásico sem o envolvimento do terra, representando o caso que o indicador DDP_AB atingiu o maior valor.

Tabela 4.5 - Valores das linhas de potencial gerado por um curto-circuito trifásico sem o envolvimento do terra com pico na fase $A$

\begin{tabular}{c|c}
\hline Linha de Campo & Potencial Elétrico \\
\hline Linha à direita mais próxima da fase A (V_ProxA) & $45,6 \mathrm{kV}$ \\
\hline Linha à esquerda mais próxima da mão francesa (V_EMF) & $05,9 \mathrm{kV}$ \\
\hline Linha à direita mais próxima da mão francesa (V_DMF) & $-04,1 \mathrm{kV}$ \\
\hline Linha à esquerda mais próxima da fase C (V_ProxC) & $-20,6 \mathrm{kV}$ \\
\hline
\end{tabular}


A Figura 4.9 ilustra as linhas de potencial elétrico para um curto-circuito trifásico sem o envolvimento do terra, em uma estrutura do tipo A, com pico de tensão na fase $B$.

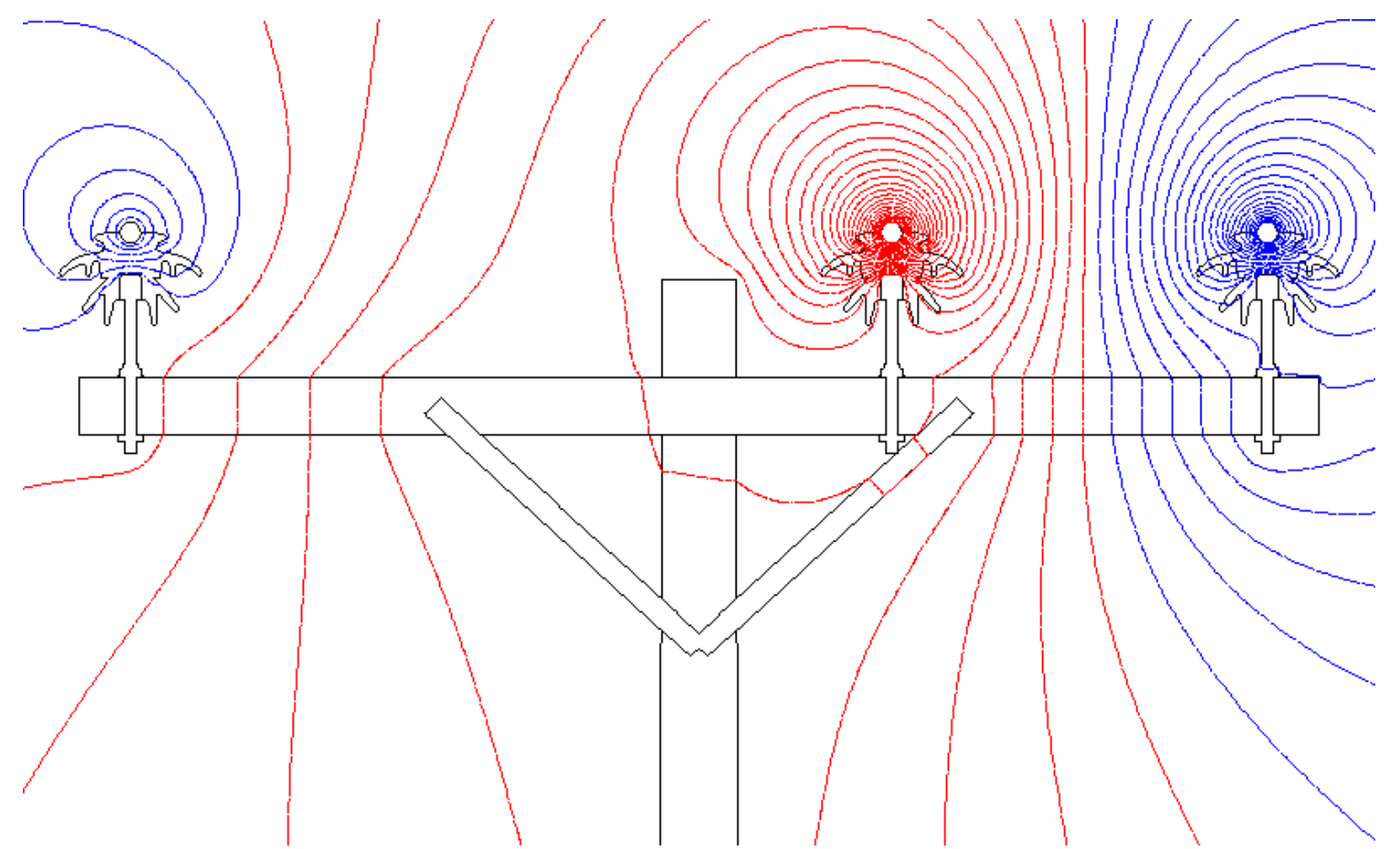

Figura 4.9 - Linhas de potencial elétrico gerado por um curto-circuito trifásico sem o envolvimento do terra com pico na fase B

A Tabela 4.6 apresenta os indicadores utilizados na Tabela 4.3 para um curto-circuito trifásico sem o envolvimento do terra, representando o caso que o indicador DDP_BC atingiu o maior valor.

Tabela 4.6 - Valores das linhas de potencial gerado por um curto-circuito trifásico sem o envolvimento do terra com pico na fase $B$

\begin{tabular}{c|c}
\hline Linha de Campo & Potencial Elétrico \\
\hline Linha à direita mais próxima da fase $\mathrm{A}\left(\mathrm{V}_{-}\right.$ProxA $)$ & $34,4 \mathrm{kV}$ \\
\hline Linha à esquerda mais próxima da mão francesa (V_EMF) & $22,8 \mathrm{kV}$ \\
\hline Linha à direita mais próxima da mão francesa (V_DMF) & $18,9 \mathrm{kV}$ \\
\hline Linha à esquerda mais próxima da fase C (V_ProxC) & $-19,9 \mathrm{kV}$ \\
\hline
\end{tabular}

A Figura 4.10 ilustra as linhas de potencial elétrico para um curto-circuito bifásico sem o envolvimento do terra, em uma estrutura do tipo A, com pico de tensão na fase $B$. 


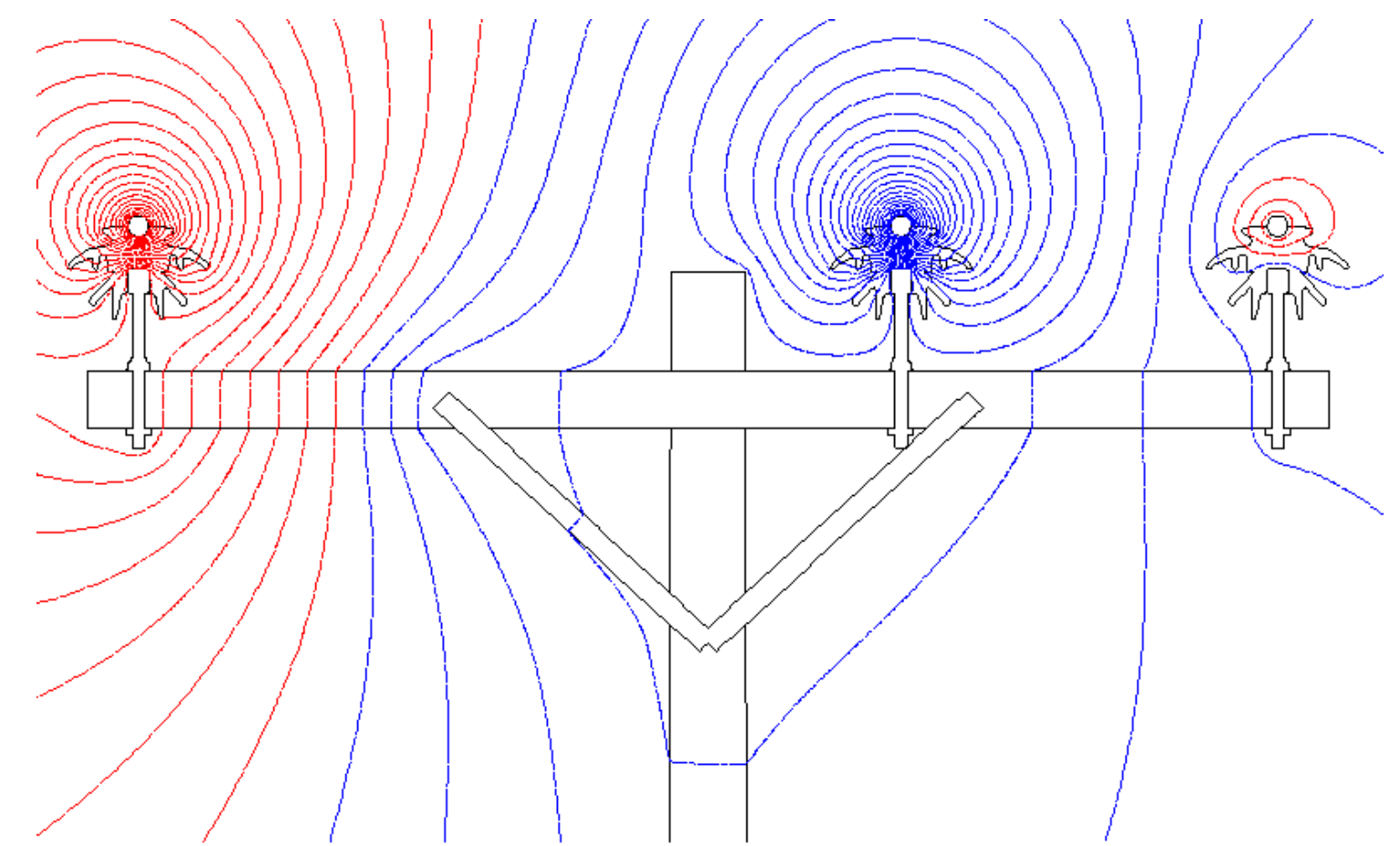

Figura 4.10 - Linhas de potencial elétrico gerado por um curto-circuito bifásico entre as fases $A$ e $B$ com pico na fase $B$

A Tabela 4.7 apresenta os indicadores utilizados na Tabela 4.4 para um curto-circuito bifásico sem o envolvimento do terra, representando o caso que o indicador DDP_AB atingiu o maior valor.

Tabela 4.7 - Valores das linhas de potencial gerado por um curto-circuito bifásico entre as fases A e B com pico na fase B

\begin{tabular}{c|c}
\hline Linha de Campo & Potencial Elétrico \\
\hline Linha à direita mais próxima da fase $\mathrm{A}\left(\mathrm{V} \_\right.$ProxA $)$ & $25,1 \mathrm{kV}$ \\
\hline Linha à esquerda mais próxima da mão francesa (V_EMF) & $-09,5 \mathrm{kV}$ \\
\hline Linha à direita mais próxima da mão francesa (V_DMF) & $-13,3 \mathrm{kV}$ \\
\hline Linha à esquerda mais próxima da fase C (V_ProxC) & $-21,0 \mathrm{kV}$ \\
\hline
\end{tabular}

A Figura 4.11 ilustra as linhas de potencial elétrico para um curto-circuito bifásico sem o envolvimento do terra, em uma estrutura do tipo A, com pico de tensão na fase $C$. 


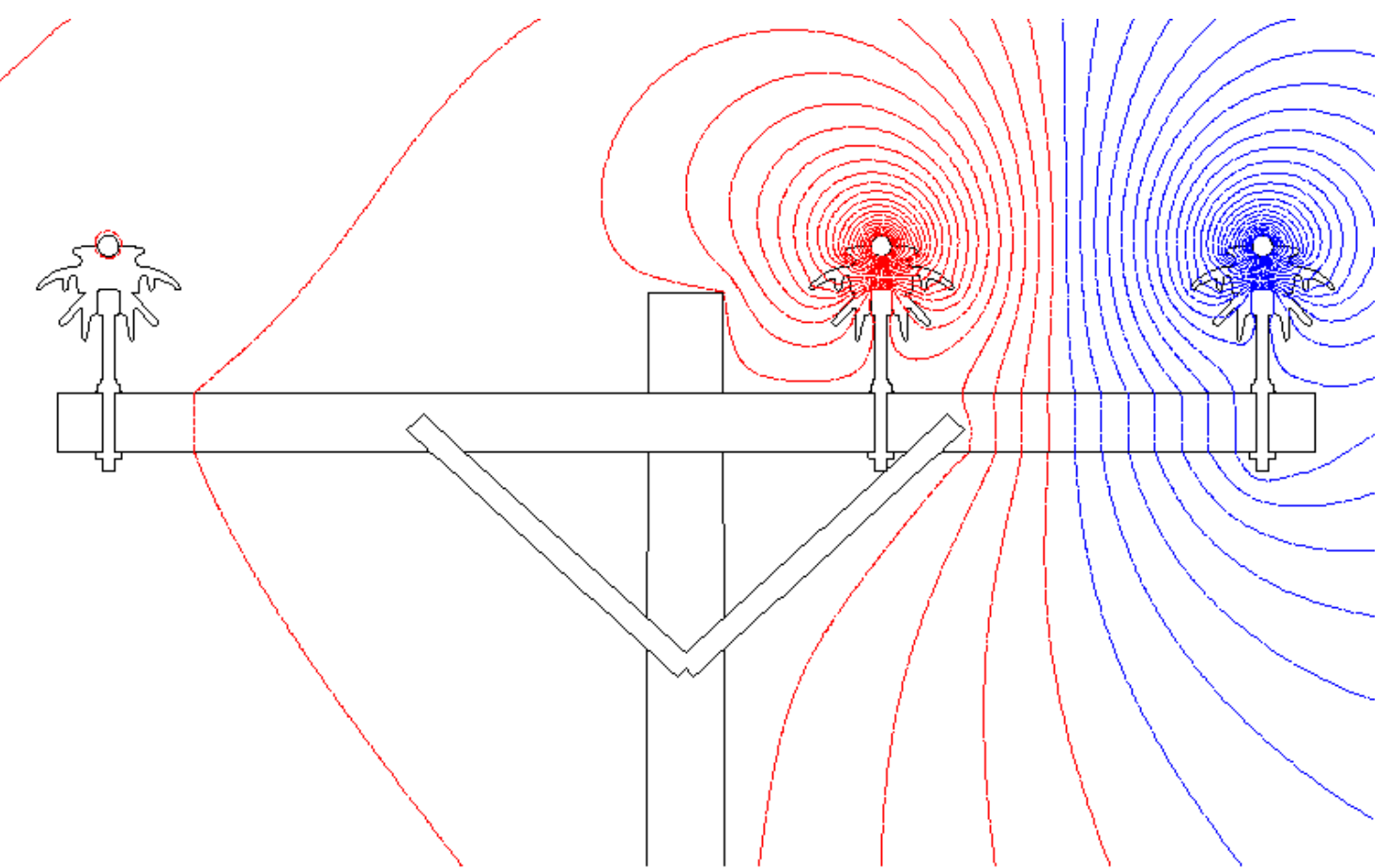

Figura 4.11 - Linhas de potencial elétrico gerado por um curto-circuito bifásico, envolvendo as fases B e C, com pico na fase C

A Tabela 4.8 apresenta os indicadores utilizados na Tabela 4.4 para um curto-circuito bifásico sem o envolvimento do terra, representando o caso que o indicador DDP_BC atingiu o maior valor.

Tabela 4.8 - Valores das linhas de potencial gerado por um curto-circuito bifásico, envolvendo as fases B e C, com pico na fase $\mathbf{C}$

\begin{tabular}{c|c}
\hline Linha de Campo & Potencial Elétrico \\
\hline Linha à direita mais próxima da fase A (V_ProxA) & - \\
\hline Linha à esquerda mais próxima da mão francesa (V_EMF) & - \\
\hline Linha à direita mais próxima da mão francesa (V_DMF) & $12,4 \mathrm{kV}$ \\
\hline Linha à esquerda mais próxima da fase C (V_ProxC) & $-26,4 \mathrm{kV}$ \\
\hline
\end{tabular}

Analogamente à Tabela 4.3 e à Tabela 4.4, foram construídas a Tabela 4.9 e a Tabela 4.10, onde as variáveis VA, VB e VC, são os valores obtidos em cada fase a partir dos curtos-circuitos aplicados na linha. Nessas tabelas é avaliada a possibilidade de ocorrerem descargas elétricas entre os condutores pelo ar. Logo, DDP_AB e DDP_BC são as diferenças de potencial encontradas entre a fase "A" e a 
fase "B" e entre a fase "B" e a fase "C", respectivamente. Considerando a rigidez dielétrica do ar como $600 \mathrm{kV} / \mathrm{m}$ (IEEE STD 1410, 2004), as distâncias entre as fases da estrutura tipo "A" (Figura 4.3) e as linhas equipotenciais fornecidas pelo software FLUX $^{\circledR}$, pode-se concluir que não haverá descargas elétricas pelo ar quando a linha for convertida para a tensão de $69 \mathrm{kV}$. Tal fato pode ser observado na coluna "Condição" da Tabela 4.9 e Tabela 4.10. 
Tabela 4.9 - Diferença de potencial elétrico entre as fases pelo ar para picos de tensão positivos

\begin{tabular}{|c|c|c|c|c|c|c|}
\hline Tipo de Falta & VA & VB & vc & DDP_AB & DDP_BC & Condição \\
\hline ABC-T (A) & $121.799,2$ & $10.667,3$ & $10.546,2$ & $111.131,9$ & 121,0 & Suportável \\
\hline ABC-T (B) & $-74.636,1$ & $115.964,5$ & $-9.013,0$ & $190.600,6$ & $124.977,5$ & Suportável \\
\hline ABC-T (C) & $-15.850,9$ & $-36.835,6$ & $97.539,3$ & $20.984,7$ & $134.374,9$ & \\
\hline$A B C(A)$ & $120.288,6$ & $-45.233,3$ & $-45.510,5$ & $165.521,9$ & 277,1 & Suportável \\
\hline$A B C(B)$ & & $110.099,6$ & $-83.949,4$ & $133.095,6$ & $194.049,0$ & Suportável \\
\hline $\mathrm{ABC}(\mathrm{C})$ & $-35.789,2$ & $-37.758,7$ & $90.233,3$ & $1.969,5$ & $127.992,1$ & Suportável \\
\hline AB-T (A) & $116.041,7$ & $9.050,7$ & $-5.713,2$ & $106.991,0$ & \begin{tabular}{|l|}
$14.763,9$ \\
\end{tabular} & Suportável \\
\hline AB-T (B) & $22.279,6$ & $120.361,1$ & $-20.193,1$ & $98.081,5$ & $140.554,2$ & Supor \\
\hline AB-T (C) & $-11.285,0$ & $9.748,2$ & $97.593,7$ & $21.033,2$ & $87.845,6$ & Supor \\
\hline$A B(A)$ & $100.908,5$ & $-63.406,2$ & $-12.438,7$ & $164.314,7$ & $50.967,5$ & Suportável \\
\hline$A B(B)$ & $-41.898,0$ & $80.544,2$ & $-34.844,1$ & $122.442,2$ & $115.388,3$ & Supo \\
\hline$A B(C)$ & $-21.320,0$ & $-44.713,6$ & $72.353,0$ & $23.393,6$ & $117.066,6$ & Suportável \\
\hline BC-T (A) & $84.643,7$ & $-2.509,4$ & $-16.539,6$ & $87.153,1$ & $14.030,2$ & Suportável \\
\hline BC-T (B) & $-39.142,1$ & $119.721,5$ & $10.838,3$ & $158.863,6$ & $108.883,2$ & Suportável \\
\hline BC-T (C) & $-23.793,5$ & 309,8 & $98.276,8$ & $24.103,3$ & $97.967,0$ & Suportável \\
\hline$B C(A)$ & $63.448,3$ & $-29.969,8$ & $-29.113,1$ & $93.418,1$ & 856,7 & Suportável \\
\hline$B C(B)$ & $-40.951,2$ & $101.609,4$ & $-66.297,3$ & $142.560,7$ & $167.906,8$ & rtável \\
\hline$B C(C)$ & $-20.198,3$ & $-57.427,9$ & $81.935,5$ & $37.229,6$ & $139.363,4$ & tável \\
\hline CA-T (A) & $119.311,8$ & $-20.333,9$ & $9.910,8$ & $139.645,8$ & $30.244,8$ & Suportável \\
\hline CA-T (B) & $15.663,9$ & $110.408,6$ & $-16.248,7$ & $94.744,8$ & $126.657,4$ & Suportável \\
\hline CA-T (C) & $-16.651,3$ & $-5.363,1$ & $100.113,8$ & $11.288,2$ & $105.476,8$ & Suportável \\
\hline $\mathrm{CA}(\mathrm{A})$ & $103.414,9$ & $1.229,7$ & $-82.722,9$ & $102.185,2$ & $83.952,6$ & Suportável \\
\hline CA (B) & $-51.798,7$ & $71.679,9$ & $-16.391,7$ & $123.478,6$ & $88.071,6$ & Suportável \\
\hline $\mathrm{CA}(\mathrm{C})$ & $-67.117,7$ & $-1.836,7$ & $70.489,7$ & 81,0 & $2.326,4$ & Suportável \\
\hline$A-T(A)$ & 113. & $-27.225,1$ & $-11.987,6$ & $141.154,5$ & 237,5 & Suportável \\
\hline$A-T(B)$ & $-17.066,1$ & $76.507,3$ & $-19.470,9$ & $93.573,4$ & $95.978,2$ & Suportável \\
\hline A-T (C) & $-49.642,9$ & $8.546,0$ & $76.009,8$ & $58.188,8$ & $67.463,8$ & Suportável \\
\hline B-T (A) & $84.281,0$ & $41.386,5$ & $15.481,5$ & $42.894,5$ & $25.905,0$ & Suportável \\
\hline B-T (B) & $-11.809,4$ & $111.855,4$ & $-27.652,7$ & $123.664,8$ & $139.508,1$ & Suportável \\
\hline $\mathrm{B}-\mathrm{T}(\mathrm{C})$ & $-2.411,5$ & $-28.668,9$ & $92.260,9$ & $26.257,4$ & $120.929,8$ & Suportável \\
\hline C-T (A) & $78.197,6$ & $-17.779,7$ & $24.012,9$ & $95.977,3$ & $41.792,6$ & Suportável \\
\hline C-T (B) & $-12.142,8$ & $96.431,5$ & $-28.050,9$ & $108.574,4$ & $124.482,5$ & Suportável \\
\hline C-T (C) & $-20.108,0$ & $-20.647,9$ & $86.830,6$ & 539,9 & $107.478,5$ & Suportável \\
\hline
\end{tabular}


Tabela 4.10 - Diferença de potencial elétrico entre as fases, pelo ar, para picos de tensão negativos

\begin{tabular}{|c|c|c|c|c|c|c|}
\hline Tipo de Falta & VA & VB & VC & DDP_AB & DDP_BC & Condição \\
\hline ABC-T (A) & $-102.282,4$ & $28.440,4$ & $12.627,4$ & $130.722,8$ & $15.813,1$ & Suportável \\
\hline ABC-T (B) & $30.589,1$ & $-88.148,5$ & $28.449,9$ & $118.737,6$ & $116.598,4$ & Suportável \\
\hline ABC-T (C) & $55.112,2$ & $-2.893,0$ & $-114.264,4$ & $58.005,2$ & $111.371,5$ & Suportável \\
\hline$A B C(A)$ & $-90.556,9$ & $82.802,2$ & $-20.916,7$ & $173.359,1$ & $103.718,9$ & Suportável \\
\hline$A B C(B)$ & $24.158,8$ & $-82.544,5$ & $48.730,8$ & $106.703,3$ & $131.275,2$ & Suportável \\
\hline$A B C(C)$ & $-18.966,5$ & $96.936,3$ & $-102.770,6$ & $115.902,7$ & $199.706,9$ & Suportável \\
\hline $\mathrm{AB}-\mathrm{T}(\mathrm{A})$ & $-101.533,3$ & $19.113,5$ & $-29.240,2$ & $120.646,8$ & $48.353,7$ & Suportável \\
\hline AB-T (B) & $-24.137,3$ & $-94.326,2$ & $30.985,4$ & $70.188,9$ & $125.311,6$ & Suportável \\
\hline AB-T (C) & $12.923,6$ & $-7.290,2$ & $-104.221,4$ & $20.213,7$ & $96.931,2$ & Suportável \\
\hline$A B(A)$ & $-73.782,2$ & $15.900,5$ & $45.006,6$ & $89.682,7$ & $29.106,1$ & Suportável \\
\hline$A B(B)$ & $92.153,1$ & $-99.569,2$ & $12.284,7$ & $191.722,4$ & $111.853,9$ & Suportável \\
\hline$A B(C)$ & $30.932,1$ & $42.040,8$ & $-84.870,2$ & $11.108,8$ & $126.911,1$ & Suportável \\
\hline BC-T (A) & $-109.073,7$ & $28.992,7$ & $-20.011,9$ & $138.066,4$ & $49.004,6$ & Suportável \\
\hline $\mathrm{BC}-\mathrm{T}(\mathrm{B})$ & $5.850,7$ & $-93.200,3$ & $23.528,8$ & $99.050,9$ & $116.729,0$ & Suportável \\
\hline $\mathrm{BC}-\mathrm{T}(\mathrm{C})$ & $22.942,9$ & $-7.955,6$ & $-118.786,1$ & $30.898,5$ & $110.830,5$ & Suportável \\
\hline $\mathrm{BC}(\mathrm{A})$ & $-70.612,4$ & $47.023,6$ & $14.531,8$ & $117.636,0$ & $32.491,8$ & Suportável \\
\hline$B C(B)$ & $-313,0$ & $-80.221,8$ & $75.350,7$ & $79.908,8$ & $155.572,5$ & Suportável \\
\hline$B C(C)$ & $8.283,9$ & $91.872,0$ & $-101.954,9$ & $83.588,1$ & $193.827,0$ & Suportável \\
\hline CA-T (A) & $-102.542,7$ & 368,9 & $-1.586,6$ & $102.911,6$ & $1.955,5$ & Suportável \\
\hline CA-T (B) & $12.604,6$ & $-90.059,0$ & $13.853,9$ & $102.663,6$ & $103.912,9$ & Suportável \\
\hline CA-T (C) & $-1.288,8$ & $12.128,4$ & $-119.660,7$ & $13.417,2$ & $131.789,1$ & Suportável \\
\hline CA (A) & $-86.381,3$ & $59.208,1$ & $23.210,7$ & $145.589,4$ & $35.997,4$ & Suportável \\
\hline CA (B) & $55.023,6$ & $-63.388,1$ & $9.177,9$ & $118.411,8$ & $72.566,0$ & Suportável \\
\hline CA (C) & $100.658,1$ & $-8.084,8$ & $-89.427,2$ & $108.743,0$ & $81.342,4$ & Suportável \\
\hline A-T (A) & $-87.104,1$ & $10.286,6$ & $29.235,4$ & $97.390,7$ & $18.948,8$ & Suportável \\
\hline A-T (B) & $4.435,0$ & $-68.843,0$ & $30.130,2$ & $73.278,0$ & $98.973,2$ & Suportável \\
\hline A-T (C) & $31.866,9$ & $6.724,3$ & $-89.095,2$ & $25.142,6$ & $95.819,5$ & Suportável \\
\hline B-T (A) & $-87.381,0$ & $16.710,2$ & $-3.484,3$ & $104.091,2$ & $20.194,4$ & Suportável \\
\hline B-T (B) & $21.761,6$ & $-87.799,6$ & $19.831,2$ & $109.561,2$ & $107.630,8$ & Suportável \\
\hline B-T (C) & $19.649,6$ & $-37.337,9$ & $-79.599,3$ & $56.987,6$ & $42.261,3$ & Suportável \\
\hline C-T (A) & $-90.268,5$ & $29.941,8$ & $-386,5$ & $120.210,2$ & $30.328,3$ & Suportável \\
\hline C-T (B) & $-23.680,4$ & $-97.165,4$ & $-65.159,6$ & $73.485,0$ & $32.005,8$ & Suportável \\
\hline C-T (C) & $27.440,8$ & $12.109,4$ & $-112.643,8$ & $15.331,4$ & $124.753,2$ & Suportável \\
\hline
\end{tabular}

Uma análise dos resultados obtidos das simulações realizadas neste capítulo é apresentada a seguir.

Como já foi mencionado, das estruturas encontradas sobre o sistema de 34,5 kV em análise, cabe afirmar que a mais problemática foi a do tipo " $\mathrm{A}$ ", por apresentar as distâncias mais críticas entre as fases. Sendo assim, os estudos 
apresentados e comentados com relação à aplicação do software FLUX $^{\circledR}$ foram direcionados a este tipo de estrutura, tomando como verdade que, caso a mesma não viesse a apresentar problemas para uma futura repotenciação, as demais também não são contrárias a esta situação.

Tomando como base a estrutura do tipo "A", as diferenças de potencial obtidas na Tabela 4.3, Tabela 3.4, Tabela 4.9 e Tabela 4.10 foram avaliadas de acordo com a rigidez dielétrica de cada material, avaliando-se as tensões as quais a cruzeta de madeira foi submetida, bem como as tensões entre as fases, considerando-se a rigidez dielétrica do ar.

Cabe lembrar que a rigidez dielétrica da madeira varia entre $330 \mathrm{kV} / \mathrm{m}$ a 500 kV/m (SCHMIDT, 1979) e para a rigidez dielétrica do ar, considerando condições ambientais que podem influenciar seu valor, o valor observado é de $600 \mathrm{kV} / \mathrm{m}$ (IEEE STD 1410, 2004).

A última coluna da Tabela 4.3 e da Tabela 4.4 indica que para todos os casos simulados, os valores de tensão em que a cruzeta foi avaliada, e que, provavelmente poderá experimentar em campo, não excedem o valor suportável que, para um tamanho de $0,595 \mathrm{~m}$ de madeira, entre os pinos laterais e a mão francesa, seria de 196,35 kV/m, considerando o valor mínimo da rigidez dielétrica da madeira que é $330 \mathrm{kV} / \mathrm{m}$.

Sendo assim, os resultados indicam que os espaçamentos da estrutura do tipo "A" (34,5 kV) suportam a classe de tensão de 69 kV. No entanto, para operar nessa nova classe de tensão, devem-se utilizar os materiais de isolação da classe de $69 \mathrm{kV}$, como pinos e isoladores. Isto se deve ao fato de que os estudos realizados verificaram apenas a suportabilidade de tensão considerando as distâncias entre as fases de cada estrutura. 
Como se utilizou para a análise a estrutura com as menores distâncias entre fases (tipo "A"), e concluiu-se que a estrutura suportará a classe de tensão de 69 kV, infere-se que as demais estruturas, por possuírem distâncias maiores entre fases, também poderão operar na classe de $69 \mathrm{kV}$.

Ressalta-se, portanto, que a utilização do software FLUX ${ }^{\circledR}$ trouxe grandes vantagens para o trabalho, pois a partir dele, puderam ser realizadas as análises baseadas na teoria de elementos finitos, simulando campos elétricos e a interação destes entre os componentes da linha de subtransmissão, objetivando a utilização de estruturas do padrão de tensão de 34,5 kV operando na classe de tensão de 69 $k V$.

Os resultados apresentados neste capítulo foram todos obtidos com o software $F L U X^{\circledR}$ na versão $2 D$, no entanto, o software também possui o módulo 3D que, amplia imensamente a possibilidade de casos e a riqueza de detalhes a ser simulada.

A Figura 4.12 ilustra a estrutura tipo "A" modelada no software FLUX ${ }^{\circledR} 3 D$ inclusive com as arestas da cruzeta de madeira arredondadas, isolador tipo pino da classe de $69 \mathrm{kV}$ e, $2 \mathrm{~m}$ de condutor acima do isolador.

Para demonstrar a riqueza de detalhes que pode ser aplicada na versão 3D do software $F L U X^{\circledR}$, a Figura 4.13 ilustra em destaque, um isolador tipo pino da classe de $69 \mathrm{kV}$ sobre a cruzeta de madeira.

Um exemplo da MEF em 3D pode ser observado na Figura 4.14. 

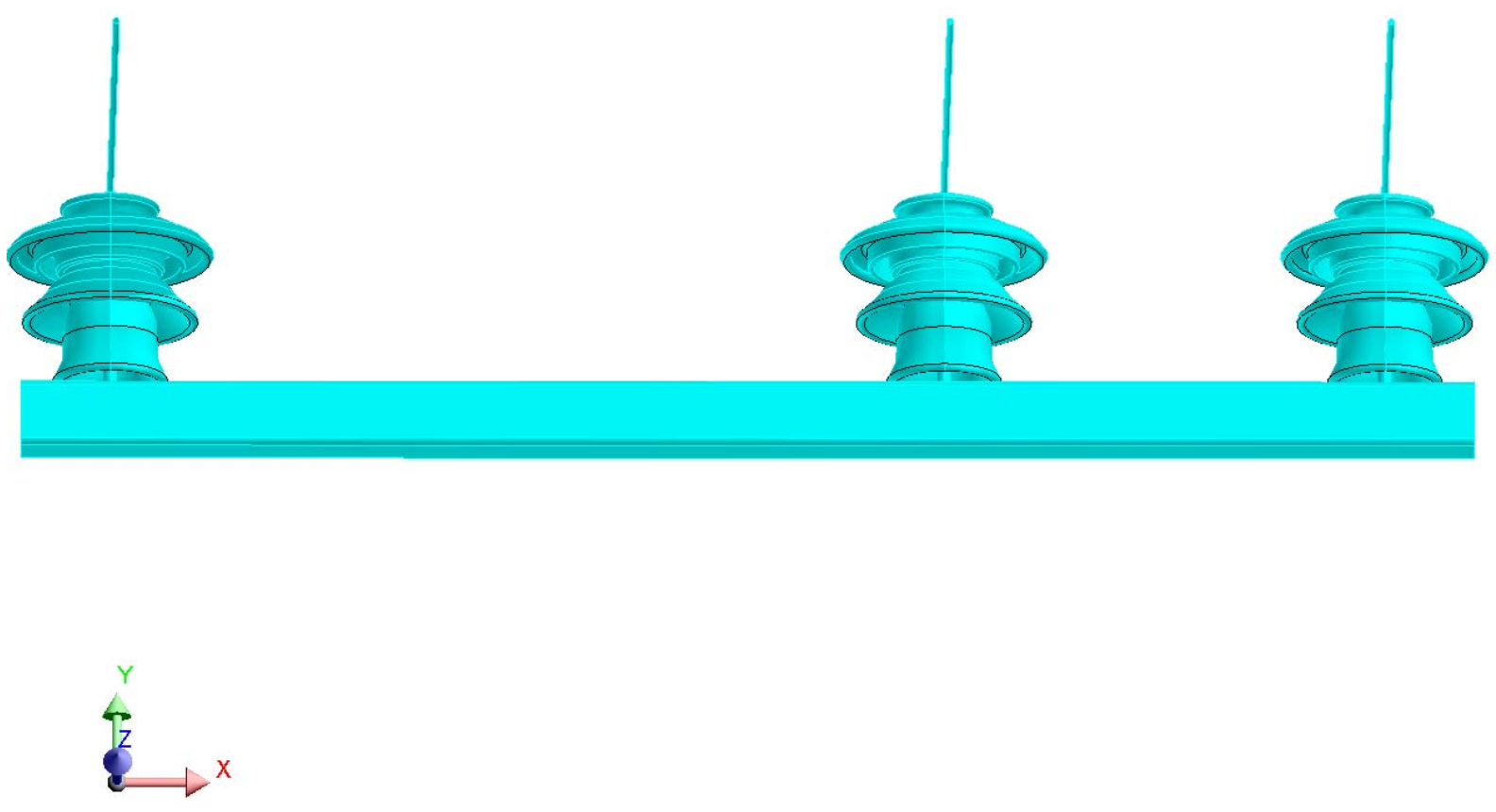

Figura 4.12 - Estrutura do tipo "A" modelada no FLUX ${ }^{\circledR}$ 3D

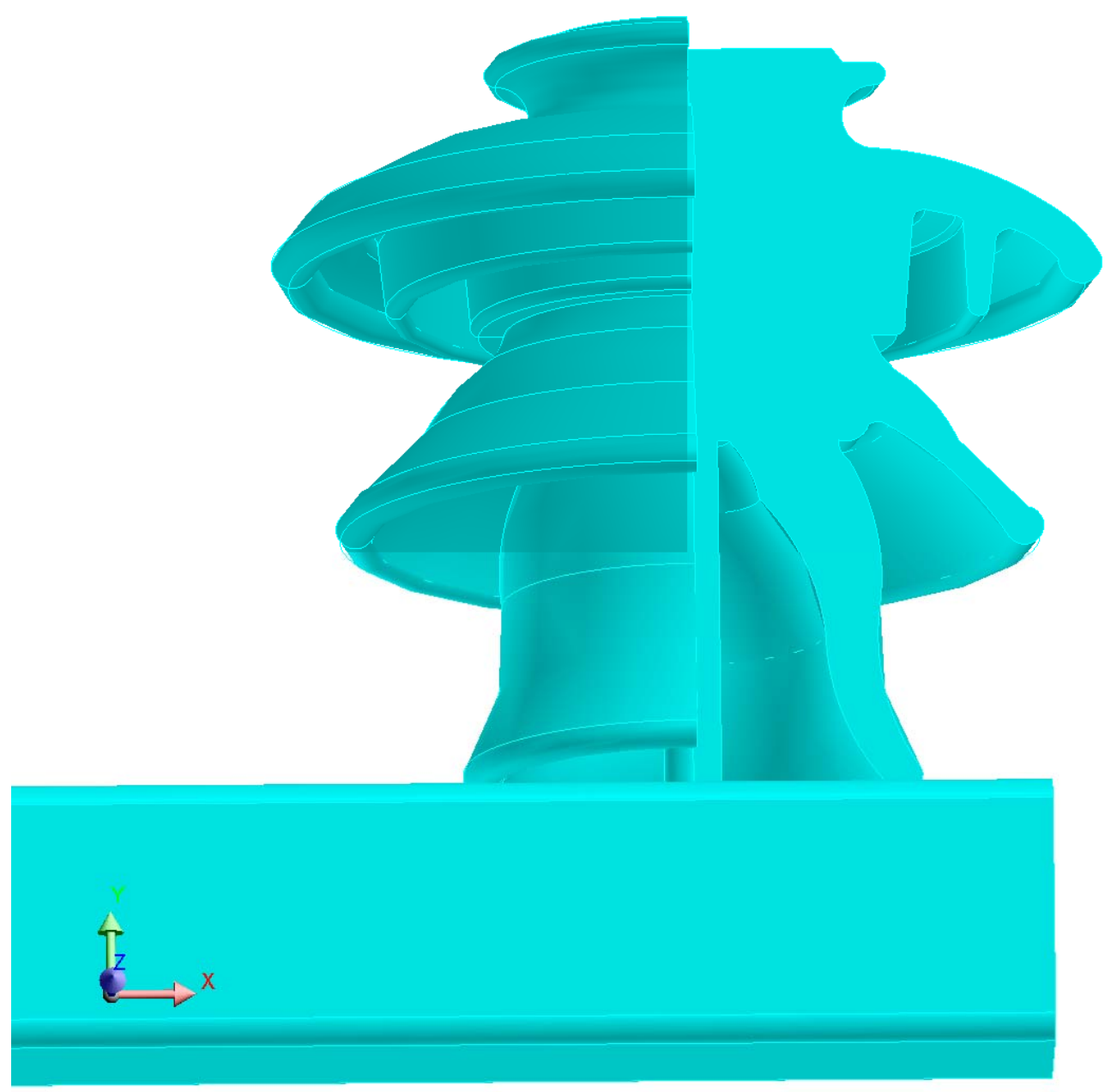

Figura 4.13 - Isolador tipo pino da classe de $69 \mathrm{kV}$ modelado no FLUX ${ }^{\circledR}$ 3D 


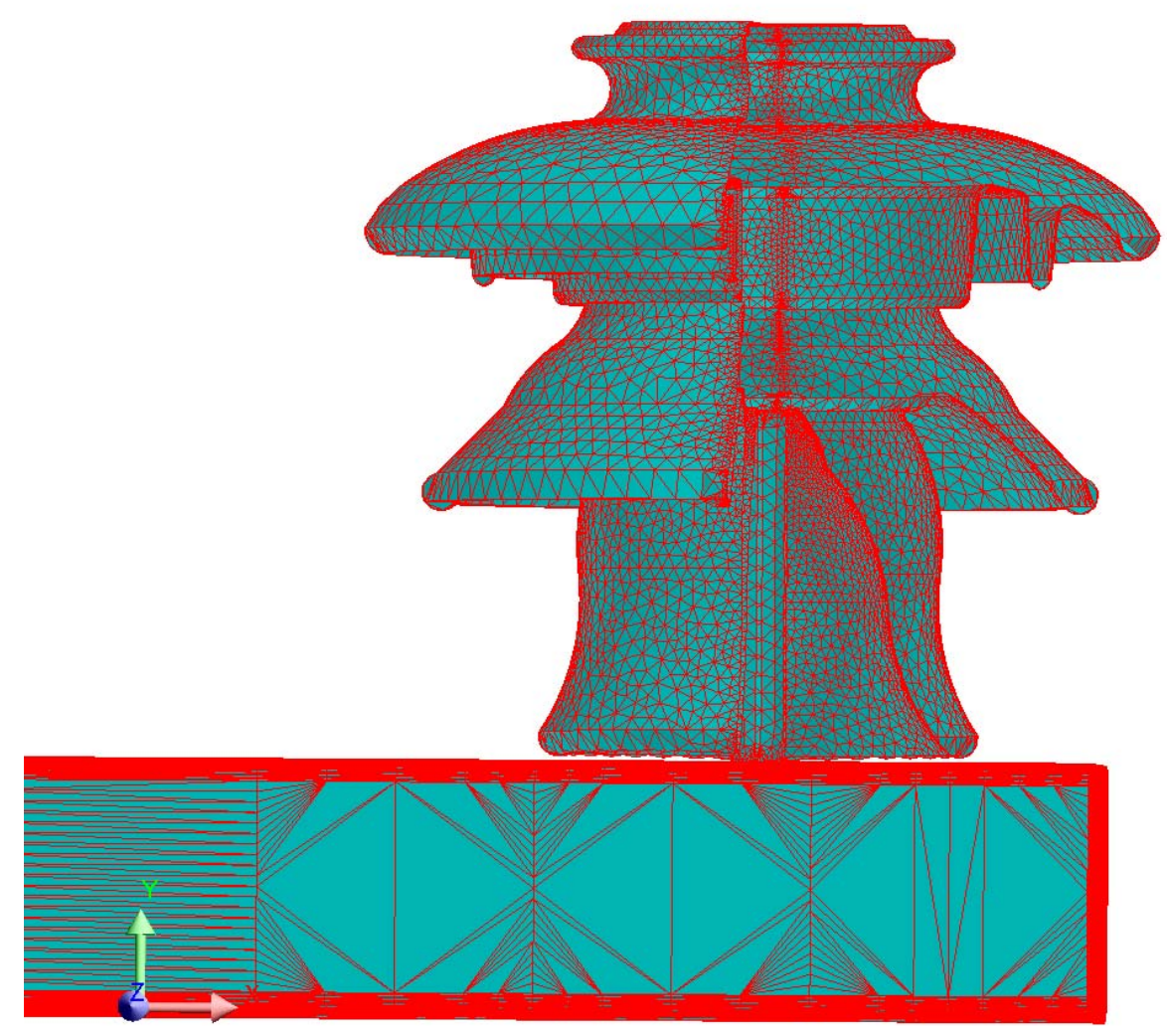

Figura 4.14 - MEF em um isolador tipo pino da classe de $69 \mathrm{kV}$ modelado no $\mathrm{FLUX}^{\circledR}$ 3D

Para finalizar, as conclusões sobre as simulações realizadas são feitas no Capítulo 5. 


\section{Capítulo 5 Conclusões}

Conforme abordado no Capítulo 1, a repotenciação de linhas de transmissão surge como forma de ampliar a capacidade de transmissão das linhas diante de um cenário de necessidade de expansão. Dentre as alternativas de repotenciação de linhas, existe a elevação da classe de tensão operativa da linha, técnica abordada neste trabalho, e o recondutoramento, seja por adição de um novo condutor, substituição do condutor existente por um de melhor desempenho ou mesmo a utilização de condutores termo-resistentes.

Este trabalho propôs uma análise metodológica que objetiva a realização de uma repotenciação elevando a classe de tensão de linhas de distribuição da classe de $34,5 \mathrm{kV}$ para a classe de subtransmissão de $69 \mathrm{kV}$, mantendo o maior número possível de estruturas já existentes na linha. Cabe comentar que apenas o NBI da estrutura é considerado para viabilizar a sua reutilização no novo padrão de tensão, ficando ainda a serem analisados fatores mecânicos que as estruturas devem suportar como, esforços verticais, horizontais e longitudinais.

Para tanto e destacando-se como importante contribuição deste trabalho, propôs-se utilizar dois softwares em conjunto a fim de prover uma maior confiabilidade e exatidão dos resultados: o ATP e o Flux ${ }^{\circledR}$. O software ATP foi empregado na modelagem da linha e aplicação de transitórios eletromagnéticos para obtenção das maiores sobretensões observadas. Em seguida, os picos de tensão registrados foram utilizados no software FLUX $^{\circledR}$ e, a partir de estruturas modeladas pelo MEF, obtiveram-se as linhas de potencial e campo elétrico, 
considerando as características elétricas dos materiais e isoladores pertencentes à linha de distribuição.

As simulações computacionais resumiram-se em verificar se as distâncias entre as fases das estruturas da classe de $34,5 \mathrm{kV}$ suportariam a classe de tensão de $69 \mathrm{kV}$. A partir dos resultados obtidos, de acordo com a Tabela 4.3, Tabela 4.4, Tabela 4.9 e Tabela 4.10 , verificou-se que os indicadores que representavam a diferença de potencial entre os pontos principais da estrutura do tipo "A" para avaliar seu NBI não excederam, em nenhum dos casos simulados, os valores limites estabelecidos.

Assim, pelos estudos realizados, fica clara a possibilidade da realização da repotenciação da linha, uma vez que as estruturas que apresentavam as menores distâncias entre fases suportariam a classe de tensão de $69 \mathrm{kV}$, considerando cruzetas de madeira. Sendo assim, o NBI das estruturas existentes na linha em estudo, de acordo com as simulações, suportaria a nova classe de tensão de $69 \mathrm{kV}$.

Como a estrutura avaliada é a mais crítica, ou seja, a que possui as menores distâncias entre as fases, conclui-se que as demais estruturas da classe de $34,5 \mathrm{kV}$ existentes na linha, sendo elas a "A", "B", "G", "E", estão aptas a operar na classe de tensão de $69 \mathrm{kV}$, desde que sejam utilizados os equipamentos de isolação do respectivo nível de tensão.

Para a repotenciação da linha, faz-se necessário ainda um estudo referente aos esforços mecânicos proporcionados pela substituição dos equipamentos de isolação da classe de $34,5 \mathrm{kV}$ pelos equipamentos da classe de $69 \mathrm{kV}$. Este estudo pode ser feito usando softwares específicos, como o PLSCAD (software utilizado em projetos de linhas de transmissão). 
Cabe comentar que para a real repotenciação da linha e, consequente aumento da classe de tensão de operação, deve ser considerado um estudo de proteção contemplando todas as alterações físicas propostas. Dentre essas alterações está a substituição dos transformadores, verificação da necessidade de troca dos relés de proteção com as funcionalidades que a nova classe de tensão exige de acordo com as normas da concessionária de energia e substituição ou não do condutor.

A realização do estudo de proteção é imprescindível para a confiabilidade e seletividade da proteção, uma vez que a repotenciação mudará totalmente os valores de curto-circuito dos barramentos, mudando a dinâmica do sistema frente a distúrbios.

Embora fuja do escopo deste trabalho, devem ser considerados na prática os investimentos necessários para a realização da repotenciação como, projeto da linha repotenciada, compra de equipamentos (relés, transformadores, isoladores, postes, cruzetas), execução da obra e verificação de possíveis desligamentos da linha para a reforma (não deve ultrapassar valores estabelecidos por indicadores da qualidade da energia).

Este estudo avalia quais estruturas existentes em uma linha de distribuição estão aptas a operar em uma classe de tensão mais elevada baseando-se em uma série de simulações computacionais. As concessionárias de energia podem usar esta metodologia para direcionar o re-projeto de uma linha a ser repotenciada, em que as estruturas que forem aprovadas pelo estudo possam ser mantidas no novo projeto da linha, trazendo vantagens significativas a alternativa de elevação da classe de tensão para ganhos de potência. 


\section{1 - CONTINUIDADE DO TRABALHO}

O grande diferencial do trabalho foi a utilização do MEF para viabilizar a elevação da tensão de operação de uma determinada linha de transmissão.

Este tipo de análise possibilita um vasto campo de aplicações dentro dos SEPs. A própria utilização da versão 3D do software FLUX ${ }^{\circledR}$ oferece uma enorme gama de detalhes e situações a serem simuladas e analisadas.

Esta mesma metodologia proposta pode ser utilizada no:

- Refinamento na modelagem dos componentes presentes nas estruturas analisadas. Detalhamento da cruzeta, mão francesa, isolador, poste, condutor e demais equipamentos que possam influenciar na propagação dos campos elétricos;

- Repotenciação de linhas de transmissão de diferentes níveis de tensão, variando-se apenas os padrões de estrutura de cada classe;

- Desenvolvimento de novos padrões de estruturas tanto para linhas de distribuição como para linhas de transmissão de energia elétrica;

- A avaliação de defeitos em isoladores com a ajuda do MEF é um tema bastante difundido, bem como, por exemplo, o efeito do acúmulo de sal nos mesmos em regiões costeiras;

A utilização do MEF na análise de campo elétrico em SEPs possui inúmeras áreas de interesse que podem e devem ser exploradas a fim de melhorar a eficiência e o desempenho dos sistemas elétricos. 


\section{Artigos Publicados}

No decorrer do trabalho alguns artigos foram publicados em congressos nacionais e internacionais com o objetivo de disseminar os resultados obtidos. Estes trabalhos estão listados abaixo em ordem cronológica.

OLIVEIRA, P. S., BIASOTTO, COURY, D. V., OLESKOVICZ, M., VIEIRA, J. C. M., BARBOSA, D., AHN, S. U., SUZUKI, M., Uma análise direta das regiões do campo elétrico em um isolador cerâmico, tipo pino, da classe de $34,5 \mathrm{kV}$, Eighth LatinAmerican Congress on Electricity Generation and Transmission, Ubatuba-SP, 2009.

BIASOTtO, E., OlIVEIRA, P. S., OLESKOVICZ, M., VIEIRA, J. C. M., COURY, D. V., BARBOSA, D., AHN, S. U., SUZUKI, M., A repotenciação de uma linha de subtransmissão através da elevação da classe de tensão operativa, Eighth LatinAmerican Congress on Electricity Generation and Transmission, Ubatuba-SP, 2009.

BIASOTTO, E., OLIVEIRA, P. S., LIMA, M. A. A., OLESKOVICZ, M., VIEIRA, J. C. M., COURY, D. V., SUZUKI, M., MIRANDA, S. A. N., Análise da elevação da tensão operativa de linhas de distribuição baseada na simulação computacional de campos elétricos e de linhas equipotenciais utilizando o método dos elementos finitos, XVIII Congresso Brasileiro de Automática, Bonito-MS, 2010. 
OLIVEIRA, P. S., BIASOTTO, E., LIMA, M. A. A., COURY, D. V., OLESKOVICZ, M., VIEIRA, J. C. M., SUZUKI, M., MIRANDA, S. A. N, QUERNE, H. F. R., Avaliação da elevação da tensão operativa de linhas de distribuição pelo método de elementos finitos, IEEE/PES T\&D Latin America, São Paulo-SP, 2010. 


\section{Referências Bibliográficas}

ALBIZU, I., MAZÓN, A. J., ZAMORA, I., Methods for increasing the rating of overhead lines, IEEE Power Tech, St. Petersburg-Russia, 6 p, 2005.

AREND, E. R., Estudo de aterramento em baixas frequências usando a formulação eletrocinética associada ao método de elementos finitos, Dissertação de Mestrado, Universidade Federal de Santa Catarina, Programa de Pós-Graduação em Engenharia Elétrica, Florianópolis, 2009.

ABNT, NBR 5422: projeto de linhas aéreas de transmissão de energia elétrica: procedimentos, 1985.

BARROSO, L. A., PORRUA, F., PEREIRA, M. V., BEZERRA, B., Solving the major challenges in transmission asset investment in the competitive environment: the Brazilian case, IEEE Power \& Energy Society General Meeting, Calgary-AB, 2009.

BRAGA, A. E., BRAGA, M. L., VEIGA, D., MOREIRA, I. S., Upgrading and refurbishment of an energized transmission line, IEEE 9th International Conference on Transmission and Distribution Construction, Operation and Live-Line Maintenance, p.p. 11-20, Montreal-Quebec, 2000.

CHOWDHURI, P., Power System Transients: The Electric Power Engineering Handbook, Ed. L.L. Grigsby, Boca Raton: CRC Press LLC, 2001. 
CPFL, Estrutura do tipo "G", desenho padrão n BX-A-9370-SP, 05 de agosto de 1970.

CPFL, Estrutura do tipo "A", desenho padrão n BX-A4-11.826, Campinas-SP, 30 de março de 1984a.

CPFL, Estrutura do tipo "B", desenho padrão n BX-A4-11.828, Campinas-SP, 03 de abril de 1984b.

CPFL, Estrutura do tipo "E", desenho padrão n BX-A3-11.832, Campinas-SP, 09 de abril de 1984c.

CPFL, Estrutura do tipo "HS", desenho padrão n BX-A3-11.836, Campinas-SP, 07 de junho de 1984d.

CPFL, Estrutura do tipo "HT", desenho padrão n BX-A3-11.844, Campinas-SP, 04 de junho de 1984e.

DA COSTA, A., RUEDA, F. A., MARÇO, L. C., MORENO, R. F., Repotenciação de linhas de transmissão: aspectos técnicos e ambientais, XVI Seminário Nacional de Produção de Transmissão de Energia Elétrica, 6 p, Uberlândia, 2001.

DIESENDORF, W., Insulation co-ordination in high-voltage electric power systems, London, Butterworths, 1974. 
DUTRA, J. F., LAGO, F. F., CESAR, E. L., CARPEGGIANI, G., UEDA, S. M., SCHAUFFERT, W., Repotenciação e recapacitação de LTs de 230 kV através de novos cabos condutores e aumento da capacidade de carga dos suportes. A Experiência da Eletrosul, XVIII Seminário Nacional de Produção de Transmissão de Energia Elétrica, Curitiba, 6 p, 2005.

EEUG, Alternative transients program rule book, LEC, 1987.

ELGERD, O. I., Introdução a Teoria de Sistemas de Energia Elétrica, McGrawHill, 1981.

FEMLAB, Quick start and quick reference, 2004.

FLUX2D, Finite element software for electromagnetic applications, version 10.2.4, Cedrat (CEE), Magsoft-USA, 2009.

FONSECA, B. Q. A., CIMINI, C. A. Jr., Análise de vida útil de cabos condutores de linhas aéreas de transmissão, XVII Seminário Nacional de Produção de Transmissão de Energia Elétrica, Uberlândia, 6 p, 2003.

FUCHS, R. D., Transmissão de energia elétrica: linhas aéreas; teoria das linhas em regime permanente. Rio de Janeiro, Livros Técnicos e Científicos, 1979. 
GOMEZ, P., Validation of ATP transmission line models for a Monte Carlo study of switching transients, NAPS 39th North American Power Symposium, pp. 124-129, 2007.

HANSON, J. G., Upgrading transmission lines, IEEE Power Engineering Society Transmission and Distribution Conference, Dallas-Texas, 4 p, 1991.

IEEE Guide for improving the lightning performance of electric power overhead distribution lines, IEEE Std 1410 ${ }^{\mathrm{TM}}$-2004, (Revision of IEEE Std 1410-1997).

KOPSIDAS, K., ROWLAND, S. M., Evaluating opportunities for increasing power capacity of existing overhead line systems, IET Generation, Transmission \& Distribution, Vol. 5, N. 1, 10 p, 2010.

LU, M. L., PFRIMMER, G., KIELOCH, Z., Upgrading an existing 138 kV transmission line in Manitoba, IEEE Power Engineering Society General Meeting, MontrealQuebec, 2006.

MARTI, J. R., Accurate modelling of frequency-dependent transmission lines in electromagnetic transient simulations, IEEE Transactions on Power Apparatus and Systems, Vol. PAS-101, pp. 147-157, 1982.

MOREIRA, I. S., MELLO, J. L. S., PROSDÓCIMO, N., SOUZA, R. L., Reisolamento e reformas de linhas de transmissão - a experiência da COPEL, XV Seminário 
Nacional de Produção de Transmissão de Energia Elétrica, Foz do Iguaçu, 6 p, 1999.

OLIVEIRA, C. M. F., Recapacitação de linhas de transmissão, Dissertação de Mestrado, Pontifícia Universidade Católica do Rio de Janeiro, Programa de PósGraduação em Engenharia Elétrica, Rio de Janeiro, 2000.

PEREIRA FILHO, M. L., CARDOSO, J. R., SARTORI, C. A. F., COSTA, M. C., AlVARENGA, B. P., DIETRICH, A. B., MENDES, L. M. R, DOMINGUES, I. T., LOPES, J. C. R., Upgrading urban high voltage transmission line: impact on electric and magnetic fields in the environment, IEEE/PES Transmission \& Distribution Conference \& Exposition: Latin America, 2004.

PIHLER, J., TICAR, I., Design of systems of covered overhead conductors by means of electric field calculation, IEEE Transactions on Power Delivery, Vol. 20, N. 2, pp. 807-814, 2005.

PRIKLER, L., HOIDALEN H. K., ATPDraw v5 User's Manual, 2007.

QUEIROZ, I. B, NERI, M. G. G, COSTA, E. G., Mapeamento do campo elétrico em isoladores poliméricos, Simpósio Brasileiro de Sistemas Elétricos, Campina Grande-PB, 2006. 
RASOLONJANAHARY, J. R., KRÄHENBÜHL, L., NICOLAS, A., Computation of electric fields and potential on polluted insulators using a boundary element method, IEEE Transactions on Magnetics, Vol. 28, N. 2, pp. 1473-1476, 1992.

SALARI, J. C., MPALANTINOS, A., SILVA, J. I., Comparative analysis of 2- and 3-D methods for computing electric and magnetic fields generated by overhead transmission lines, IEEE Transactions on Power Delivery, Vol. 24, N. 1, pp. 338344, 2009.

SCHMIDT, W., Materiais elétricos isolantes e magnéticos, $2^{\mathrm{a}}$ ed. São Paulo: Ed. Edgard Blucher Ltda, 2 v., 1979.

SEBESTYÉN, I., Electric-field calculation for HV insulators using domaindecomposition method, IEEE Transactions on Magnetics, Vol. 38, N. 2, pp. 12131216, 2002.

SEMLYEN, A., DABULEANU, A., Fast and accurate switching transient calculations on transmission lines with ground return using recursive convolutions, IEEE Transactions Power Apparatus and Systems, Vol. 94, N. 2, pp. 561-571, 1975.

SILVA, A. O., RICCO, V. H. G., SANTIAGO, N. H. C., NOGUEIRA, R. L. S., NOEL, R., CAVALCANTE, I., BORGES, P. S. P., Reforma da linha de transmissão 230kV Bandeirantes - Brasília geral, XIX Seminário Nacional de Produção de Transmissão de Energia Elétrica, Rio de Janeiro, 8 p, 2007. 
STEPHAN, J. C. S., COSTA, C. F., Recapacitação, repotenciação e avaliação da capacidade de carga de suportes e fundações de linhas aéreas de transmissão segurança e confiabilidade, XIX Seminário Nacional de Produção de Transmissão de Energia Elétrica, Rio de Janeiro, 8 p, 2007.

TZINEVRAKIS, A. E., TSANAKAS, D. K., MIMOS, E. I., Analytical Calculation of the Electric Field Produced by Single-Circuit Power Lines, IEEE Transactions on Power Delivery, Vol. 23, N. 3, pp. 1495-1505, 2007.

VASSILIKI, T. K., GONOS, I. F., STATHOPOULOS, I. A., MICHAELIDES, A. M., Simulation of the electric field on high voltage insulators using the finite element method, 12th Biennial IEEE Conference on Eletromagnetic Field Computation, pp. 373-373, 2006.

VECTOR FIELDS, OPERA 3-d reference manual, England: Vector Fields Limited, 2004a.

VECTOR FIELDS, OPERA 2-d reference manual, England: Vector Fields Limited, 2004b.

VLASTOS, A. E, GUBANSKI, S. M., Surface structural changes of naturally aged silicone and EPDM composite insulators, IEEE Transactions on Power Delivery, Vol. 6, N. 2, pp. 888-900, 1991. 
WATSON, N., ARRILLAGA, J., Power systems electromagnetic transients simulation, Ed. The Institution of Electrical Engineers, London: United Kingdom, 2003.

ZIENKIEWICZ, O. C., TAYLOR, R. L., The finite element method, Volume 1: The Basis, Butterworth Heinemann, 2000. 